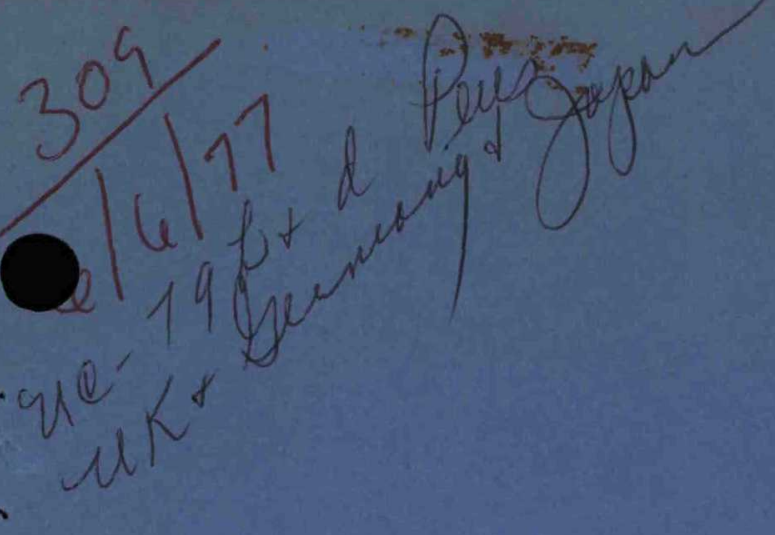

HEDL-TME 76-88

$$
\mathrm{UC}-79 \mathrm{~b}, \mathrm{~d}
$$

Dr 1084

MEASUREMENT AND CALCULATION

OF NEUTRON SPECTRA

IN THE FTR

ENGINEERING MOCKUP CRITICAL

Hanford Engineering Development Laboratory

\begin{tabular}{|c|c|c|}
\hline $\begin{array}{l}\text { Operated by the } \\
\text { Westinghouse } \\
\text { Hanford Company }\end{array}$ & $\begin{array}{l}\text { A Subsidiary of } \\
\text { Westinghouse Electric } \\
\text { Corporation }\end{array}$ & $\begin{array}{l}\text { for the United States } \\
\text { Energy Research and } \\
\text { Development Administration } \\
\text { Contract No EY .76-C } 14.270\end{array}$ \\
\hline
\end{tabular}




\section{DISCLAIMER}

Portions of this document may be illegible in electronic image products. Images are produced from the best available original document. 
This report was prepared as an account of work sponsored by the United States Government. Neither the United States nor the U.S. ERDA, nor any of their employees, nor any of their contractors, subcontractors, or their employees, makes any warranty, express or implied, or assumes any legal liability or responsibility for the accuracy, completeness or usefuiness of any information, apparatus, product or process disclosed, or represents that its use would not infringe privately owned rights.

\author{
Printed in the United States of America \\ Available from \\ National Technical Information Service \\ U.S. Department of Commerce \\ 5285 Port Royal Road \\ Springfield, Virginia 22161 \\ Price: Printed Copy \$ \$\$\$
}


MEASUREMENT AND CALCULATION

OF NEUTRON SPECTRA

IN THE FTR

ENGINEERING MOCKUP CRITICAL
J. V. Nelson
E. P. Lippincott
R. A. Bennett
W. N. McElroy
J. W. Daughtry

February 1977

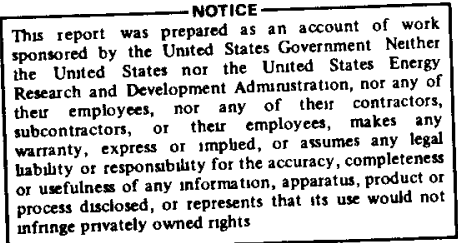

\begin{tabular}{|c|c|c|}
\hline $\begin{array}{l}\text { Operted thy the } \\
\text { Westinghouse } \\
\text { Hanford Company }\end{array}$ & 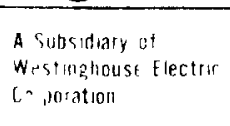 & 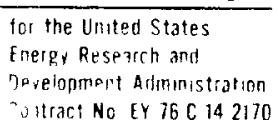 \\
\hline
\end{tabular}


○

' 
HEDL-TME 76-88

\title{
MEASUREMENT AND CALCULATION OF NEUTRON SPECTRA \\ IN THE FTR ENGINEERING MOCKUP CRITICAL
}

\author{
J. V. Nelson \\ E. P. Lippincott \\ R. A. Bennett \\ W. N. McElroy \\ J. W. Daughtry
}

\begin{abstract}
The neutron spectrum in the FTR Engineering Mockup Critical has been measured at six looations using proton-recoil techniques. At three of these looations, multiple foil irradiations were also conducted. Two-dimensional diffusion theory calculations using 42 energy group ENDF/B-III cross seotion data were made and the spectra from these aaloulation were oompared to the proton-reaoil data and spectra inferred from analyses of the irradiated foils. In general, the diffusion theory results agree quite well with the proton-recoil results. Good agreement was also obtained using the multiple foil teahnique for in-aore locations. However, low fluence levels led to unreliable multiple foil results for the shield Zocation.
\end{abstract}


-

,

, 
Abstract

Page No.

List of Figures

List of Tables

vi

$v i j$

1.0 Introduction

2.0 Summary 1

3.0 Measurements 2

3.1 Core Configurations 3

3.2 Proton-Recoil Measurements 6

3.3 Multiple Foil Irradiations 7

$\begin{array}{lll}4.0 & \text { Analytical Methods } & 10\end{array}$

4.1 Analyses of Irradiated Foils 10

4.2 ANL Fine-Group Calculations 12

4.3 Broad Group Spectrum Calculations 12

4.3.1 Cross Section Data 12

$\begin{array}{lll}\text { 4.3.2 Calculational Models } & 14\end{array}$

$\begin{array}{lll}5.0 & \text { Comparison of Results and Discussion } & 15\end{array}$

5.1 Comparison of ANL Fine Group Calculations to Proton-Recoil Measurements

5.2 Results of Multiple Foil Analysis $\quad 17$

5.3 Comparisons of Broad Group Diffusion Theory Calculations and Proton-Recoil Measurements 31

$\begin{array}{lll}5.4 & \text { Spectral Shifts in the EMC } & 39\end{array}$

6.0 Conclusions, Recommendations and Applications 39

$\begin{array}{lll}7.0 & \text { Acknowledgements } & 43\end{array}$

$\begin{array}{lll}8.0 & \text { References } & 44\end{array}$

Appendix A - Results of Proton-Recoil Measurements A-1 - A-10

Appendix B - Results of 42-Group Spectrum Calculations B-1 - B-3 
Figure No.

Page No.

3.1 EMC Configuration for In-Core Spectrum Measurements

3.2 EMC Configuration for Reflector and Shield Spectrum Mea surements

5.1 Comparison of Proton-Recoil Measurements and Fine Group Calculation of the Core Center Spectrum

5.2 SAND Monte Carlo Unfolded Spectrum - GP-201

5.3 SAND Monte Carlo Unfolded Spectrum - SP-625

5.4 Comparison of SAND, Proton-Recoil and Calculated Spectra in GP-201

5.5 Comparison of SAND, Proton-Recoil and Calculated Spectra in SP-625

5.6 Comparison of SAND, Proton-Recoil and Calculated Spectra-LLFM

5.7 Comparison of Proton-Recoil and Calculated Spectra at the Core Center

5.8 Comparison of Proton-Recoil and Calculated Spectra - GP-201

5.9 Comparison of Proton-Recoil and Calculated Spectra - SP-625

5.10 Comparison of Proton-Recoil and Calculated Spectra at Core-Reflector Boundary

5.11 Comparison of Proton-Recoil and Calculated Spectra in the Reflector

5.12 Comparison of Proton-Recoil and Calculated Spectra in the Shield

5.13 Comparison of Proton-Recoil Spectra for Core Center and SP-625

5.14 Comparison of Calculated Spectra at Core Center, SP-625 and Core-Reflector Interface

5.15 Comparison of Calculated Spectra at Core-Reflector Interface, Reflector and Shield 


\section{LIST OF TABLES}

Table No.

3.1 Locations of Spectrum Measurements

Page No.

3.2 Foil Set Description - EMC Positions 1 and 2

3.3 Foil Set Description - EMC Position 3 - LLFM

4.1 42-Group Energy Structure

5.1 Reaction Rates - EMC Position 1 - GP-201

5.2 Reaction Rates - EMC Position 2 - SP-625

5.3 Reaction Rates - EMC Position 3 - LLFM

5.4 SAND Monte Carlo Unfolding Results - Position 1 GP-201

5.5 SAND Monte Carlo Unfolding Results - Position 2 SP- 625

5.6 SAND Monte Carlo Unfolding Results - Position 1 GP-201 Using Selected Set of Foils

5.7 SAND Monte Carlo Unfolding Results - Position 2 SP-625 Using Selected Set of Foils

5.8 SAND-II Unfolding Results - EMC Position 3 - LLFM

5.9 Multiple Foil Results 


\subsection{Introduction}

Neutron spectrum measurements at a number of locations in the Fast Test Reactor (FTR) Engineering Mockup Critical (EMC) have been performed. Measurement techniques included use of proton-recoil proportional counters and foil packets. The purpose of this experiment was to provide information about the neutron flux-spectral environment in FTR, to verify the multiple foil irradiation techniques planned for use in the FTR Reactor Characterization Program, to determine the spatial variation of the neutron flux spectrum in the EMC, and to verify or evaluate calculational techniques to be used for FTR.

This report describes the analysis of the spectrum measurements. Section 2.0 contains a summary of the work done. Section 3.0 contains descriptions of the measurements and the core configurations in which they were made. Section 4.0 contains a description of the analyses performed.

The results of the measurements and analyses are the subject of Section 5.0 and conclusions and recommendations are given in Section 6.0 .

\subsection{Summary}

Measurements of the neutron flux spectrum in EMC beginning-of-life configurations were made using proton-recoil techniques at six locations: at the core center, in two test loops (GP-201 and SP-625), at the corereflector interface, in the reflector region and at a simulated low level flux monitor (LLFM) position in the shield sector. Under identical conditions, multiple foil irradiations were made in the two test loops and in the shield.

Two-dimensional diffusion theory calculations with 42 energy group cross-section data were performed. In general, the results of these calculations agree quite well with the proton-recoil measurements at all six locations. This indicates that broad group diffusion theory calculations can be used to follow spectral shifts in the FTR from the core center out into the shield. 
Data obtained from the multiple foil irradiations have been analyzed and spectra unfolded. Comparisons with calculated and proton-recoil spectra have been made and good agreement is obtained for the two locations in the core. Results from the third location in the shield were not sufficiently accurate for comparison due to the low fluence obtainable. However, the results for the in-core locations provide further validation of the accuracy of the multiple foil technique for the FTR Reactor Characterization Program.

\subsection{Measurements}

Experimental measurements of the neutron spectra were made at six different locations in two core configurations of the EMC that are based on the BOL-REF-5S loading (described in Refs. 1 and 2). The six locations are given in Table 3.1. Measurements were made at all locations using the proton-recoil technique described in Reference 3. Also, multiple foil irradiations were made at three of the six locations as indicated in Table 3.1. Neutron spectra at these locations were inferred from postirradiation analysis of the foil data and SAND-II (4) calculations. Details of the core configurations involved and measurement techniques employed are discussed in the following sections.

TABLE 3.1

LOCATIONS OF SPECTRUM MEASUREMENTS

\begin{tabular}{|c|c|c|c|}
\hline \multirow[b]{2}{*}{ Location } & \multirow{2}{*}{$\begin{array}{c}\text { ZPR-9 } \\
\text { Matrix Position }\end{array}$} & \multicolumn{2}{|c|}{ Measurements $*$} \\
\hline & & Proton-Recoil & Foil Irradiations \\
\hline $\begin{array}{l}\text { Core Center } \\
\text { GP- } 201 \\
\text { SP- } 625 \\
\text { Core-Reflector Interface } \\
\text { Reflector } \\
\text { Shield (LLFM position) }\end{array}$ & $\begin{array}{l}23-23 \\
23-20 \\
32-24 \\
18-13 \\
29-35 \\
36-38\end{array}$ & $\begin{array}{l}x \\
x \\
x \\
x \\
x \\
x\end{array}$ & $\begin{array}{l}x \\
x\end{array}$ \\
\hline
\end{tabular}




\subsection{Core Configurations}

For measurements made at the core center, in the two test loop positions (GP-201 and SP-625) and at the core-reflector interface, the BOL-REF-5S configuration was modified by putting sodium channel composition in GP-201 and SP-625, and adding six peripheral shim rods (PSR) giving a total of nine. The resulting configuration is shown in Figure 3.1. The extra PSRs, designated $705,717,729,736,712$ and 724 in Figure 3.1 , were inserted to reduce the subcritical flux to a level where proton-recoil measurements could be made. The reactivity of this configuration is approximately -2100 In (i.e., $\sim 2.1 \% \Delta k / k$ or $\sim 7 \$$ subcritical).

With the hydrogen chamber inserted, measurements were made with the core at this reactivity. With the more sensitive methane chamber inserted, measurements were made with all fuel-bearing control rods withdrawn and boron rods $1,3,7,9,10$ and 12 inserted so that the reactivity was approximately $-4300 \mathrm{Ih}$, or $214 \$$ subcritical. These chambers, which were used in the proton-recoil measurements, are described in Reference 3 and discussed briefly in Section 3.2.

For measurements in the radial reflector location, the BOL-REF-5S configuration was modified such that GP-201 and SP-625 contained sodium channel, as in the configuration previously described, and matrix positions 13-30 and 14-30 contained outer core material. With the methane chamber inserted, only fuel-bearing rods 2, 4, 6 and 9 were withdrawn and the core reactivity was -350 Ih. With the hydrogen chamber inserted, only fuel-bearing rods 2 and 6 were withdrawn and the reactivity was $-160 \mathrm{Ih}$.

This configuration, with only fuel-bearing rods 2 and 6 withdrawn, was also used for the measurements in the LLFM location made with the methane chamber. The core reactivity was $-164 \mathrm{Ih}$. However, when the hydrogen chamber was used for the LLFM measurements, GP composition was loaded into the GP-201 drawers and a Kirn-type fission counter placed in matrix position 23-23. This configuration was near critical. 
IIINER DRIVER

OUTER DRIVER

GEIIERAL PURPOSE LOOP

SPECIAL PURPNSE LOOP
SR SAFETY ROD

CR COIITROL ROD

PSR PERIPIIERAL SHIM ROD

HT MATERIAL TEST

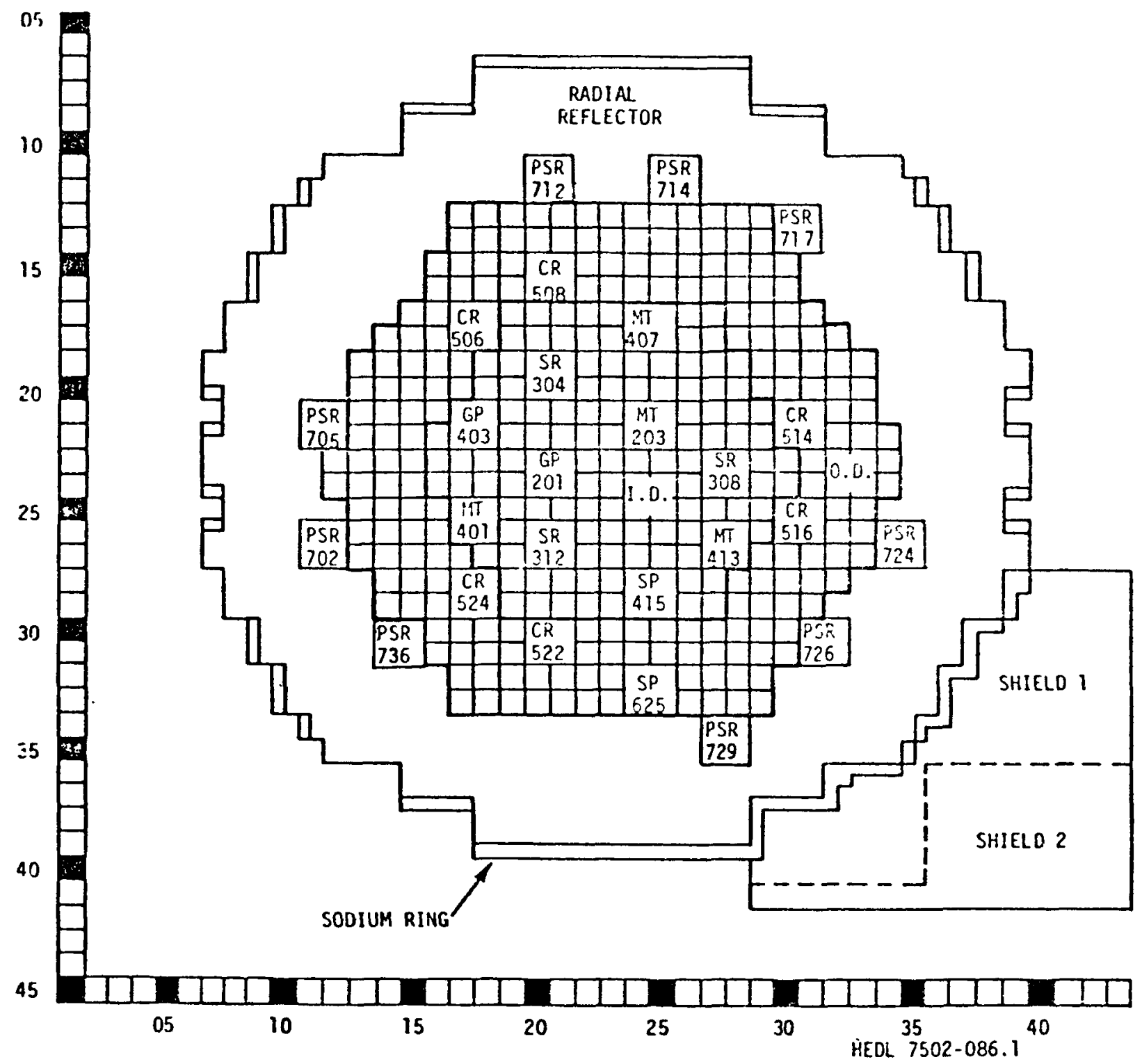

Figure 3.1. EMC Configuration for In-Core Spectrum Measurements 

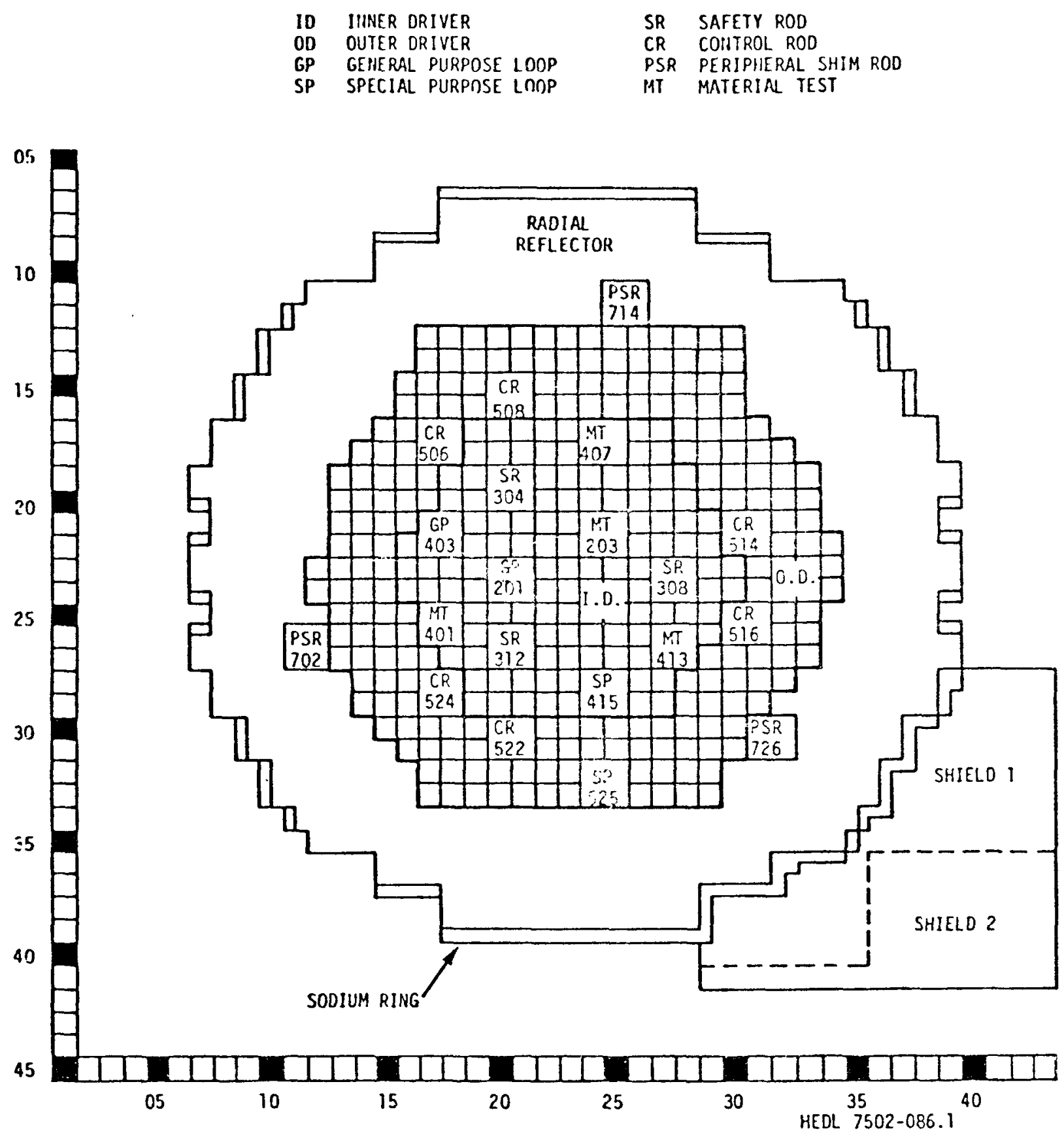

Figure 3.2. EMC Configuration for Reflector and Shield Spectrum Measurements 
The three locations at which foil irradiations were made are: GP-201, SP-625 and the LLFM shield location (see Table 3.1). The core configurations during these irradiations were identical to those used for corresponding proton-recoil measurements except that the foils and holder replaced the chamber. For all measurements, available platelets were used to duplicate as closely as possible the average drawer material composition in the vicinity of the experiment and hence to create conditions most amenable for comparison with calculated spectra.

\subsection{Proton-Recoil Measurements}

The proton recoil technique employed by ANL for the spectrum measurements in the EMC is described in detail in Reference 3 and the measurements in the EMC are described in Reference 5. A brief summary of these measurements is contained in the following paragraphs.

Two types of counting tubes were used, one filled with hydrogen gas and the other filled with methane in order to extend the energy range in which reliable experimental data could be obtained. Proton-recoil chambers were placed in the lower right-hand corner of the drawers with respect to Figures 3.1 and 3.2. In this way, the chambers were as close as possible to the center of the four-drawer clusters constituting the GP-201 and SP-625 positions. In all cases, the drawers containing the proton recoil chambers were loaded such that the perturbations caused by the material rearrangements necessary to accommodate the chambers were minimized.

The two largest sources of systematic error in proton-recoil measurements occur at the low- and high-energy extremes. For energies telow about $6 \mathrm{keV}$ (for protons in hydrogen), variations in the energy lost by a proton per ion pair formed, $W$, will affect the results. However, $W$ from protons stopping in hydrogen is reasonably constant to very low energies and the assumption of a constant weverywhere is justified on this basis.

For higher-energy neutrons, wal1-end effects, wherein a proton leaves the active volume of the detector before stopping, will cause measurement errors. This effect sets in strongly at about $1 \mathrm{MeV}$ and, for the counters used in these experiments, effectively terminates the measurements at 2 to 
$3 \mathrm{MeV}$. Proton-recoil data were reported in Reference 5 only for energies where the wall-end correction procedure employed indicated a correction of less than $20 \%(21.6 \mathrm{MeV})$.

For the energy range ( $10 \mathrm{KeV}$ to $1 \mathrm{MeV}$ ), the proton-recoil technique is not subject to wall-end effects or variations in $W$ and should yield very reliable results.

\subsection{Multiple Foil Irradiations}

Because of the importance of the multiple foil technique to the FTR Reactor Characterization Program, foil irradiations were made at three of the locations used for proton recoil measurements, as indicated in Table 3.1. The three locations are:

Position 1 - near the core center in GP-201

Position 2 - just inside the core-reflector interface in SP-625

Position 3 - at a simulated LLFM position in the radial shield sector.

The drawers at these locations were identical for both types of measurements, except for the substitution of the foil packets for the proton recoil counters.

Foils were chosen to include reactions which respond to the entire range of neutron energies at each position. Unfortunately, due to the low amount of fluence obtainable in the EMC, not all of the reactions normally included in high-power irradiations could be used; therefore some other reactions with shorter half-lives had to be substituted. In addition, the dosimeters irradiated contained, of necessity, much larger amounts of material in order to obtain suitable counting rates, thereby increasing resonance self-shielding and spatial neutron flux spectrum perturbations. At the LLFM position, only an even more limited set of reactions produced adequate counting rates due to the very low flux at this position. Especially difficult were measurements of higher energy flux using threshold reactions. The foils included in each set are listed in Tables 3.2 and 3.3. 
TABLE 3.2

FOIL SET DESCRIPTION - EMC POSITIONS 1 AND 2

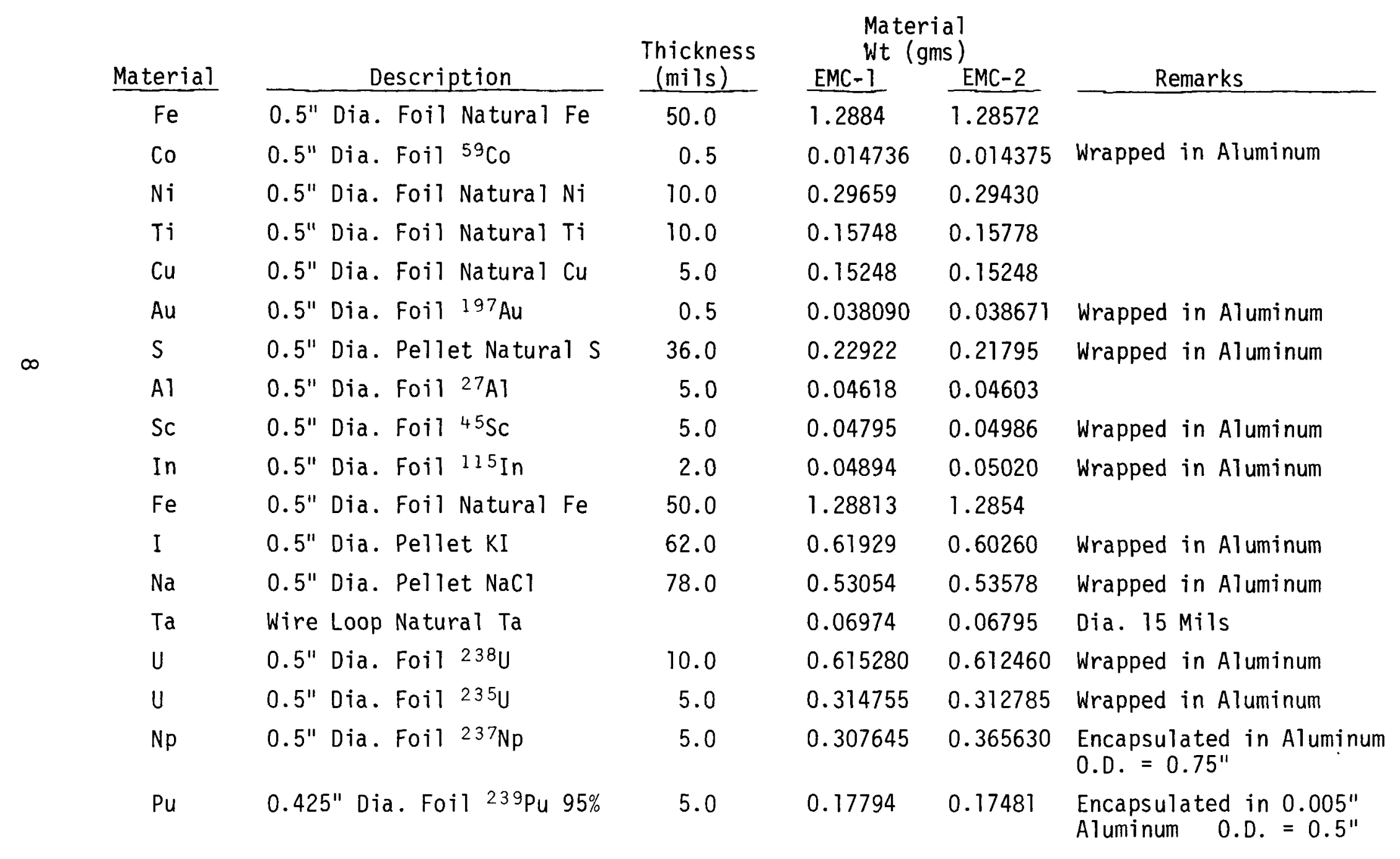


TABLE 3.3

FOIL SET DESCRIPTION - EMC POSITION 3 - LLFM

\begin{tabular}{|c|c|c|c|c|}
\hline Material & & $\begin{array}{l}\text { Thickness } \\
\text { (mils) }\end{array}$ & $\begin{array}{l}\text { Material } \\
\text { Wt. (gms) }\end{array}$ & Remarks \\
\hline $\mathrm{Fe}$ & 0.5" Dia. Foil Natural Fe & 50.0 & 1.28422 & \\
\hline Co & $0.5^{\prime \prime}$ Dia. Foil ${ }^{59} \mathrm{Co}$ & 0.5 & 0.014735 & Wrapped in Aluminum \\
\hline $\mathrm{Cu}$ & 0.5" Dia. Foil Natural Cu & 5.0 & 0.15365 & \\
\hline $\mathrm{Au}$ & 0.5" Dia. Foil ${ }^{197} \mathrm{Au}$ & 0.5 & 0.031616 & Wrapped in Aluminum \\
\hline$S$ & $0.5^{\prime \prime}$ Dia. Pellet Natural $\mathrm{S}$ & 82.0 & 0.53300 & Wrapped in Aluminum \\
\hline Al & $0.5^{\prime \prime}$ Dia. Foil ${ }^{27} \mathrm{Al}$ & 20.0 & 0.18723 & \\
\hline Sc & $0.5^{11}$ Dia. Foil ${ }^{45} \mathrm{Sc}$ & 5.0 & 0.04935 & Wrapped in Aluminum \\
\hline In & $0.5^{\prime \prime}$ Dia. Foil ${ }^{115}$ In & 2.0 & 0.04882 & Wrapped in Aluminum \\
\hline $\mathrm{Fe}$ & 0.5" Dia. Foil Natural Fe & 50.0 & 1.28683 & \\
\hline $\mathrm{Na}$ & 0.5" Dia. Pellet $\mathrm{NaCl}$ & 77.0 & 0.51541 & Wrapped in Aluminum \\
\hline $\mathrm{Ta}$ & Wire Loop Natural Ta & & 0.06571 & Dia. $15 \mathrm{mi} 7 \mathrm{~s}$ \\
\hline$u$ & $0.5^{\prime \prime}$ Dia. Foil 238U & 10.0 & 0.601215 & Wrapped in Aluminum \\
\hline$u$ & $0.5^{\prime \prime}$ Dia. Foil 235U & 5.0 & 0.302425 & Wrapped in Aluminum \\
\hline$N p$ & $0.5^{\prime \prime}$ Dia. Foil ${ }^{237} \mathrm{~Np}$ & 5.0 & 0.455427 & $\begin{array}{l}\text { Encapsulated in Aluminum } \\
0 . D .=0.75^{\prime \prime}\end{array}$ \\
\hline $\mathrm{Pu}$ & $0.425 "$ Dia. Foil 95\% 239Pu & 5.0 & 0.16915 & $\begin{array}{l}\text { Encapsulated in } 0.005^{\prime \prime} \\
\text { Aluminum } 0 . \mathrm{D}=0.5^{\prime \prime}\end{array}$ \\
\hline
\end{tabular}


The irradiation was carried out on January 30, 1974 and terminated at 12:18 pm after 86 minutes at a nominal power of 1750 Watts. After the irradiation, the foils were recovered and divided into two groups. The first group included all reactions with a half-life of less than one day and selected others. This group was counted at ANL and the longer half-life foils were shipped to HEDL for counting at a later time. The second group of foils was sent to HEDL immediately and was available for counting on the day following the irradiation.

\subsection{Analytical Methods}

Calculations on the EMC configurations in which spectrum measurements were made were performed using the two-dimensional diffusion theory program, $2 D B S,(6)$ with 42 energy group cross-section data. Neutron spectra at all six locations where proton-recoil measurements were made were extracted from these calculations and compared to the proton-recoil data. For three positions, comparisons were also made with neutron spectra inferred via the foil irradiations from SAND-II analyses.

In the following paragraphs, the details of the SAND-II analyses and the diffusion theory calculations along with a brief description of finegroup spectrum calculations performed by ANL are given.

\subsection{Analyses of Irradiated Foils}

Flux and fluence characterization by the multiple foil technique utilizes measured reaction rates and an iterative code, SAND-II, (4) to determine the neutron spectrum and the absolute flux level.

The accuracy of the spectrum determined in this way is not only dependent on the reaction rate measurement accuracy and the adequacy of the input spectrum but also the cross sections. Therefore, validation of these cross sections for self-consistency in benchmark spectra ${ }^{(7)}$ and in EBR-II ${ }^{(8)}$ is an important goal of current dosimetry efforts. $(9,10)$

In addition, a number of direct comparisons have been made between multiple foil spectral determinations, differential measurement techniques, and calculations. The comparisons with differential measurements are of 
necessity made in low-power nuclear facilities because high-power reactors such as EBR-II and FFTF are not generally accessible for differential spectrum measurements. Comparisons of multiple foil measurements with calculations have been made at a number of locations in EBR-II (11) and will be made in FFTF as part of the FFTF Reactor Characterization Program. These comparisons, in general, show good relative agreement with in the reactor core away from large perturbations and boundaries. (11)

Comparisons of differential measurements with multiple foil results in fast reactor-type benchmark spectra have been made in ECEL core 16 with proton-recoil, $(12)$ in CFRMF with proton-recoil ${ }^{(7)}$ and more recently ${ }^{6} \mathrm{Li}_{\mathrm{i}}$ spectrometry, ${ }^{(13)}$ in $\Sigma \Sigma$ with proton-recoil, ${ }^{3} \mathrm{He}$ and ${ }^{6} \mathrm{Li},{ }$ (13) and in BIG-10 with proton-recoil and ${ }^{6 i}$ (13) In addition, recent comparisons with measurements of the ${ }^{235} \mathrm{U}$ and ${ }^{252} \mathrm{Cf}$ fission spectra have been made. (10)

The results of these comparisons have varied. In some cases, good agreement was obtained and in others biases were observed. Some of these biases tended to indicate an energy shift between multiple foil and proton recoil but the shapes appeared similar. In other cases, such as the fission spectra, differences in certain regions occurred, indicating either a consistent spectral measurement error (e.g., neglect of scattering in the ${ }^{235} U$ target) or an error in the cross sections of reactions covering that energy range. (10)

The SAND-II program starts with an input spectral estimate, usually from a multigroup calculation, and modifies this estimate to derive an inferred neutron flux spectrum $\phi(E)$ such that calculated reaction rates $R_{j}$ as determined by the equation

$$
R_{i}=\int \phi(E) \sigma_{i}(E) d E
$$

are in agreement with the measured values. Constraints imposed by the program, however, prevent an exact solution being reached when reaction rates which are sensitive to the same neutron energies are inconsistent. In other words, the amount of spurious structure in the spectrum that can be introduced by data inconsistencies is limited both in regions where good 
overlap of reactions occurs and in energy regions of poor foil coverage. For this study a new version of the SAND-II Monte Carlo code was used which utilized reaction rate and cross section uncertainty weighting to achieve a best solution. $(14,15)$

\subsection{ANL Fine-Group Calculations}

Calculations of the EMC spectrum at the core center were performed by $\operatorname{ANL}^{(5,16)}$ using the SDX ${ }^{(17)}$ program and a 132-group cross section set $(\Delta u=0.1)$. A comparison of the calculated results plotted in References 5 and 16 will reveal some differences. The earlier calculations (Reference 16) lacked a heterogeneity correction, while the results reported in Reference 5 (and reproduced in Section 5.0 of this report) included this correction. Correcting for heterogeneity had the effect of softening the calculated spectrum and improving the agreement with the proton-recoil measurements.

\subsection{Broad Group Spectrum Calculations}

The 42-group 20BS ${ }^{(6)}$ (2-D) diffusion theory calculations performed as a part of this analysis were based on cross-section data and modeling techniques consistent with other HEDL analyses of EMC experiments. $(2,18,19)$ These cross section data and calculational models are described below.

\subsubsection{Cross-Section Data}

The 42-group cross-section data employed in this analysis originated with the FTR Set 300-S 1ibrary. (20) This library contains 42-group infinitely dilute cross-section data together with tables of F-factors in the Bondarenko ${ }^{(21)}$ format. The Set 300-S library was generated with the ETOX ${ }^{(22)}$ program from ENDF/B-II data and subsequently modified such that it is nearly consistent with ENDF/B-III data.

The bounds of the 42 energy groups are shown in Table 4.1 . The lethargy width of each group is 0.5 with the exception of groups 7 and 8 which encompass the $440 \mathrm{KeV}$ oxygen resonance, groups 13, 14 and 15 which isolate the iron "window" at about $24 \mathrm{KeV}$, groups 19, 20 and 21 which span the large sodium resonance at about $3 \mathrm{KeV}$, and group 42, which is the thermal group. 
TABLE $4 \cdot 1$

42-GROUP ENERGY STRUCTURE

\begin{tabular}{|c|c|c|}
\hline GROUP & LOWER ENERGY BOUNDARY * (ev) & LETHARGY INTERVAL \\
\hline 1 & $6.065+6$ & .5 \\
\hline 2 & $3.679+6$ & .5 \\
\hline 3 & $2.231+6$ & .5 \\
\hline 4 & $1.353+6$ & .5 \\
\hline 5 & $8.208+5$ & .5 \\
\hline 6 & $4.979+5$ & .5 \\
\hline 7 & $3.877+5$ & .25 \\
\hline 8 & $3.020+5$ & .25 \\
\hline 9 & $1.832+5$ & .5 \\
\hline 10 & $1.111+5$ & .5 \\
\hline 11 & $6.738+4$ & .5 \\
\hline 12 & $4.087+4$ & .5 \\
\hline 13 & $2.554+4$ & .47 \\
\hline 14 & $1.989+4$ & .25 \\
\hline 15 & $1.503+4$ & .28 \\
\hline 16 & $9.119+3$ & .5 \\
\hline 17 & $5.531+3$ & .5 \\
\hline 18 & $3.355+3$ & .5 \\
\hline 19 & $2.840+3$ & .167 \\
\hline 20 & $2.404+3$ & .167 \\
\hline 21 & $2.035+3$ & .167 \\
\hline 22 & $1.234+3$ & .5 \\
\hline 23 & $7.485+2$ & .5 \\
\hline 24 & $4.540+2$ & .5 \\
\hline 25 & $2.754+2$ & .5 \\
\hline 26 & $1.670+2$ & .5 \\
\hline 27 & $1.013+2$ & .5 \\
\hline 28 & $6.144+1$ & .5 \\
\hline 29 & $3.727+1$ & .5 \\
\hline 30 & $2.260+1$ & .5 \\
\hline 31 & $1.371+1$ & .5 \\
\hline 32 & $8.315+0$ & .5 \\
\hline 33 & $5.043+0$ & .5 \\
\hline 34 & $3.059+0$ & .5 \\
\hline 35 & $1.855+0$ & .5 \\
\hline 36 & $1.125+0$ & .5 \\
\hline 37 & $6.826-1$ & .5 \\
\hline 38 & $4.140-1$ & .5 \\
\hline 39 & $2.511-1$ & .5 \\
\hline 40 & $1.523-1$ & .5 \\
\hline 41 & $9.237-2$ & .5 \\
\hline 42 & Thermal + & \\
\hline
\end{tabular}


Details of the procedures used to obtain effective cross-section data from the Set 300-S library data are given in Reference 18, and are summarized briefly here.

All heavy element cross sections were heterogeneously resonance self-shielded. Asymmetric plate Dancoff factors were computed explicitly for each typical fuel plate in the EMC inner and outer two-drawer cells. The fuel cross sections were then elastic-removal corrected over the appropriate spectra using a one-dimensional model of the EMC and the 1DX (23) program. Finally, the fuel cross sections were corrected by energy group for the spatial structure of the cell group fluxes using the one-dimensional transport theory code DTF-IV. (24) The core structural materials, test loops, reflectors and shields are homogeneously resonance self-shielded and elasticremoval corrected separately in a single pass through 1DX. The cellhomogenized fuel cross sections and homogeneous nonfuel isotopes are combined to serve as input cross sections for the 2DBS reactor calculations.

\subsubsection{Calculational Models}

Calculational models employed in this analysis were twodimensional midplane representations of the EMC. In general, the models contained one noda1 point per EMC drawer (i.e., the mesh spacing was $~ 2$ " in both $X$ and $Y$ directions). However, there are two exceptions, which are:

1) Each drawer constituting SP-625 contained four nodal points ( 2 " mesh spacing).

2) The region in and around the ZPR-9 matrix position 18-13 (at the core-reflector interface) had one-inch mesh spacing.

The finer mesh structure was used at these two measurement locations because they are both near the core-radial reflector boundary, where rapid spectral shifts can occur.

Two calculational models were employed, one for each of the two basic configurations used in the course of the experiments (see Section 3.1). Both were based on the BOL-REF-5S loading with sodium channel in GP-201 and SP-625. The first contained a total of nine peripheral shim rods, as shown 
in Figure 3.1, while the second contained only three, as shown in Figure 3.2. Space-energy-independent axial buckling values of 0.000567 and $0.000565 \mathrm{~cm}^{-2}$ were used for the first and second models, respectively. These values were based on a buckling study reported in Appendix $C$ of Reference 25.

\subsection{Comparison of Results and Discussion}

Comparisons of results obtained by the experimental and calculational techniques described above are presented in the following sections. These comparisons are divided into four parts. In Section 5.1, a comparison of the ANL fine group calculation with the proton-recoil results is made. In Section 5.2, results of SAND-II analyses of the multiple foil irradiations are presented and comparisons with the proton-recoil measurements and broad group diffusion theory results are made. In Section 5.3, the results of the broad group diffusion theory calculations are compared to proton-recoil results. Finally, in Section 5.4, comparisons illustrating the spectral shifts with spatial location are presented.

\subsection{Comparison of ANL Fine-Group Calculations to Proton-Recoil Measurements}

Calculations of the EMC spectrum at the core center using a fine group energy structure were performed by ANL as described in Section 4.2. The results of this calculation are compared to the spectrum obtained from proton-recoil measurements in Figure 5.1, which is reproduced from Reference 5. Error bars on the measured data in this figure, and in others to follow, reflect only statistical uncertainty.

The measured and calculated spectra plotted in Figure 5.1 have been normalized such that $\int \phi(E) d E=C$ over the energy range of the experimental data, where $C$ is an arbitrary constant.

In general, the agreement between calculation and measurement in Figure 5.1 is very good. The most significant disagreement is near the high-energy limit and around $100 \mathrm{KeV}$. At energies above $1 \mathrm{MeV}$, systematic errors in the proton-recoil measurements occur, as discussed in Section 3.2. Thus, the high-energy discrepancy between calculation and experiment could well be attributable to experimental errors. However other studies ${ }^{(10)}$ have consistently shown that calculations aive too few high-energy neutrons above 1 to $2 \mathrm{MeV}$. 


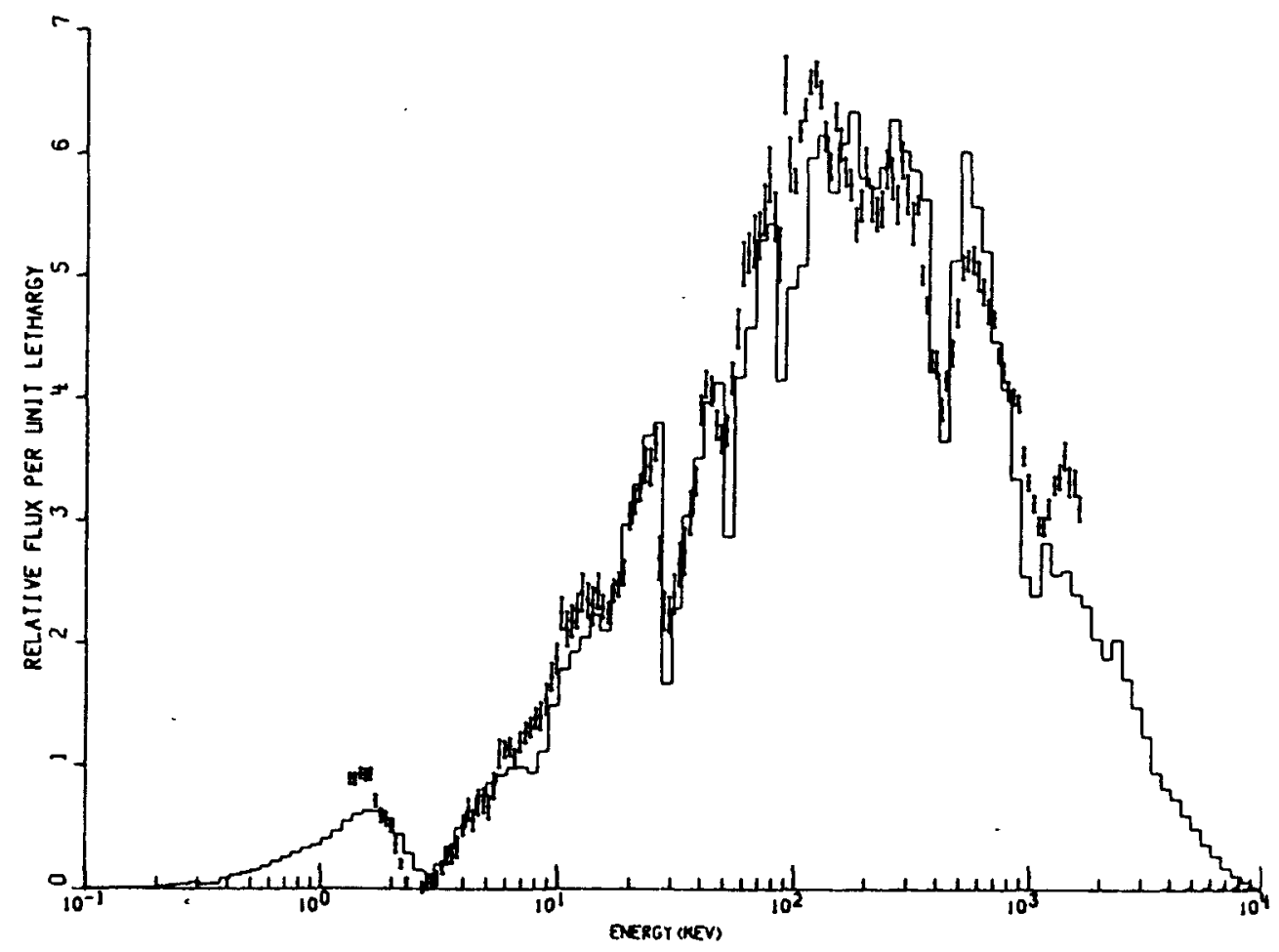

Figure 5.1. Comparison of Proton-Recoil Measurement and Fine Group Calculation of the Core Center Spectrum. 


\subsection{Results of Multiple Foil Analys is}

The measured reaction rates resulting from the foil irradiations are presented in Tables 5.1, 5.2 and 5.3. Each reaction rate is reported according to which laboratory did the counting. The reaction rates measured at both laboratories indicate inconsistencies of $10-20 \%$ for some foils, but others are much larger. This is due in part to calibration differences between the HEDL and ANL laboratories. In general, greater reliance was placed on the HEDL results because of the intercalibration with the ILRR program. (26) The ANL results were achieved with less well calibrated systems and with a geometry that was not identical with available calibration sources.

Because of the low counting rates obtainable for many of the reactions, particularly for the longer half-life reactions counted at HEDL, obtaining accurate results presented great difficulties. This is especially true for the LLFM position which will be discussed separately.

To obtain adequate reactions, the foils used were thick enough that reaction self-shielding was not negligible for nonthreshold reactions. No detailed self-shielding calculations for these foils in the EMC were available, but rough estimates indicated corrections of $210-20 \%$ for ${ }^{197} \mathrm{Au}(n, \gamma)$, ${ }^{181} \mathrm{Ta}(n, \gamma),{ }^{63} \mathrm{Cu}(n, \gamma)$ and ${ }^{59} \mathrm{Co}(n, \gamma)$.

The starting spectra for SAND-II unfolding were obtained from the 42group diffusion theory calculations described in Section 4.3. These groups were expanded by SAND to 620 groups. This expansion utilizes a fission spectrum shape at the high energy end and maintains integral consistency with the 42-group fluxes.

Spectra from GP-201 and SP-625 were first unfolded using all foils which were reasonably consistent with the starting spectrum. The reaction rates for these foils are underlined in Tables 5.1 and 5.2. Ones showing a deviation larger than about 50\% from the mean were deleted as being erroneous. The foils used and the final calculated activities are shown in Tables 5.4 and 5.5 and compared with the experimental values. The cross sections used were taken from the SAND-II library ${ }^{(27)}$ except for the ${ }^{235} U$, 
TABLE 5.1

REACTION RATES - EMC POSITION 1 - GP201

Reaction Rate ${ }^{a}$

Reaction

HEDL $\%$ Error $^{d}$

ANL

Ratio

ANL/HEDL

\begin{tabular}{|c|c|c|c|c|}
\hline \multicolumn{3}{|l|}{${ }^{23} \mathrm{Na}(n, \gamma){ }^{24} \mathrm{Na}$} & \multicolumn{2}{|l|}{$1.437-17$} \\
\hline${ }^{27} \mathrm{Al}(n, \alpha){ }^{24} \mathrm{Na}$ & & & $2.119-18$ & \\
\hline${ }^{32} S(n, p)^{32} p$ & $2.142-16$ & 3.0 & & \\
\hline${ }^{45} S c(n, \gamma)^{46} S c$ & $1.239-15$ & 3.0 & & \\
\hline${ }^{47} \mathrm{Ti}(\mathrm{n}, \mathrm{p})^{47} \mathrm{Sc}$ & $6.91-17$ & 6.0 & & \\
\hline$\left.{ }^{48} \mathrm{Ti}(n, p)\right)^{48} \mathrm{Sc}$ & $9.62-19$ & 3.8 & & \\
\hline${ }^{54} \mathrm{Fe}(n, p){ }^{54} \mathrm{Mn}$ & $2.485-16$ & 5.9 & $2.904-15$ & 17.6 \\
\hline${ }^{56} \mathrm{Fe}(n, p){ }^{56} \mathrm{Mn}$ & & & $3.328-18$ & \\
\hline${ }^{58} \mathrm{Fe}(n, \gamma){ }^{59} \mathrm{Fe}$ & not detectable & & & \\
\hline${ }^{59} \mathrm{Co}(n, \alpha){ }^{56} \mathrm{Mn}$ & & & $4.847-19$ & \\
\hline${ }^{59} \mathrm{Co}(n, \gamma){ }^{60} \mathrm{Co}$ & $4.088-15$ & 3.3 & $6.235-15$ & 1.53 \\
\hline${ }^{58} \mathrm{Ni}(n, p){ }^{58} \mathrm{Co}$ & $\underline{3.981-16}$ & 3.2 & $5.903-16$ & 1.48 \\
\hline${ }^{63} \mathrm{Cu}(n, \gamma){ }^{64} \mathrm{Cu}$ & $2.282-15$ & 2.4 & $2.535-15$ & 1.11 \\
\hline${ }^{115} \operatorname{In}\left(n, n^{\prime}\right)^{115 m_{I n}}$ & & & $1.009-15$ & \\
\hline${ }^{115} \operatorname{In}(n, \gamma)^{116} \operatorname{In}$ & & & $1.257-14$ & \\
\hline${ }^{127} I(n, 2 n)^{126} I$ & not available & & & \\
\hline${ }^{181} \mathrm{Ta}(\mathrm{n}, \gamma)^{182} \mathrm{Ta}$ & $3.463-14$ & 3.1 & & \\
\hline $197 \mathrm{Au}(\mathrm{n}, \gamma){ }^{198} \mathrm{Au}$ & $2.849-14$ & 2.2 & $3.494-14$ & 1.23 \\
\hline${ }^{23} U(n, f) F P^{b}$ & $7.183-14$ & 2.1 & & \\
\hline${ }^{238} U(n, f) F P^{b}$ & $1.454-15$ & 3.1 & & \\
\hline${ }^{238} U(n, \gamma)^{239} \mathrm{~Np}$ & $1.083-14$ & 4.7 & & \\
\hline${ }^{237} \mathrm{~Np}(n, f) F P C$ & $9.848-15$ & 4.0 & & \\
\hline $23{ }^{9} \mathrm{Pu}(n, f) \mathrm{FP}^{\mathrm{C}}$ & $6.663-14$ & 5.8 & & \\
\hline
\end{tabular}

1.48

1.11

11.6

a. Reactions per nucleus per sec. The notation 2.142-16 is equivalent to $2.142 \times 10^{-16}$. Underlined reaction rate values are those used in the SAND-II unfolding.

b. Average of reaction rate as determined from ${ }^{140} \mathrm{Ba},{ }^{95} \mathrm{Zr}$, and ${ }^{103} \mathrm{Ru}$.

c. Reaction rate determined from ${ }^{140} \mathrm{Ba}$.

d. Counting uncertainty only. 
TABLE 5.2

REACTION RATES - EMC POSITION 2 - SP-625

Reaction

\begin{tabular}{cr} 
& React \\
\hline$\underline{\text { HEDL }}$ & \% Error \\
& \\
& \\
$2.585-16$ & 3.0 \\
$\underline{9.315-16}$ & 3.8 \\
$\underline{4.44-17}$ & 10.4 \\
$\underline{4.07-19}$ & 5.0 \\
$\underline{1.453-16}$ & 7.5
\end{tabular}

Ratio

ANL/HEDL

${ }^{23} \mathrm{Na}(\mathrm{n}, \gamma){ }^{24} \mathrm{Na}$

$1.097-17$

${ }^{27} \mathrm{Al}(\mathrm{n}, \alpha)^{24} \mathrm{Na}$

$1.303-18$

${ }^{32} S(n, p){ }^{32} p$

3.0

${ }^{45} S c(n, \gamma)^{46} S c$

3.8

${ }^{47} \mathrm{Ti}(n, p){ }^{47} \mathrm{Sc}$

0.4

${ }^{48} \mathrm{Ti}(n, p)^{48} \mathrm{SC}$

5.0

${ }^{54} \mathrm{Fe}(n, p){ }^{54} \mathrm{Mn}$

7.5

$1.958-15$

13.5

${ }^{56} \mathrm{Fe}(n, p){ }^{56} \mathrm{Mn}$

not detectable

2.133-18

${ }^{58} \mathrm{Fe}(\mathrm{n}, \gamma){ }^{59} \mathrm{Fe}$

7.520-14

${ }^{59} \mathrm{Co}(\mathrm{n}, \alpha){ }^{56} \mathrm{Mn}$

2.985-19

${ }^{59} \mathrm{Co}(n, y){ }^{60} \mathrm{Co}$

5.974-15

5.6

6.170-15

1.03

${ }^{58} \mathrm{Ni}(n, p){ }^{58} \mathrm{Co}$

2.358-16

3.4

3. $506-16$

1.49

${ }^{63} \mathrm{Cu}(n, \gamma){ }^{64} \mathrm{Cu}$

$\underline{1.575-15}$

2.5

$1.837-15$

1.16

${ }^{115} \operatorname{In}\left(n, n^{\prime}\right)^{115 \mathrm{~m}} \mathrm{In}$

6.384-16

${ }^{115} \operatorname{In}(n, \gamma)^{116} \operatorname{In}$

$\underline{1.274-14}$

${ }^{127} I(n, 2 n)^{126} I$

$2.611-18$

4.1

${ }^{181} \mathrm{Ta}(\mathrm{n}, \gamma)^{182} \mathrm{Ta}$

$3.002-14$

3.1

${ }^{197} \mathrm{Au}(\mathrm{n}, \gamma){ }^{198} \mathrm{Au}$

$3.212-14$

2.1

$3.663-14$

1.14

${ }^{23}{ }^{5} U(n, f) F P^{b}$

5.242-14

2.1

${ }^{238} \mathrm{U}(\mathrm{n}, \mathrm{f}) \mathrm{FP}^{\mathrm{b}}$

$8.970-16$

3.5

${ }^{238} U(n, \gamma)^{239} \mathrm{~Np}$

$8.749-15$

3.7

${ }^{237} \mathrm{~Np}(n, f) F P C$

$\underline{5.972-15}$

6.6

${ }^{239} \mathrm{Pu}(\mathrm{n}, \mathrm{f}) \mathrm{FPC}$

4.805-14

4.2

a. Reactions per nucleus per sec. The notation 2.142-16 is equivalent to $2.142 \times 10^{-16}$. Underlined reaction rate values are those used in the SAND-II unfolding.

b. Average of reaction rate as determined from ${ }^{140} \mathrm{Ba},{ }^{9} \mathrm{Zr}$, and ${ }^{10{ }^{3} \mathrm{Ru}}$.

c. Reaction rate determined from ${ }^{140} \mathrm{Ba}$. 
TABLE 5.3

\section{REACTION RATES - EMC POSITION 3 - LLFM}

Reaction Rate ${ }^{a}$

\section{Reaction}

HEDL $\quad$ E Error ${ }^{\mathrm{e}}$

$\underline{\text { ANL }}$

Ratio

ANL/HEDL

${ }^{23} \mathrm{Na}(n, \gamma){ }^{24} \mathrm{Na}$

${ }^{27} \mathrm{Al}(\mathrm{n}, \alpha){ }^{24} \mathrm{Na}$

${ }^{32} S(n, p){ }^{32} \mathrm{p}$

${ }^{45} \mathrm{Sc}(n, \gamma){ }^{46} \mathrm{Sc}$

${ }^{54} \mathrm{Fe}(n, p){ }^{54} \mathrm{Mn}$

${ }^{56} \mathrm{Fe}(n, p){ }^{56} \mathrm{Mn}$

${ }^{59} \mathrm{Co}(n, \gamma){ }^{60} \mathrm{Co}$

${ }^{6} \mathrm{Cu}(\mathrm{n}, \gamma){ }^{64} \mathrm{Cu}$

$115 \mathrm{In}\left(\mathrm{n}, \mathrm{n}^{\prime}\right)^{115 \mathrm{~m}_{\mathrm{In}}}$

${ }^{115} \operatorname{In}(n, \gamma)^{116}$ In

${ }^{181} \mathrm{Ta}(\mathrm{n}, \gamma)^{182} \mathrm{Ta}$

${ }^{197} \mathrm{Au}(n, \gamma){ }^{198} \mathrm{Au}$

$235 U(n, f) F P^{b}$

$238 U(n, f) F P C$

${ }^{238} U(n, \gamma)^{239} \mathrm{~Np}$

$23{ }^{7} \mathrm{~Np}(n, f) \mathrm{FP}$

$2{ }^{3} \mathrm{Pu}(n, f) F \mathrm{Fd}^{\mathrm{d}}$
1.766-18
not detectable

3.5

3.6

not detectable

3.466-16

1.070-19

6.4

2.5

1.919-16

0.15

$1.492-18$

4.563-15

3.1

2.5

$1.249-14$

1.06

2.7

8.0

6.0

not available

2.606-14 5.3

a. Reactions per nucleus per sec. The notation 2.142-16 is equivalent to $2.142 \times 10^{-16}$. Underlined reaction rate values are those used in the SAND-II unfolding.

b. Average of reaction rate as determined from ${ }^{140} \mathrm{Ba},{ }^{95} \mathrm{Zr}$, and ${ }^{103} \mathrm{Ru}$.

c. Weighted average of ${ }^{140} \mathrm{Ba}$ and ${ }^{95} \mathrm{Zr}$ fission products.

d. Reaction rate determined from ${ }^{140} \mathrm{Ba}$.

e. Counting uncertainty only. 
${ }^{238} \mathrm{U}$, and ${ }^{239} \mathrm{Pu}$ fission reactions which were from ENDF/B-IV. Crosssection uncertainties are from McElroy and Kellogg. (7) The unfolding process weighted each foil according to assigned reaction rate measurement and crosssection uncertainties. $(7,14)$

A number of inconsistencies are noted after the unfolding process. These remain because constraints in the SAND-II code prevent complete convergence to zero deviations when foil data covering the same energy range appear inconsistent. Spectral adjustment in these cases, if not prevented by smoothness criteria, will introduce spurious structure into the spectrum to force a fit. Examples of these data inconsistencies are the $27 \%$ difference between ${ }^{181} \mathrm{Ta}(n, \gamma)$ and ${ }^{197} \mathrm{Au}(n, \gamma)$ at position 1 (GP-201) and the $15 \%$ difference between ${ }^{115} \operatorname{In}\left(n, n^{\prime}\right)$ and ${ }^{237} \mathrm{~Np}(n, f)$ at position 2 (SP-625).

A second unfolding run was made using a selected set of seven foils chosen from the most reliable reactions to give the most consistent agreement from Tables 5.4 and 5.5 and giving good spectral coverage. The results of these unfolding runs are shown in Tables 5.6 and 5.7. Much greater consistency was obtained with the limited set. However, as expected because of the weighting procedure, the resultant spectra were little changed. The total fluxes agreed to within $5 \%$ and mean energies to within $10 \%$ for the two analyses.

Comparisons with the input spectrum and uncertainties in the unfolded spectra are shown in Figures 5.2 and 5.3 for the seven foil cases. It is noted that agreement is obtained within $1 \sigma$ throughout most of the spectral range on a group-averaged basis and all points fall within about $2 \sigma$ of the calculations.

The analysis of flux spectrum at the LLFM position had to rely on a smaller number of reactions which had low counting rates and large errors. Data from the various reactions were very inconsistent and it was not obvious which measurements were in error. It was particularly difficult to gain a reasonable estimate of the fast flux using the threshold reactions selected for the greatest sensitivity. The results of the best unfolding run using six foils are presented in Table 5.8. 
TABLE 5.4

SAND MONTE CARLO UNFOLDING RESULTS - POSITION 1 - GP-201

RESULTS OBTAINED AFTER 20 ITERATION LIMIT

\begin{tabular}{|c|c|c|c|c|c|c|}
\hline \multirow[b]{2}{*}{ FOIL REACTION } & \multirow{2}{*}{$\begin{array}{c}\text { SATURATED } \\
\text { MEASURED } \\
\text { ACT IVITY } \\
\text { (DPS/NUCLEYS) }\end{array}$} & \multirow{2}{*}{$\begin{array}{c}\text { SATURATED } \\
\text { CALCULATED } \\
\text { ACTIVITY } \\
\text { (DPS/NUCLEUS) }\end{array}$} & \multicolumn{2}{|c|}{$\begin{array}{c}\text { NOMINAL } \\
\text { 5.00 PERCENT } \\
\text { ACTIVITY } \\
\text { LIMITS (MEV) }\end{array}$} & \multirow{2}{*}{$\begin{array}{c}\text { RATIO } \\
\text { MEASURED TO } \\
\text { CALCULATED } \\
\text { ACTIVITIES } \\
\end{array}$} & \multirow[t]{2}{*}{$\begin{array}{c}\text { DEVIATION } \\
\text { OF MEASURED } \\
\text { FROM } \\
\text { CALCULATED } \\
\text { ACTIVITY } \\
\text { (PERCENT) } \\
\end{array}$} \\
\hline & & & LOWER & UPPER & & \\
\hline $\begin{array}{l}\text { U235(N,F)FP6 } \\
\text { U238(N,F)FP6 } \\
\text { PU239(N,F)FP6 } \\
\text { TA181(N,G)TA182 } \\
\text { C059(N,A)MN56 } \\
\text { N158(N,P)C058 } \\
\text { SC45(N,G)SC46 } \\
\text { U238(N,G)U239 } \\
\text { AU197(N,G)AU198 } \\
\text { C059(N,G)C060 } \\
\text { IN115(N,G)C060 } \\
\text { CU63(N,G)CU64 } \\
\text { FE54(N,P)MN54 } \\
\text { S32(N,P)P32 } \\
\text { TI47(N,P)SC47 } \\
\text { TI48(N,P)SC48 } \\
\text { FE56(N,P)MN56 } \\
\text { NP237(N,F)FP } \\
\text { AL27(N,A)NA24 } \\
\text { IN115(N,N)M }\end{array}$ & $\begin{array}{l}7.183 \mathrm{E}-14 \\
1.454 \mathrm{E}-15 \\
6.663 \mathrm{E}-14 \\
3.463 \mathrm{E}-14 \\
4.847 \mathrm{E}-19 \\
3.981 \mathrm{E}-16 \\
1.239 \mathrm{E}-15 \\
1.083 \mathrm{E}-14 \\
2.849 \mathrm{E}-14 \\
4.088 \mathrm{E}-15 \\
1.257 \mathrm{E}-14 \\
2.282 \mathrm{E}-15 \\
2.485 \mathrm{E}-16 \\
2.142 \mathrm{E}-16 \\
6.910 \mathrm{E}-17 \\
9.620 \mathrm{E}-19 \\
3.328 \mathrm{E}-18 \\
9.848 \mathrm{E}-15 \\
2.119 \mathrm{E}-18 \\
1.009 \mathrm{E}-15\end{array}$ & $\begin{array}{l}6.709 \mathrm{E}-14 \\
1.472 \mathrm{E}-15 \\
6.495 \mathrm{E}-14 \\
2.895 \mathrm{E}-14 \\
4.948 \mathrm{E}-19 \\
3.799 \mathrm{E}-16 \\
1.124 \mathrm{E}-15 \\
1.133 \mathrm{E}-14 \\
3.084 \mathrm{E}-14 \\
4.180 \mathrm{E}-15 \\
1.418 \mathrm{E}-14 \\
2.619 \mathrm{E}-15 \\
2.679 \mathrm{E}-16 \\
2.174 \mathrm{E}-16 \\
6.978 \mathrm{E}-17 \\
8.869 \mathrm{E}-19 \\
3.435 \mathrm{E}-18 \\
1.065 \mathrm{E}-14 \\
2.285 \mathrm{E}-18 \\
9.827 \mathrm{E}-16\end{array}$ & $\begin{array}{l}3.800 \mathrm{E}-04 \\
1.400 \mathrm{E}+00 \\
4.000 \mathrm{E}-04 \\
1.000 \mathrm{E}-04 \\
5.900 \mathrm{E}+00 \\
1.900 \mathrm{E}+00 \\
8.000 \mathrm{E}-04 \\
6.600 \mathrm{E}-05 \\
1.600 \mathrm{E}-04 \\
1.200 \mathrm{E}-04 \\
3.400 \mathrm{E}-04 \\
5.750 \mathrm{E}-04 \\
2.000 \mathrm{E}+00 \\
2.300 \mathrm{E}+00 \\
2.000 \mathrm{E}+00 \\
6.800 \mathrm{E}+00 \\
5.500 \mathrm{E}+00 \\
3.400 \mathrm{E}-01 \\
6.500 \mathrm{E}+00 \\
8.000 \mathrm{E}-01\end{array}$ & $\begin{array}{l}1.500 E+00 \\
5.800 E+00 \\
2.000 E+00 \\
3.400 E-01 \\
1.300 E+01 \\
7.300 E+00 \\
4.750 E-01 \\
6.600 E-01 \\
2.800 E-01 \\
1.600 E-01 \\
8.000 E-01 \\
3.200 E-01 \\
7.800 E+00 \\
7.400 E+00 \\
6.600 E+00 \\
1.400 E+01 \\
1.210 E+01 \\
4.000 E+00 \\
1.280 E+01 \\
5.100 E+00\end{array}$ & $\begin{array}{l}1.0706 \\
.9877 \\
1.0259 \\
1.1960 \\
.9795 \\
1.0479 \\
1.1026 \\
.9558 \\
.9239 \\
.9779 \\
.8865 \\
.8714 \\
.9276 \\
.9852 \\
.9902 \\
1.0846 \\
.9689 \\
.9243 \\
.9274 \\
1.0264\end{array}$ & $\begin{array}{r}7.06 \\
-1.23 \\
2.59 \\
19.60 \\
-2.05 \\
4.79 \\
10.26 \\
-4.42 \\
-7.61 \\
-2.21 \\
-17.35 \\
-12.86 \\
-7.24 \\
-1.48 \\
-.98 \\
8.46 \\
-3.11 \\
-7.57 \\
-7.26 \\
2.64\end{array}$ \\
\hline & & STA & DEVIATION & F MEASURED & IVITIES (PERCENT) & 7.96 \\
\hline
\end{tabular}


TABLE 5.5

SAND MONTE CARLO UNFOLDING RESULTS - POSITION 2 - SP-625

RESULTS OBTAINED AFTER 20 ITERATION LIMIT

\begin{tabular}{|c|c|c|c|c|c|c|}
\hline \multirow[b]{2}{*}{ FOIL REACTION } & \multirow{2}{*}{$\begin{array}{c}\text { SATURATED } \\
\text { MEASURED } \\
\text { ACTIVITY } \\
\text { (DPS/NUCLEUS) } \\
\end{array}$} & \multirow{2}{*}{$\begin{array}{c}\text { SATURATED } \\
\text { CALCULATED } \\
\text { ACTIVITY } \\
\text { (DPS/NUCLEUS) }\end{array}$} & \multicolumn{2}{|c|}{$\begin{array}{c}\text { NOMINAL } \\
\text { 5.00 PERCENT } \\
\text { ACTIVITY } \\
\text { LIMITS (MEV) }\end{array}$} & \multirow{2}{*}{$\begin{array}{c}\text { RATIO } \\
\text { MEASURED TO } \\
\text { CALCULATED } \\
\text { ACTIVITIES } \\
\end{array}$} & \multirow{2}{*}{$\begin{array}{c}\text { DEVIATION } \\
\text { OF MEASURED } \\
\text { FROM } \\
\text { CALCULATED } \\
\text { ACTIVITY } \\
\text { (PERCENT) }\end{array}$} \\
\hline & & & LOWER & UPPER & & \\
\hline $\begin{array}{l}\text { U235(N,F)FP6 } \\
\text { U238(N,F)FP6 } \\
\text { PU239(N,F)FP6 } \\
\text { TA181 (N,G)TA182 } \\
\text { C059(N,A)MN56 } \\
\text { NI58(N,P)C058 } \\
\text { SC45(N,G)SC46 } \\
\text { AU197 (N,G)AU198 } \\
\text { C059(N,G)C060 } \\
\text { IN115(N,G) IN1 16M } \\
\text { CU63(N,G)CU64 } \\
\text { FE54(N,P)MN54 } \\
\text { I127(N,2N) I126 } \\
\text { TI47(N,P) SC47 } \\
\text { TI48(N,P) SC48 } \\
\text { FE56(N,P)MN56 } \\
\text { NP237(N,F)FP } \\
\text { AL27(N,A)NA24 } \\
\text { IN115(N,N)M }\end{array}$ & $\begin{array}{l}5.242 \mathrm{E}-14 \\
8.970 \mathrm{E}-16 \\
4.805 \mathrm{E}-14 \\
3.002 \mathrm{E}-14 \\
2.985 \mathrm{E}-19 \\
2.358 \mathrm{E}-16 \\
9.315 \mathrm{E}-16 \\
3.212 \mathrm{E}-14 \\
5.974 \mathrm{E}-15 \\
1.274 \mathrm{E}-14 \\
1.575 \mathrm{E}-15 \\
1.453 \mathrm{E}-16 \\
2.611 \mathrm{E}-18 \\
4.440 \mathrm{E}-17 \\
4.070 \mathrm{E}-19 \\
2.133 \mathrm{E}-18 \\
5.972 \mathrm{E}-15 \\
1.303 \mathrm{E}-18 \\
6.384 \mathrm{E}-16\end{array}$ & $\begin{array}{l}4.937 \mathrm{E}-14 \\
9.010 \mathrm{E}-16 \\
4.826 \mathrm{E}-14 \\
3.165 \mathrm{E}-14 \\
2.816 \mathrm{E}-19 \\
2.283 \mathrm{E}-16 \\
8.378 \mathrm{E}-16 \\
3.169 \mathrm{E}-14 \\
6.042 \mathrm{E}-15 \\
1.422 \mathrm{E}-14 \\
1.783 \mathrm{E}-15 \\
1.605 \mathrm{E}-16 \\
2.364 \mathrm{E}-18 \\
4.203 \mathrm{E}-17 \\
4.919 \mathrm{E}-19 \\
2.034 \mathrm{E}-18 \\
6.479 \mathrm{E}-15 \\
1.262 \mathrm{E}-18 \\
5.999 \mathrm{E}-16\end{array}$ & $\begin{array}{l}3.200 E-05 \\
1.400 E+00 \\
1.500 E-05 \\
4.500 E-06 \\
5.800 E+00 \\
1.900 E+00 \\
1.900 E-05 \\
4.750 E-06 \\
1.100 E-04 \\
1.350 E-06 \\
5.750 E-04 \\
1.900 E+00 \\
1.020 E+01 \\
1.900 E+00 \\
6.600 E+00 \\
5.500 E+00 \\
3.200 E-01 \\
6.400 E+00 \\
8.000 E-01\end{array}$ & $\begin{array}{l}1.200 \mathrm{E}+00 \\
5.800 \mathrm{E}+00 \\
1.800 \mathrm{E}+00 \\
2.100 \mathrm{E}-01 \\
1.300 \mathrm{E}+01 \\
7.100 \mathrm{E}+00 \\
4.000 \mathrm{E}-01 \\
1.900 \mathrm{E}-01 \\
4.250 \mathrm{E}-02 \\
5.250 \mathrm{E}-01 \\
2.800 \mathrm{E}-01 \\
7.500 \mathrm{E}+00 \\
1.500 \mathrm{E}+01 \\
6.500 \mathrm{E}+00 \\
1.390 \mathrm{E}+01 \\
1.220 \mathrm{E}+01 \\
4.000 \mathrm{E}+00 \\
1.300 \mathrm{E}+01 \\
5.100 \mathrm{E}+00\end{array}$ & $\begin{array}{r}1.0618 \\
.9956 \\
.9956 \\
.9484 \\
1.0600 \\
1.0330 \\
1.1119 \\
1.0134 \\
.9887 \\
.8958 \\
.8835 \\
.9051 \\
1.1043 \\
1.0564 \\
.8274 \\
1.0489 \\
.9217 \\
1.0323 \\
1.0641\end{array}$ & $\begin{array}{r}6.18 \\
-.44 \\
-.44 \\
-5.16 \\
6.00 \\
3.30 \\
11.19 \\
1.34 \\
-1.13 \\
-10.42 \\
-11.65 \\
-9.49 \\
10.43 \\
5.64 \\
-17.26 \\
4.89 \\
-7.83 \\
3.23 \\
6.41\end{array}$ \\
\hline & & STANL & DEVIATION & MEASURED & VITIES (PERCENT) & 7.99 \\
\hline
\end{tabular}


SAND MONTE CARLO UNFOLDING RESULTS - POSITION 1 - GP-201 USING SELECTED SET OF FOILS

RESULTS OBTAINED AFTER 20 ITERATION LIMIT

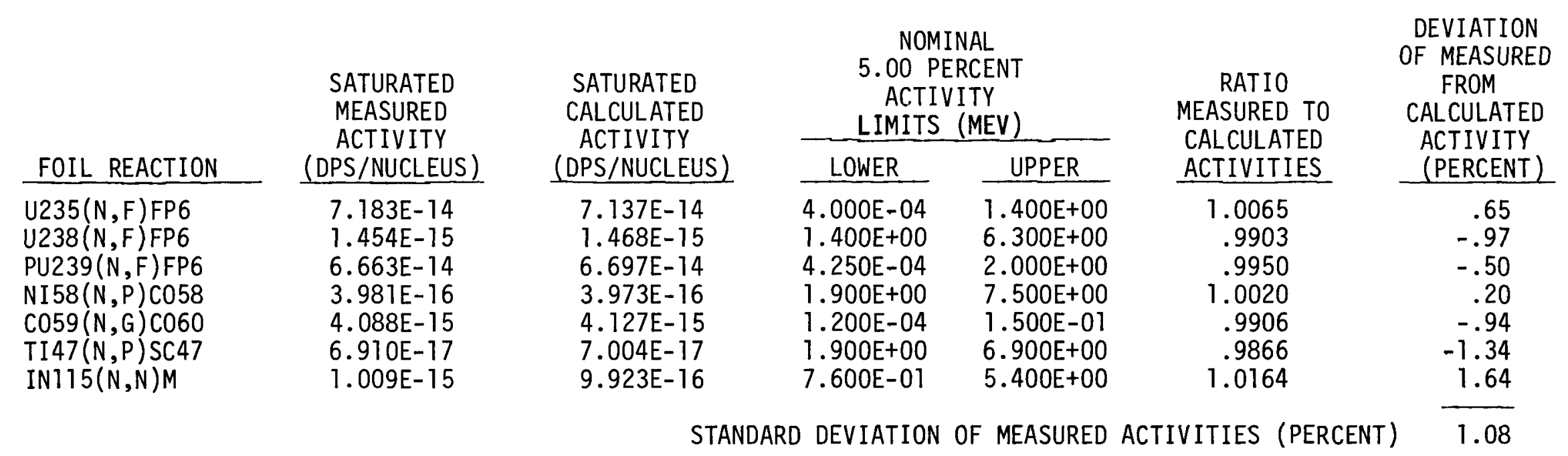

TABLE 5.7

SAND MONTE CARLO UNFOLDING RESULTS - POSITION 2 - SP-625 USING SELECTED SET OF FOILS

\begin{tabular}{|c|c|}
\hline $\begin{array}{l}\text { U235(N,F)FP6 } \\
\text { U238(N,F)FP6 } \\
\text { PU239(N,F)FP6 } \\
\text { NI58(N,P)C058 } \\
\text { C059(N,G)CO60 } \\
\text { TI47(N,P)SC47 } \\
\text { IN115(N,N)M }\end{array}$ & $\begin{array}{l}5.242 \mathrm{E}-14 \\
8.970 \mathrm{E}-16 \\
4.805 \mathrm{E}-14 \\
2.358 \mathrm{E}-16 \\
5.974 \mathrm{E}-15 \\
4.440 \mathrm{E}-17 \\
6.384 \mathrm{E}-16\end{array}$ \\
\hline
\end{tabular}

$5.166 \mathrm{E}-14$
$9.124 \mathrm{E}-16$
$4.894 \mathrm{E}-14$
$2.369 \mathrm{E}-16$
$5.989 \mathrm{E}-15$
$4.246 \mathrm{E}-17$
$6.200 \mathrm{E}-16$

$3.200 \mathrm{E}-05$
$1.400 \mathrm{E}+00$
$1.500 \mathrm{E}-05$
$1.900 \mathrm{E}+00$
$1.050 \mathrm{E}-04$
$1.900 \mathrm{E}+00$
$7.600 \mathrm{E}-01$

$1.200 E+00$

$6.200 E+00$

$1.800 \mathrm{E}+00$

7. $500 \mathrm{E}+00$

$3.000 \mathrm{E}-02$

$6.900 \mathrm{E}+00$

5. $300 \mathrm{E}+00$
1.0147
.9832
.9819
.9953
.9975
1.0457
1.0297

CALCULATED

ACTIVITY

.65

$-.97$

20

$-.94$

1.64

STANDARD DEVIATION OF MEASURED ACTIVITIES (PERCENT)

1.47

$-1.68$

$-1.81$

$-.47$

$-.25$

4.57

2.97

TABLE 5.8

SAND-II UNFOLDING RESULTS - EMC POSITION 3 - LLFM

$\begin{array}{ll}\text { U235(N,F)FP6 } & 5.934 E-15 \\ \text { SC45(N,G)SC46 } & 1.574 E-16 \\ \text { AU197(N,G)AU198 } & 1.177 E-14 \\ \text { C059(N,G)CO60 } & 1.439 E-15 \\ \text { IN115(N,G)IN116M } & 4.563 E-15 \\ \text { IN115(N,N)M } & 1.492 E-18\end{array}$

$\begin{array}{ll}6.275 \mathrm{E}-15 & 7.200 \mathrm{E}-07 \\ 1.401 \mathrm{E}-16 & 3.600 \mathrm{E}-07 \\ 1.187 \mathrm{E}-14 & 4.500 \mathrm{E}-06 \\ 1.448 \mathrm{E}-15 & 1.350 \mathrm{E}-05 \\ 4.818 \mathrm{E}-15 & 7.200 \mathrm{E}-07 \\ 1.495 \mathrm{E}-18 & 4.750 \mathrm{E}-01\end{array}$

$1.050 \mathrm{E}-01$

.9457

$5.750 \mathrm{E}-02 \quad 1.1237$

$5.000 \mathrm{E}-03 \quad .9914$

4.250E-03 $\quad .9938$

$1.900 \mathrm{E}-02 \quad .9471$

$3.400 E+00$

.9983

2.52

STANDARD DEVIATION OF MEASURED ACTIVITIES (PERCENT 


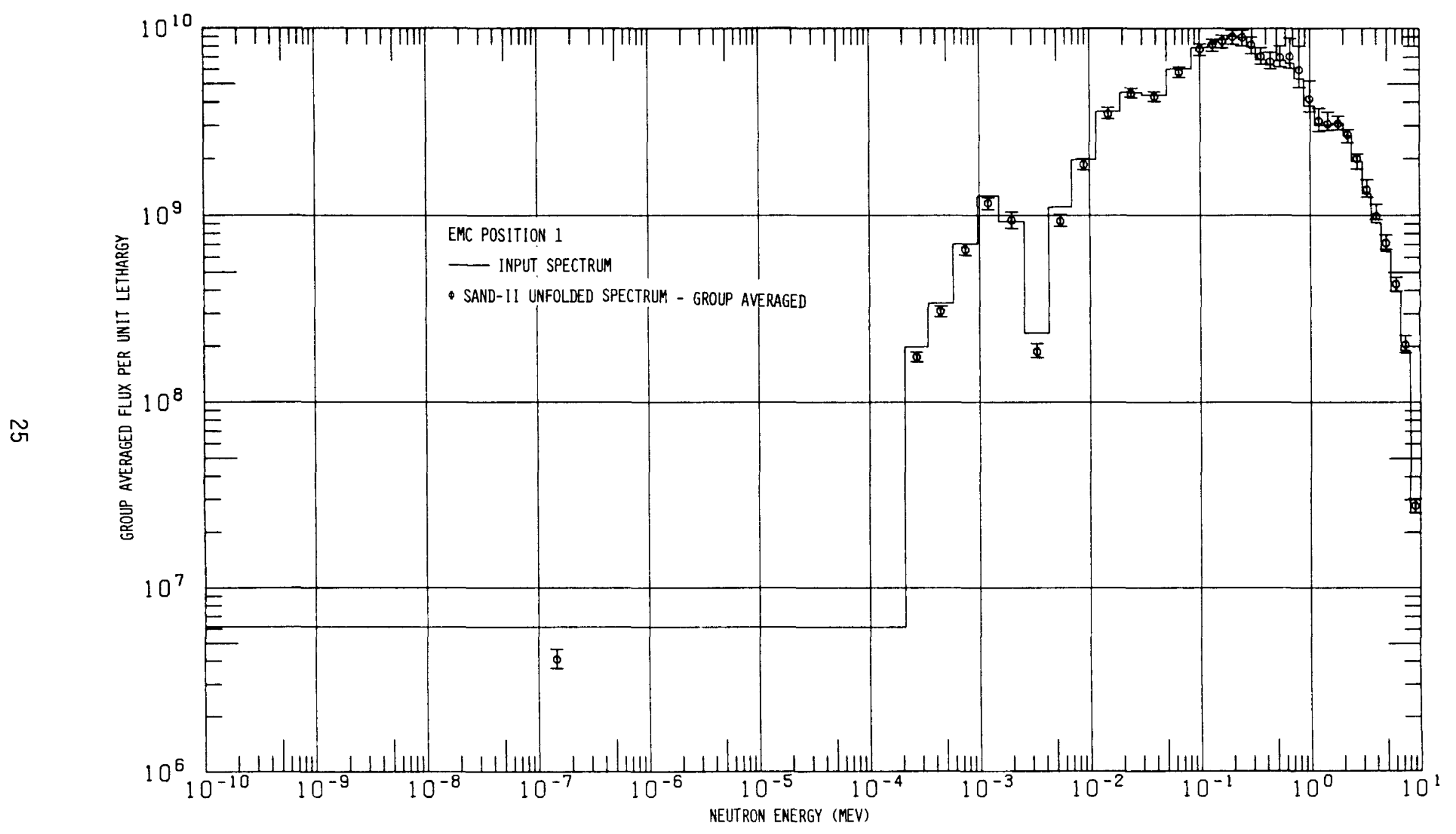

Figure 5.2. SAND Monte Carlo Unfolded Spectrum - GP-201. 


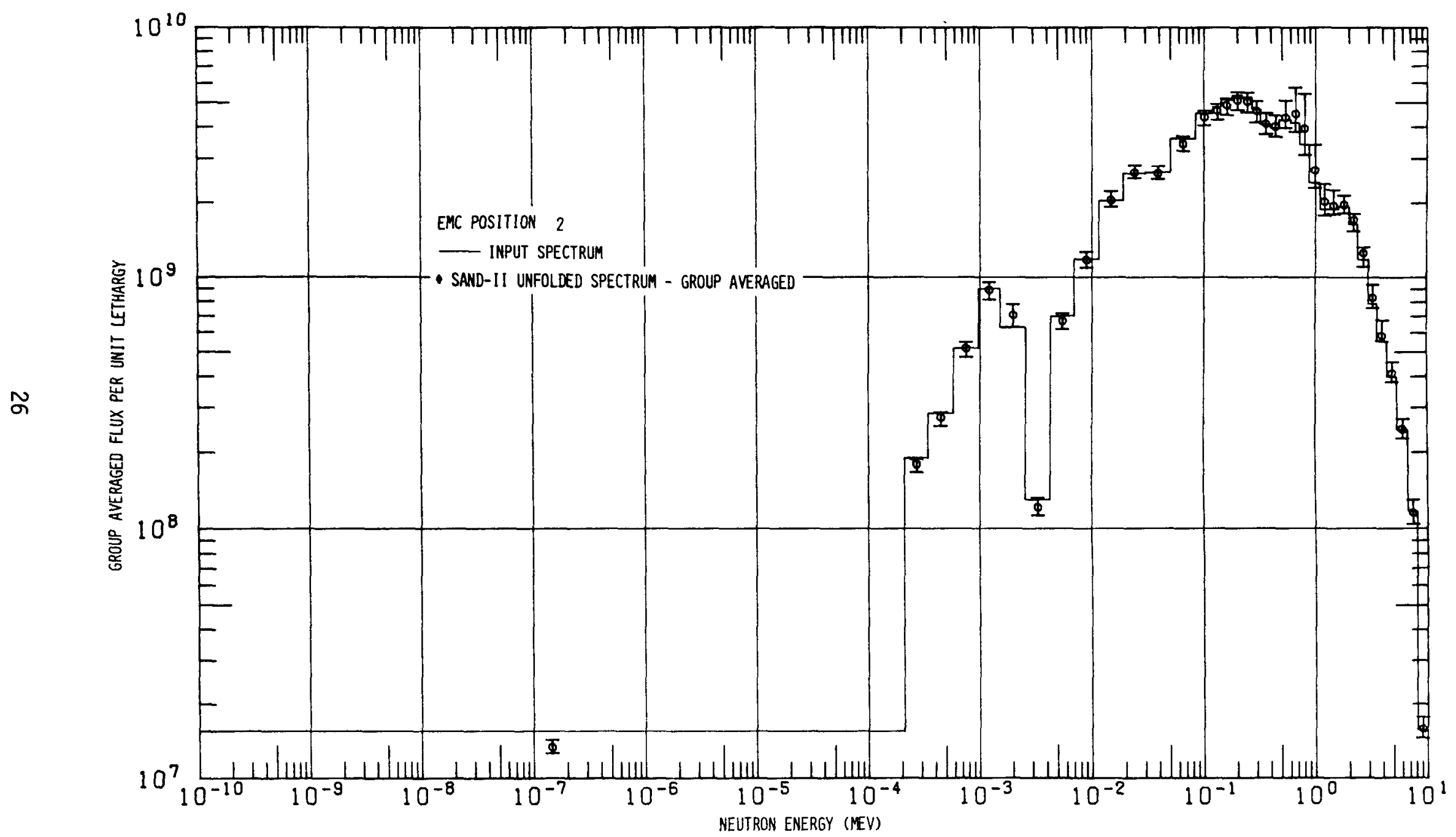

Figure 5.3. SAND Monte Carlo Unfolded Spectrum - SP-625. 
The final unfolding results for flux, flux with $E>0.1 \mathrm{MeV}$, and $\bar{E}$ are shown in Table 5.9. The values of total flux, flux $>0.1 \mathrm{MeV}$, and $\bar{E}$ (in MeV) for GP-201 and SP-625 are estimated to be accurate to 5\%, $7 \%$, and $5 \%(1 \sigma)$. respectively, using the SAND-II Monte Carlo code. The inconsistency of the data, however, indicates that the uncertainties input to this procedure are underestimated and therefore the above uncertainties are a lower bound. True uncertainties may be as much as twice the above. For the LLFM position uncertainties were not assigned in the SAND-II unfolding, but a reasonable estimate is a $1 \sigma$ uncertainty of $\sim 30 \%$.

TABLE 5.9

MULTIPLE FOIL RESULTS

\begin{tabular}{|c|c|c|c|}
\hline & GP-201 & SP-625 & LLFM \\
\hline Total Flux ${ }^{\star}$ & $3.46 \times 10^{10}$ & $2.11 \times 10^{10}$ & $9.43 \times 10^{8}$ \\
\hline Flux $(E>0.1 \mathrm{MeV})^{\star}$ & $2.11 \times 10^{10}$ & $1.26 \times 10^{10}$ & $2.38 \times 10^{8}$ \\
\hline Mean Energy (E) (MeV) & 0.45 & 0.45 & 0.10 \\
\hline
\end{tabular}

Final unfolded spectra for all three positions are compared with the multigroup calculation and with the proton-recoil results in Figures 5.4 through 5.6 .

These plots are on a $\log -\log$ scale which shows overall spectral shapes, but limits resolution of variations near the maximum flux. Detailed comparisons of the broad group calculations with the proton-recoil measurements on a linear scale are made in the next section.

For the GP-201 and SP-625 positions, good agreement between the SAND results and the broad group results is observed as noted above. Also, the general shapes of the computed spectra are in good agreement with the protonrecoil results. However, details of specific maxima in the proton-recoil spectra are not reproduced and deviations above $1 \mathrm{MeV}$ are observed, where the proton-recoil begins to lose accuracy. 


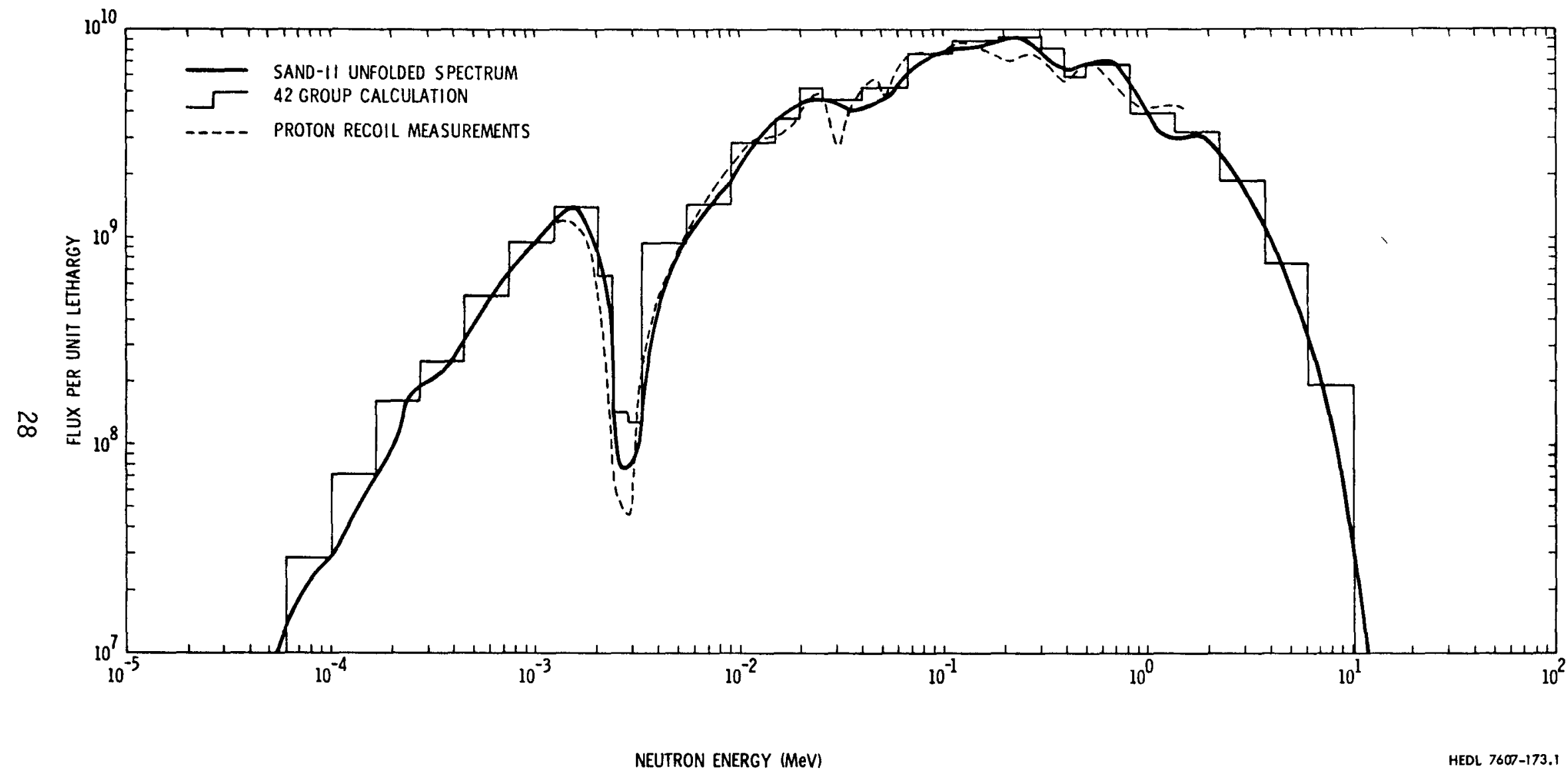

Figure 5.4. Comparison of SAND, Proton-Recoil, and Calculated Spectra - GP-201. 


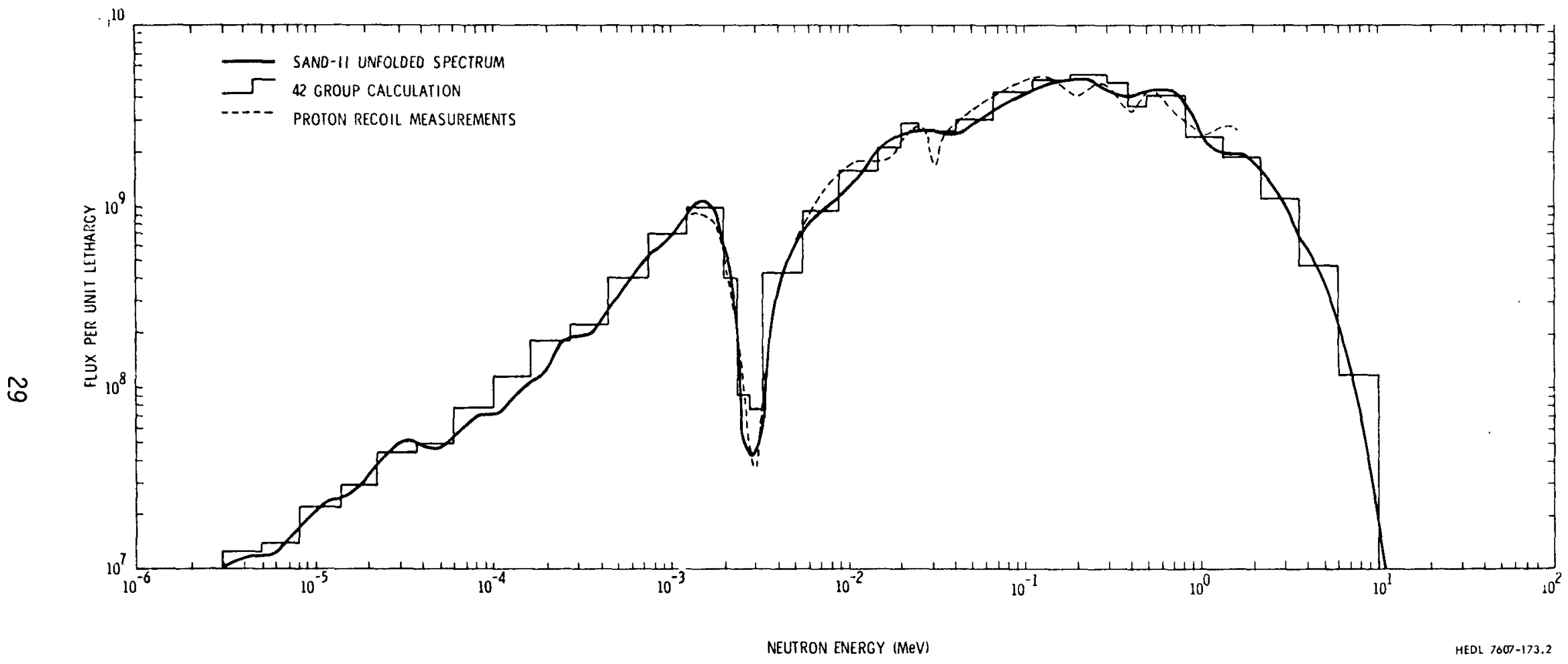

Figure 5.5. Comparison of SAND, Proton-Recoil, and Calculated Spectra - SP-625. 


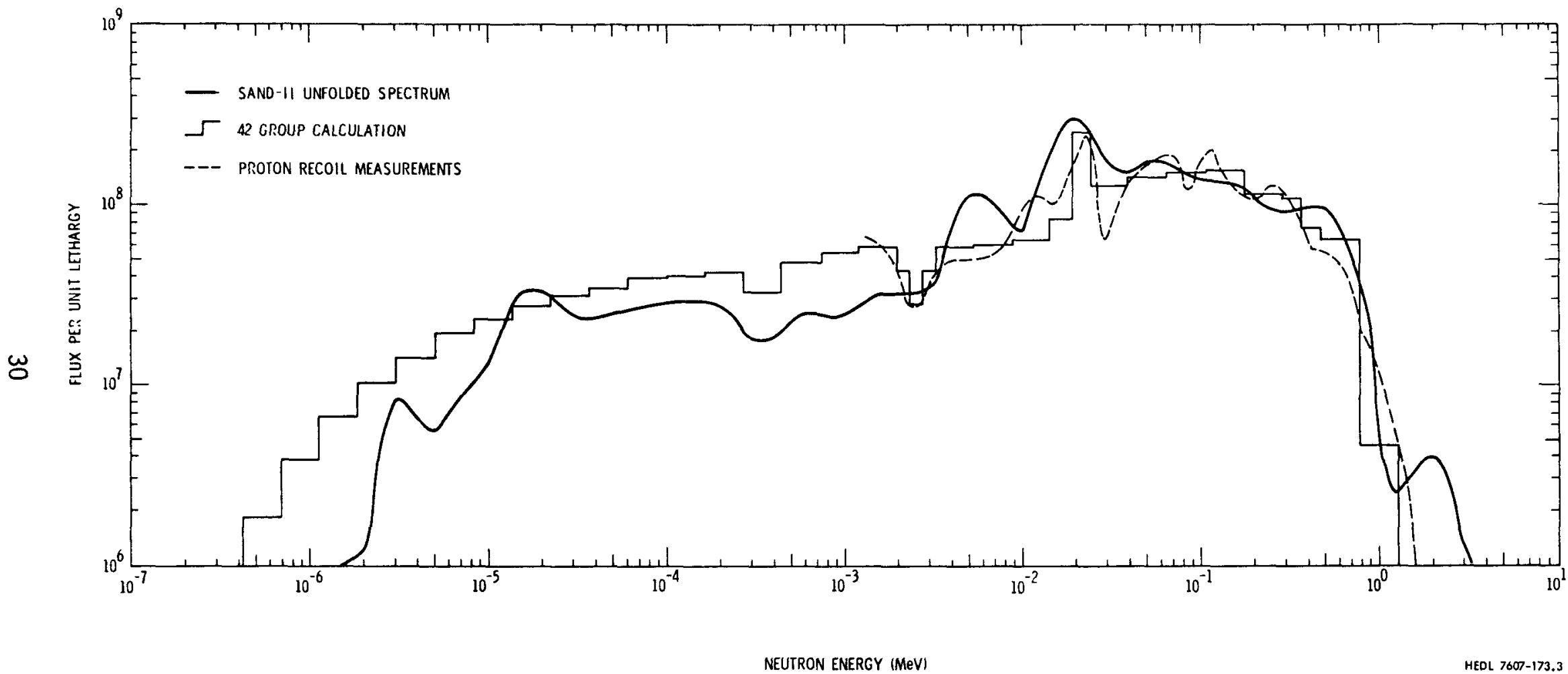

Figure 5.6. Comparison of SAND, Proton-Recoil, and Calculated Spectra - LLFM. 
For the LLFM position, comparisons are only approximate, as stated above. The multiple foil result falls below the calculation over most of the range below $2 \mathrm{KeV}$, which is probably due to neglect of self-shielding effects.

Between $20 \mathrm{KeV}$ and $1 \mathrm{MeV}$, the three curves in Fiqure 5.6 fali close together. Above $1 \mathrm{MeV}$, the multiple foil results indicate a significantly higher flux than diffusion theory results, but this region depends on the threshhold reaction data, which have rather large uncertainties at this position.

\subsection{Comparisons of Broad Group Diffusion Theory Calculations} and Proton-Recoil Measurements

Neutron spectra calculated with 42-group diffusion theory, as described in Section 4.2, are compared to the proton-recoil results for the six experimental locations in Figures 5.7 through 5.12. As before, both the calculated and measured data in these figures have been normalized such that $\int \phi(E) d E=C$ over the energy range of the measurements, where $C$ is an arbitrary constant. (For Figures 5.7 through 5.12, $C=20$. ) The unnormalized proton-recoil data are tabulated in Appendix A, while the $42-$ group flux data are tabulated in Appendix $B$. In order to facilitate com:parison of calculated and measured spectra, the normalized proton-recoil data were collapsed to the group structure of the calculation. These results are also plotted in Figures 5.7 through 5.12 .

In general, the agreement seen between calculation and experiment is quite good, even in the reflector and shield locations. For locations in the core or near the core boundary, the calculated spectra are slightiy harder than the measured spectra. The discrepancy between calculation and experiment is particularly noticeable in group 9 (183 to $302 \mathrm{KeV}$ ), where the calculated flux peaks.

For the reflector and shield locations, even though some of the flux fine structure due to scattering resonances in nickel and iron is lost in the broad group calculations, the general agreement between calculation and experiment is very good. This agreement indicates that the 42-group diffusion 
theory calculations accurately follow the spectral shifts that occur between the core center and the radial shield. ANL has previously reported $^{(28)}$ that this was the case for their 29-group diffusion theory calculations. 


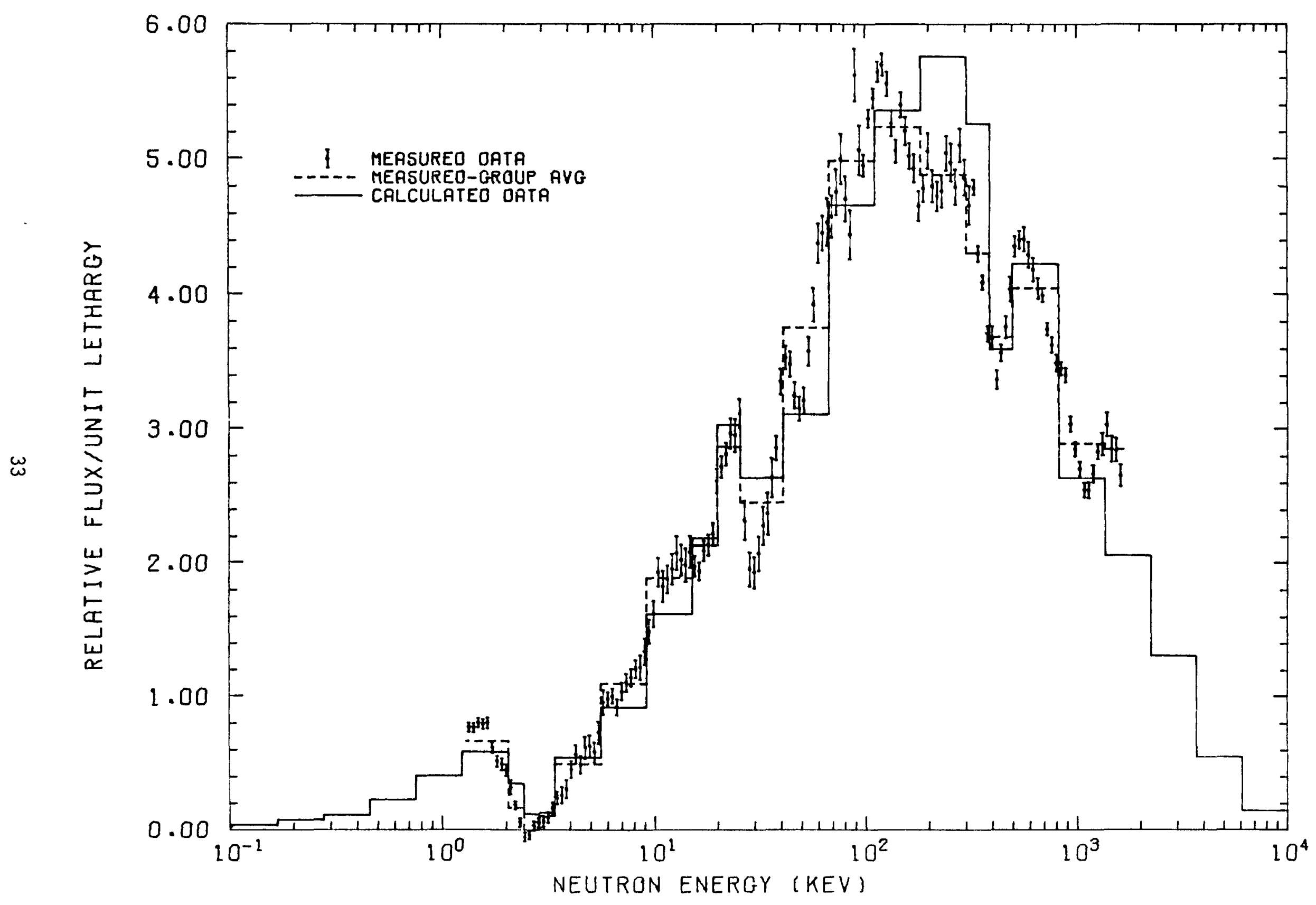

Figure 5.7. Comparison of Proton-Recoil and Calculated Spectra at Core Center. 


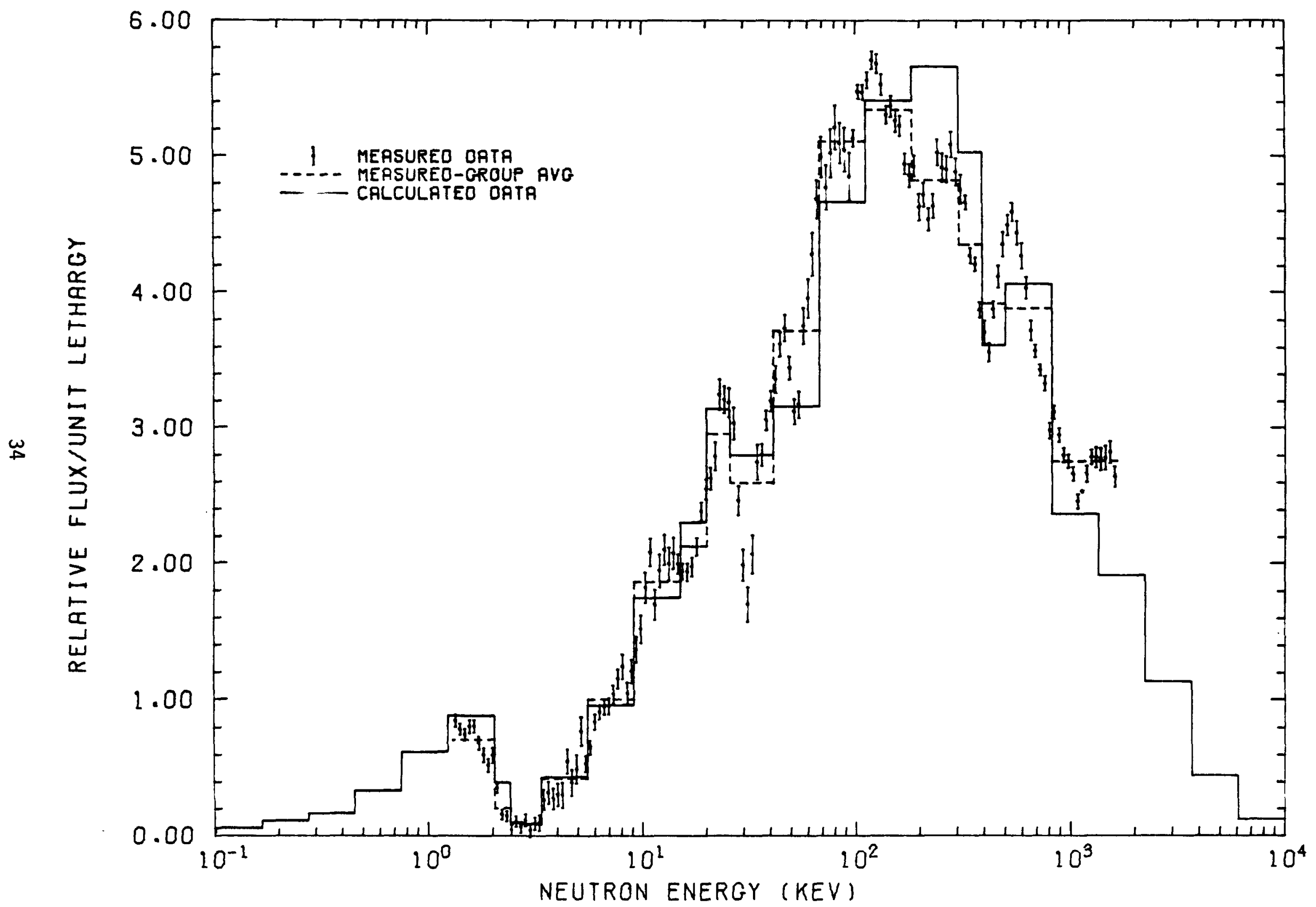

Figure 5.8. Comparison of Proton-Recoil and Calculated Spectra - GP-201. 


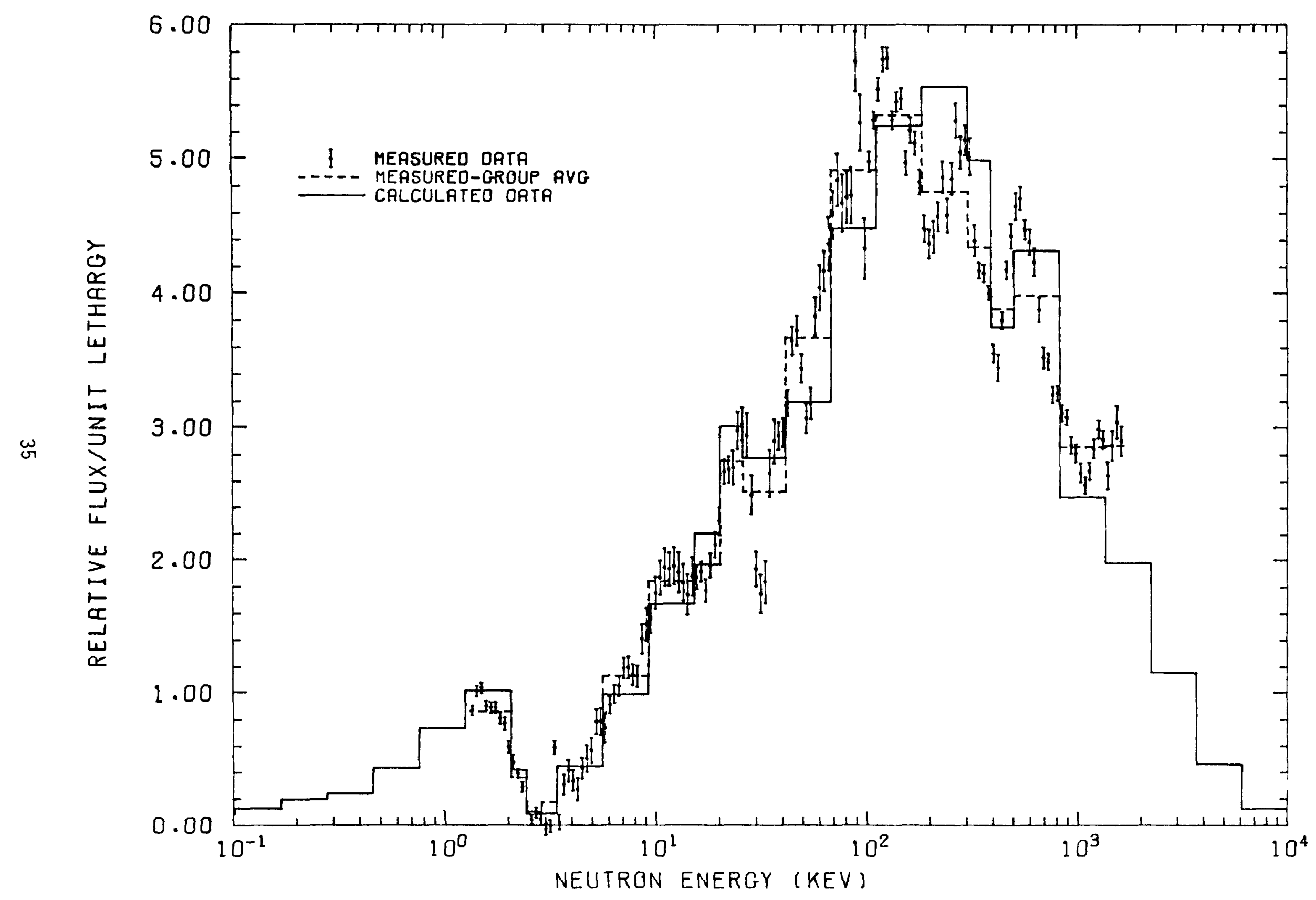

Figure 5.9. Comparison of Proton-Recoil and Calculated Spectra - SP-625. 


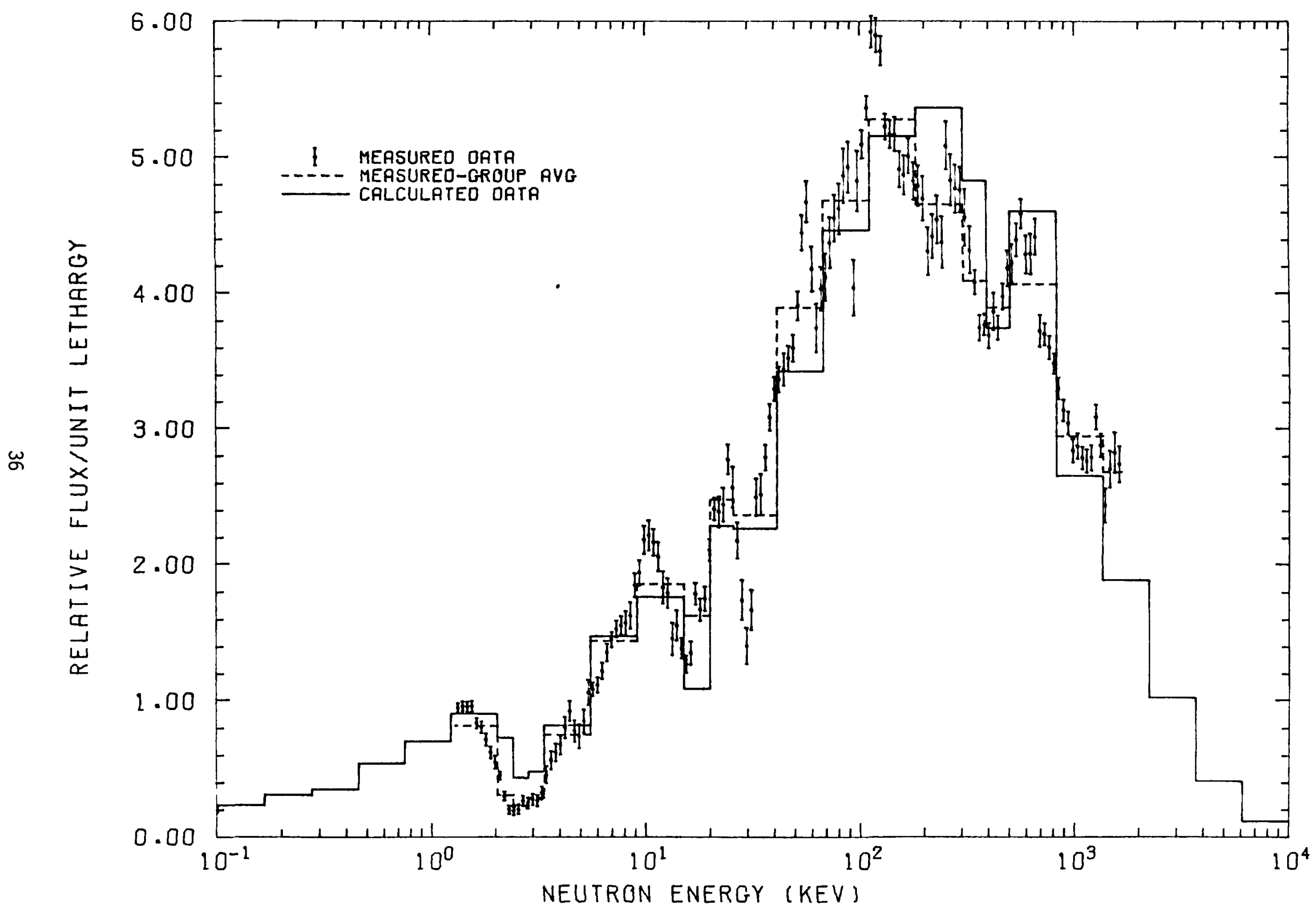

Figure 5.10. Comparison of Proton-Recoil and Calculated Spectra at the Core-Reflector Boundary. 


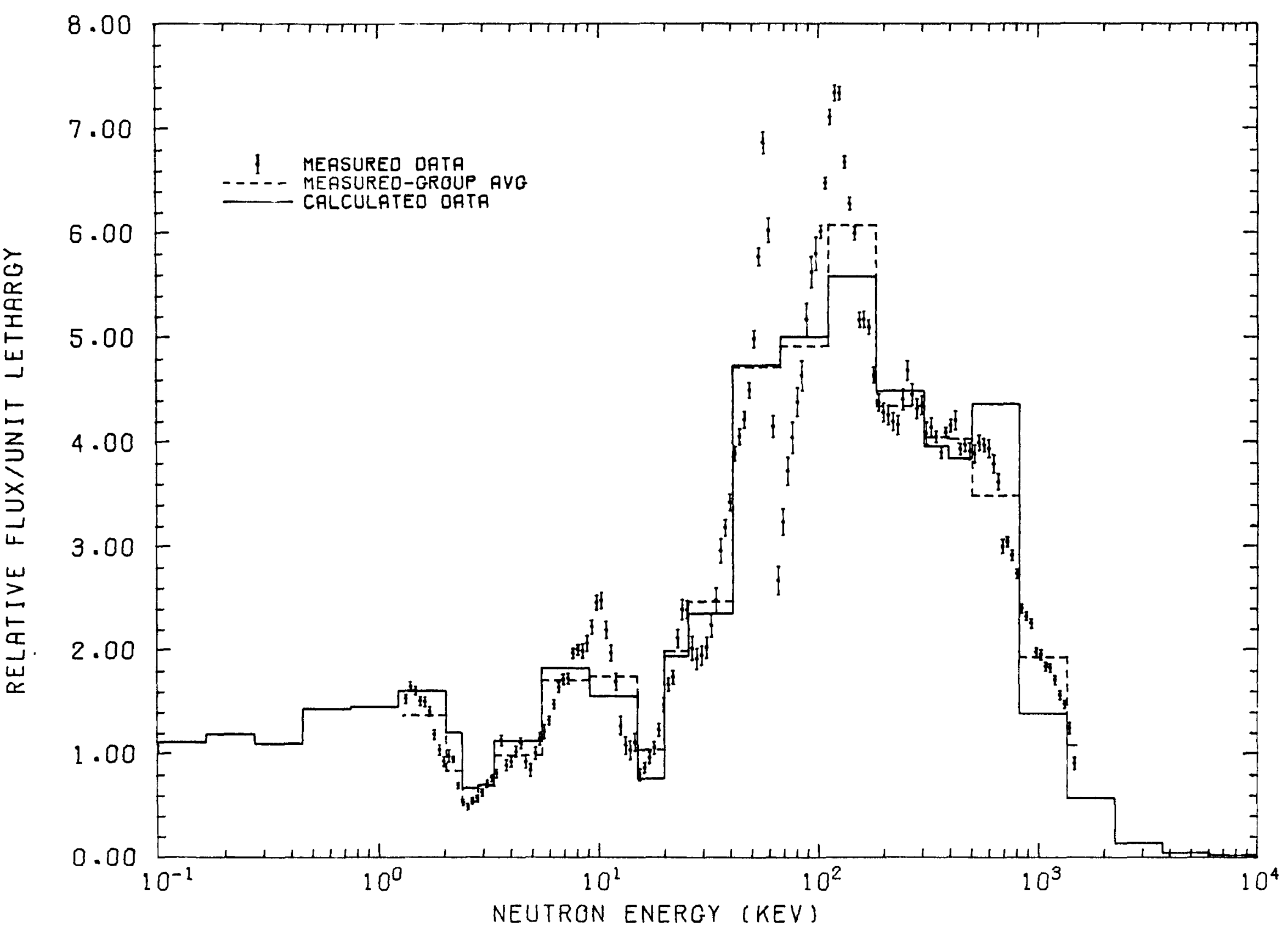

Figure 5.11. Comparison of Proton-Recoil and Calculated Spectra in the Reflector. 


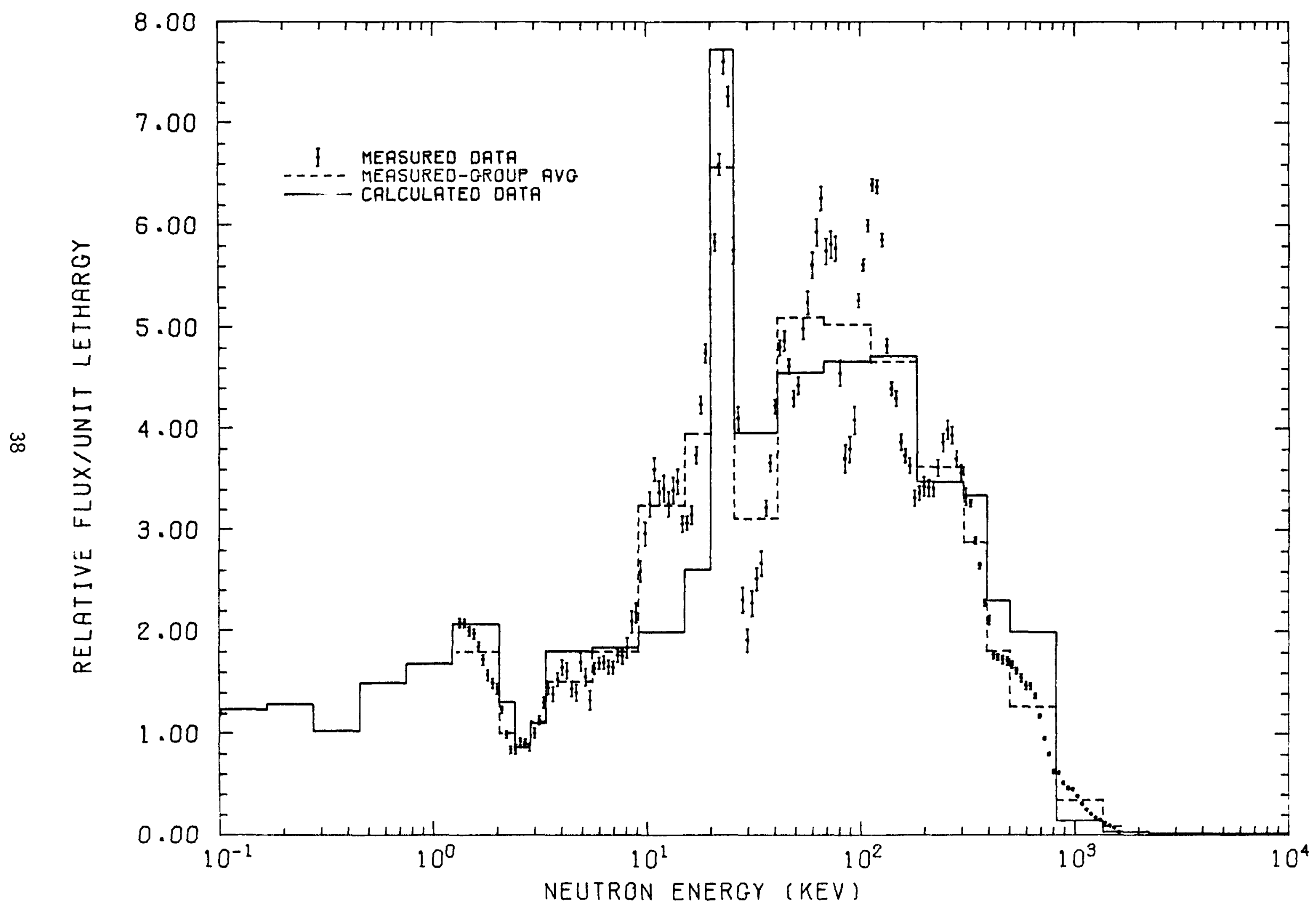

Figure 5.12. Comparison of Proton-Recoil and Calculated Spectra in the Shield. 


\subsection{Spectral Shifts in the EMC}

One of the purposes of this experiment was to characterize the spatial variations in the EMC spectrum. In this section, spectra obtained for the six measurement points are compared to show these spatial variations. In Figure 5.13 (obtained from $A N L$ ), the proton-recoil data for the core center and SP-625 locations have been visually fitted. The spectra at these two locations are very close, but as can be seen at the lower energies, the spectrum in SP-625 is slightly softer. A similar comparison of spectra at GP-201 and the core center showed that there is very little difference between these locations.

In Figure 5.14, 42-group calculated spectra for the core center, SP-625 and the core-reflector interface, are compared. In a 11 three cases, the energy-dependent fluxes were normalized such that $\phi(u) d u=1$. Although not large, a progressive softening of the spectrum can be seen. Especially noticeable in this figure is the effect of the strong $15 \mathrm{KeV}$ scattering resonance in nickel on the spectrum at the core-reflector interface. Again, the spectrum in GP-201 is not shown because it is so close to the core center spectrum.

In Figure $5.15,42$-group calculated spectra at the core-reflector interface, in the reflector, and in the shield are compared, and a large spectral shift in progressing from the core-reflector interface to the middle of the radial reflector is apparent. Also, a further spectral shift can be seen between the reflector and the shield, where scattering resonances in iron have a pronounced effect.

\subsection{Conclusions, Recommendations and Applications}

From the results of 42-group diffusion theory comparisons with experiments, it can be concluded that such calculations can be used to obtain reasonable predictions of the flux spectrum in the FTR from the core out into the shield, within the resolution permitted by the broad group structure. However, there is much fine structure in the flux, particularly in the reflector and shield regions, that is lost with the broad group calculations. 


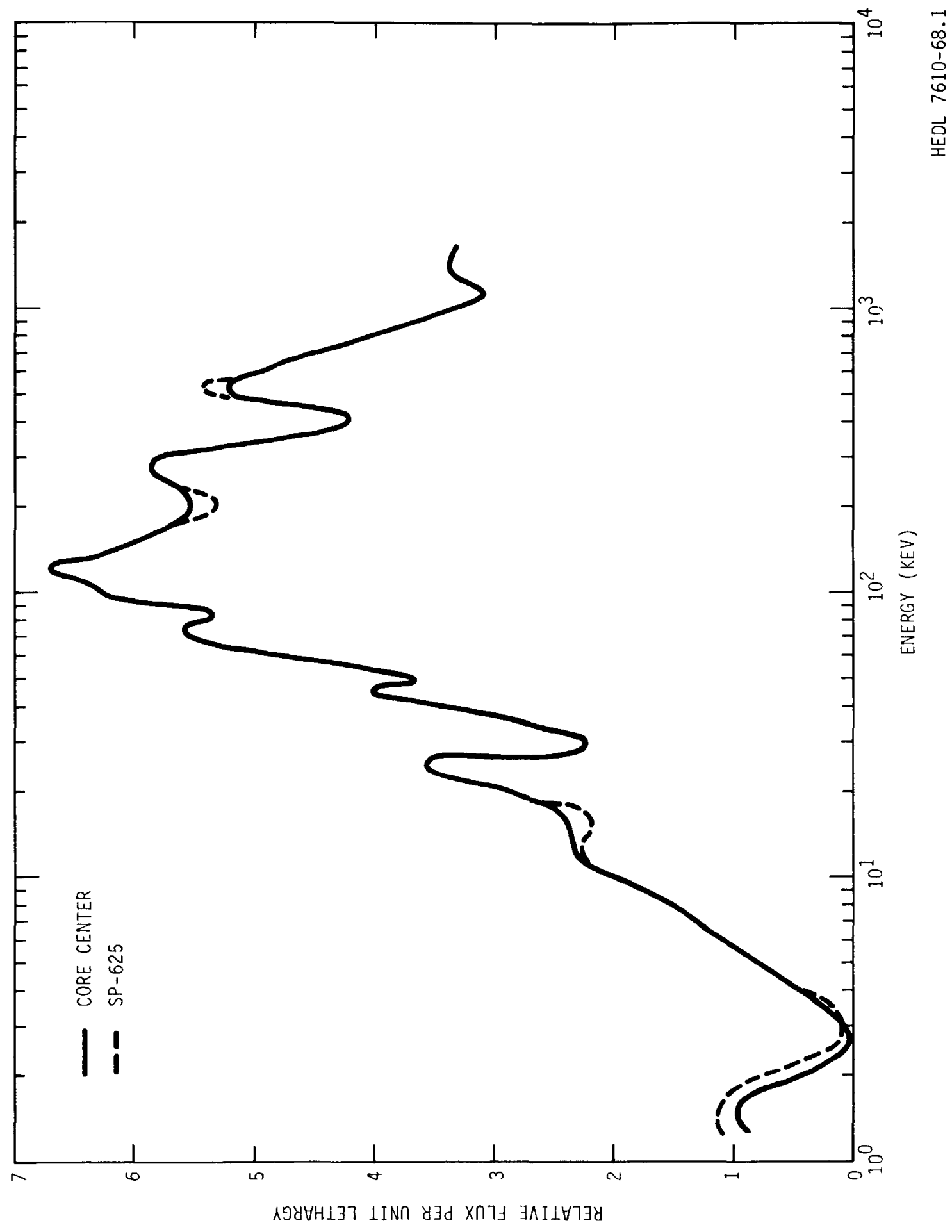

Figure 5.13. Comparison of Proton-Recoil Spectra for Core Center and SP-625. 


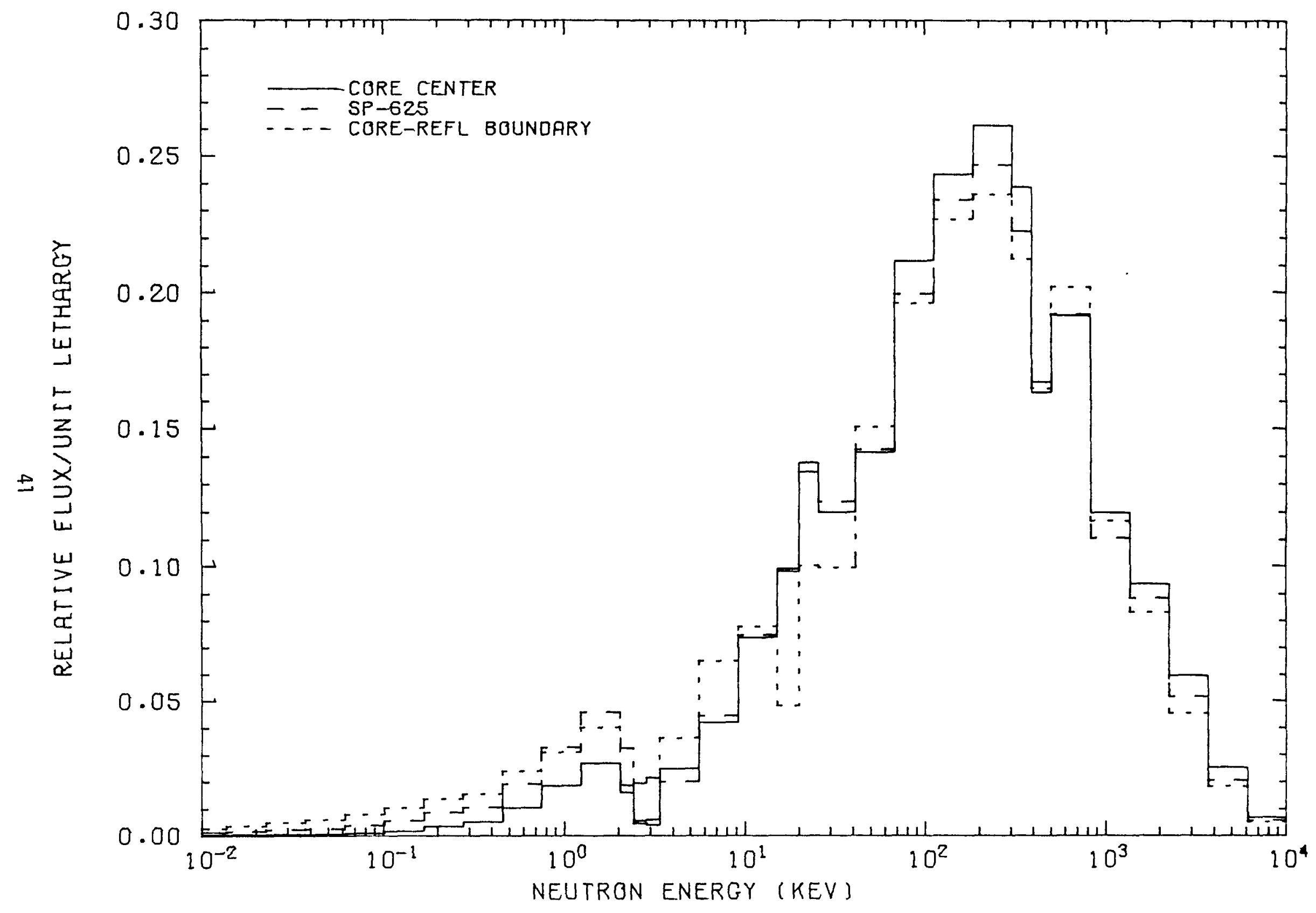

Figure 5.14. Comparison of Calculated Spectra at Core Center, SP-625 and Core-Reflector Interface. 


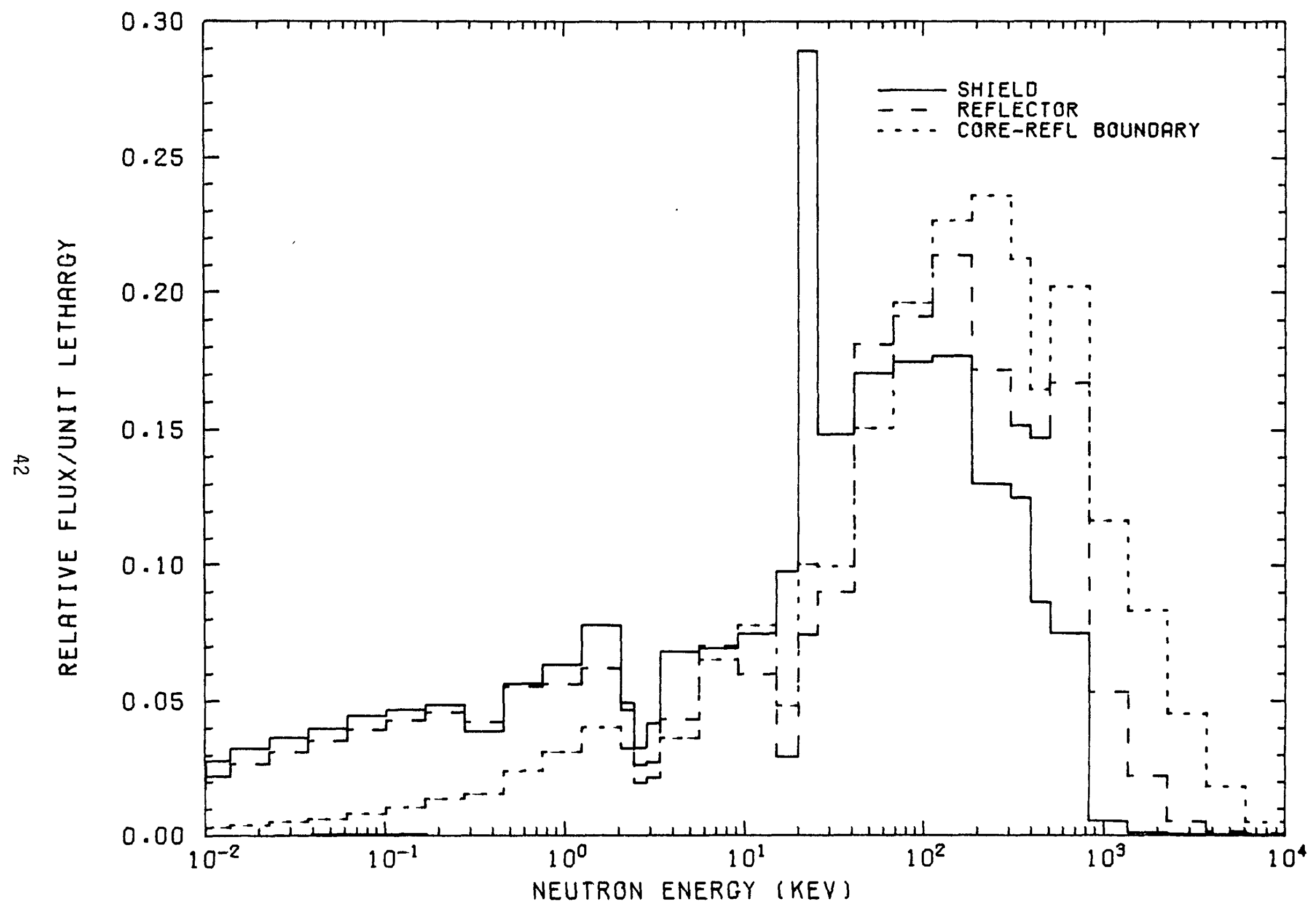

Figure 5.15. Comparison of Calculated Spectra at Core-Reflector Interface, Reflector and Shield. 
The accuracy of results obtained from analys is of the foil irradiations did not reach the level routinely obtainable in high-power facilities. This was due to the low fluence available and the resultant low counting rates. These difficulties arose from the necessity to keep activation of the EMC core to acceptable levels as required by other parts of the experimental program. In addition, self-shielding calculations for EMC were not available for the analysis -- such calculations would have been useful for the experiment design. Even with these difficulties, reasonable results were obtained for the in-core positions that show consistency between multiple foil techniques and proton-recoil. Results from this experiment will also be useful in design of low-power experiments for the FFTF Reactor Characterization Program.

\subsection{Acknowledgement}

The authors wish to acknowledge the contributions to this report of personnel associated with the ZPR-9 critical facility at Argonne National Laboratory who performed the experiments described in this report and transmitted the results to HEDL. The authors also wish to acknowledge the contributions of the following people: Quincey Baird who helped plan the experiments, Nancy Petrowicz who assisted in the diffusion theory computations and tabulation of results, Lloyd Kellogg who performed the foil counting at HEDL, Karl Porges who performed the foil counting at ANL, Byron Combs who assisted in the SAND-II analyses and the graphical display of the results, and Mary Mudd who prepared the final draft of this report. 


\subsection{References}

1. Reactor Development Program Progress Report, ANL-RDP-24, p. 6.4, January 1974.

2. J. W. Daughtry, Calculations of Eu203 and $\mathrm{B} 4 \mathrm{C}$ Worths in the Fast Test Reactor Engineering Mockup, HEDL-TME 75-34, Hanford Engineering Development Laboratory, June 1975.

3. E. F. Bennett and T. J. Yule, Techniques and Analys is of Fast Reactor Neutron Spectroscopy with Proton-Recoil Proportional Counters, ANL-7763, August 1971.

4. W. N. McElroy, S. Berg, T. Crockett, and R. G. Hawkins, A Computer-Automated I terative Method for Neutron Flux Spectra Determination by Foil Activation, I, II, III, IV, AFWL-TR-67-47, Air Force Weapons Laboratory, September 1967.

5. E. F. Bennett and T. J. Yule, "FTR-EMC Neutron Spectroscopy," Reactor Development Program Progress Report, pg. 6.17, ANL-RDP-36, January 1975.

6. D. R. Marr, A User's Manual for 2DBS, A Diffusion Theory Shielding Code, BNWL-1297, February 1970.

7. W. N. McElroy and L. S. Kellogg, "Fuels and Materials Fast Reactor Dosimetry Data Development and Testing," Nucl. Technol. 25, 180, 1975.

8. E. P. Lippincott, B. L. Combs, and A. I. Davis, "Systematic Variation of Threshold Reaction Rates in EBR-II," Trans. Am. Nucl. Soc. , 23, 636, 1976.

9. C. Dunford and M. Vlasov, Proceedings of a Consultants' Meeting on Nuclear Data for Reactor Neutron Dosimetry, INDC (NDS)-56/U, International Atomic Energy Agency, Vienna, 1973.

10. M. F. V1asov, A. Fabry, and W. N. McElroy, "Status of Neutron Cross Sections for Reactor Dosimetry," Proceedings of 1976 International Conference on the Interactions of Neutrons with Nuclei, University of Lowe11, 1976.

11. J. L. Jackson, W. N. McElroy, J. A. Ulseth, and L. S. Kellogg, EBR-II Dosimetry Test (Reactor Runs 50G and 50H), HEDL-TME 73-62, Hanford Engineering Development Laboratory, July 1973.

12. W. N. McElroy, R. J. Tuttle, L. S. Kellogg, and R. J. Armani, FTR Flux-Spectral Characterization by the Foil Activation Method, HEDL SA 431S, Hanford Engineering Development Laboratory, July 1972 . 
13. W. N. McElroy, Data Development and Testing for Fast Reactor Dosimetry," Nuclear Technology, 25, 177, 1975.

A Fabry, et al., "Reactor Dosimetry Integral Reaction Rate Data in LMFBR Benchmark and Standard Neutron Fields: Status, Accuracy and Implications," Proc. of the First ASTM-Euratom Symposium on Reactor Dosimetry, Petten, September 1975.

14. C. A. Oster, W. N. McElroy, R. L. Simons, E. P. Lippincott, G. R. Odette, A Modified Monte Carlo Program for SAND-II with Solution. Weighting and Error Analys is, HEDL-TME 76-60, Hanford Engineering Development Laboratory, 1976.

15. C. A. Oster, W. N. McElroy, J. M. Marr, A Monte Carlo Program for Sand-II Error Analysis, HEDL-TME 73-20, Hanford Engineering Development Laboratory, 1973.

16. E. F. Bennett et al, "Evaluation of Proton-Recoil Spectroscopy in FTR-EMC H1240 Experiments," Reactor Development Program Progress Report, pg. 6.22, ANL-RDP-27, Apri1 1974.

17. W. M. Stacy et a 1, A New Space-Dependent Fast Neutron Multigroup Cross Section Preparation Capability," Trans. Am. Nucl. Soc., 15, 292, 1972.

18. R. M. Fleischman, Evaluation of the Modified Source Multiplication Technique for Subcritical Reactivity Assessments in FTR, HEDL-TME 74-53, Hanford Engineering Development Laboratory, October 1974.

19. J. W. Daughtry and K. D. Dobbin, FFTF Test Loading EffectsAnalysis of Experiments in the FTR Engineering Mockup Critical, HEDL-TME 76-34, Hanford Engineering Development Laboratory, August 1976.

20. R. B. Kidman and R. E. Schenter, FTR Set 300-S, Multigroup Cross Sections for FTR Shielding Calculations, HEDL-TME 71-184, Hanford Engineering Development Laboratory, December 1971.

21. I. I. Bondarenko et a1, Group Constants for Nuclear Reactor Calculations, Consultants Bureau, New York, 1974.

22. R. E. Schenter et al, ETOX, A Code to Calculate Group Constants for Nuclear Reactor Calculations, BNWL-1002, Battelle-Northwest Laboratories, May 1969.

23. R. W. Hardie and W. W. Little, Jr., IDX, A One-Dimensional Diffusion Code for Generating Effective Nuclear Cross Sections, BNWL-954, Batte17e-Northwest Laboratories, 1969. 
24. K. D. Lathrop, ITR-IV, A FORTRAN Program for Solving the Multigroup Transport Equation with Anisotropic Scattering, LA-3373, Los ATamos Scientific Laboratory, 1965.

25. R. B. Rothrock et al, Enrichment Specifications for FTR Fuel (Cores 3 and 4), HEDL-TME 76-9, Hanford Engineering Development Laboratory, 1976.

26. W. N. McElroy et a1, LMFBR Reaction Rate and Dosimetry 10th Progress Report, June through October 1975, HEDL-TME 75-130, Hanford Engineering Development Laboratory, 1976.

27. R. L. Simons and W. N. McElroy, Evaluated Reference Cross Section Library, BNWL-1312, Battelle-Northwest Laboratories, 1970.

28. E. F. Bennett et al, "Spatially Dependent Neutron Spectra in an Engineering Mockup of the FTR," Trans. Am. Nucl. Soc., 22, 652, 1975. 
APPENDIX A

RESULTS OF PROTON-RECOIL MEASUREMENTS

Experimental data obtained from proton-recoil measurements at the six locations (see Table 3.1) are listed below. Each line of printout contains two points. For each point, the energy, flux, flux error (rms) and fullwidth-half-maximum energy resolution are given in that order. 
NARTAL COMOCSITION, COAE CENTEP $(-3,23)$

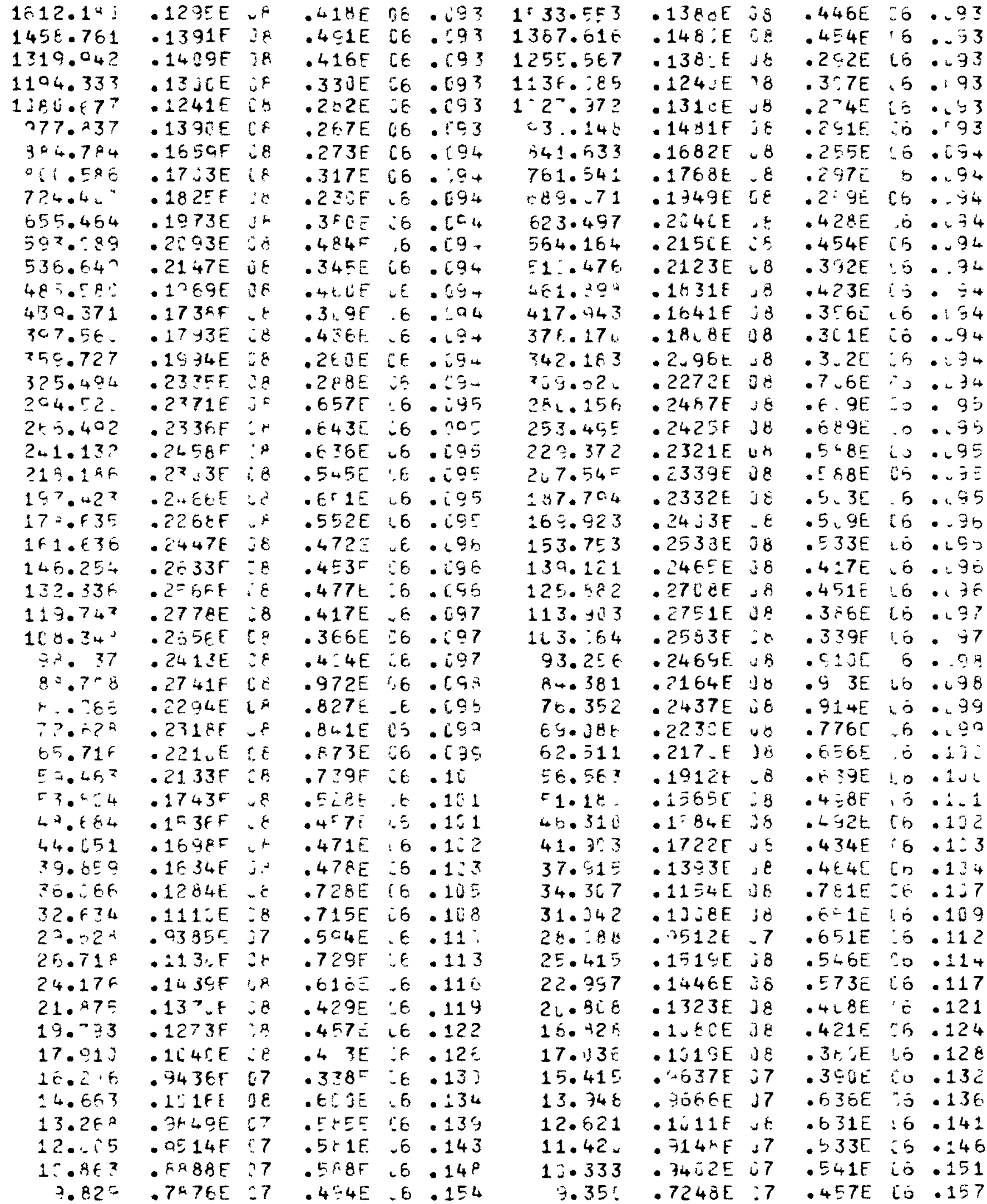




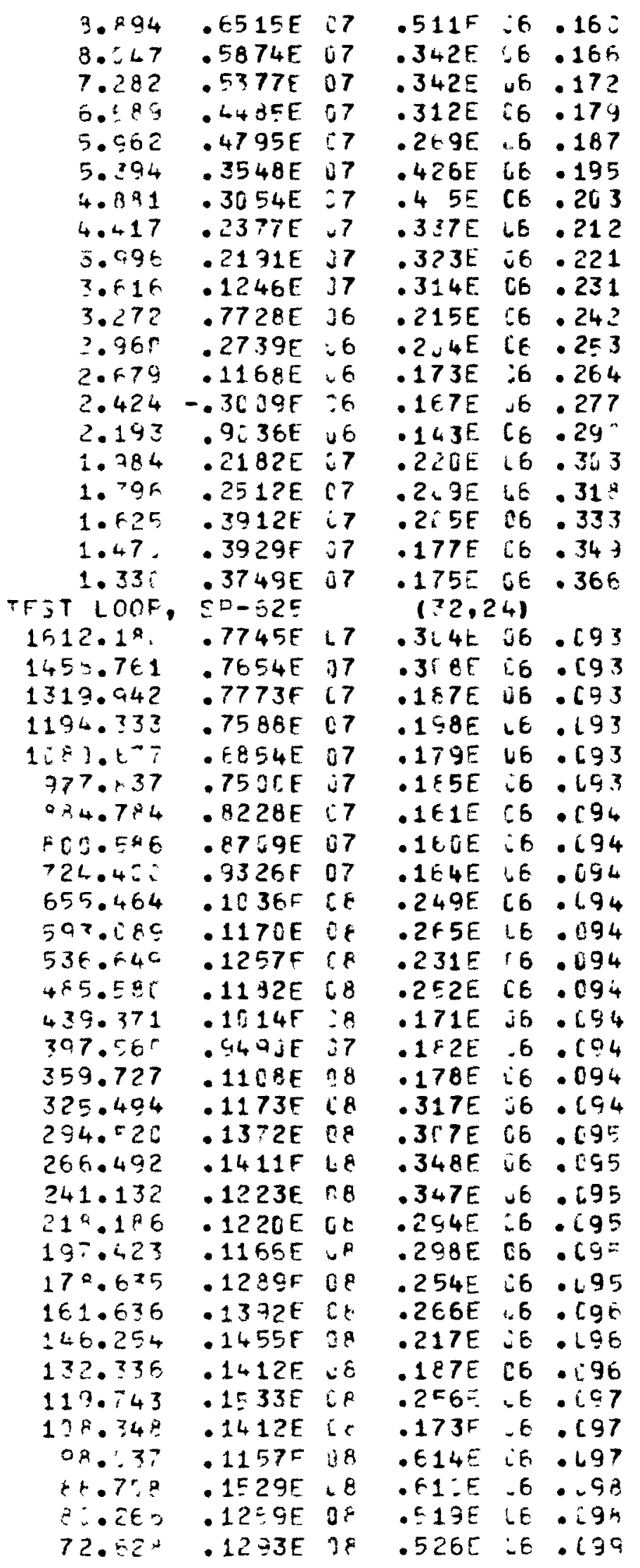

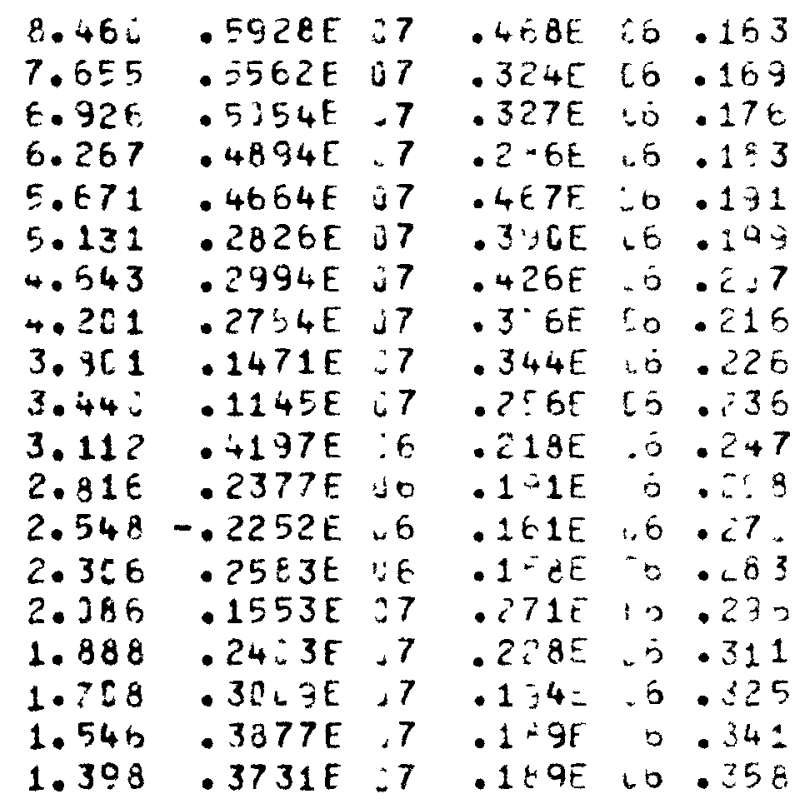

$1533.553 \cdot 8124 E \quad J 7.337 E: 0.093$ $1387.61 \mathrm{~F} .7344 E$ U7 .2H5E -O ...3 $1255.567 \quad .79 E 4 E \quad 37 \quad .191 E$ [O . $113 E .385 .713 E E$ I 7 . 1Y4E $\Rightarrow .233$

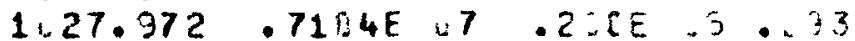
936.148 .7565F $17 \quad .173 E: 0.33$ $841.633 .8316 \mathrm{~F} J 7$.17JE LO . 94 $761.541 .9673 E 27 \quad .174 E .5 .34$ E85.071 . 94J8E $07 \quad .223 E .6 .34$ $623.497 .113 . E$ IS .2. 3E 5.994 $564.164 .1145 E$.8 . 2 2E .0..94 $51 \% 476.1241 E: 8 \quad .273 E .5: .94$ $461.998 .1114 E$ UO . $196 E$ CO. 694 $417.343 .92 U 8 E: 7.264 E \quad 5.94$

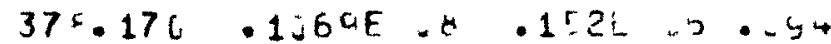
$342.183 .1113 E$ J 8 . $166 E$ vo . 94 $309.626 .1339 E \quad 36 \quad .377 E=5.594$ $28 G .156 .1347 E$ : . 324E 253.495 . 1296E Jd .322E :D . . 55 $229.372 .1299 E$ oO . 321E :0. . 35 $2 C 7.345 \quad .11865 \quad 56 \quad .325 E .6 .33$

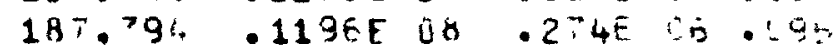
$169.923 .1366 E$ \& $.235 E$. .90 $153.753 .1326 E$ WE . $244 F$ J . .9F 134.121 .144 \& $\{.2 .0 E$ ? . .96 125.882 .153EE JE . 213E -5. .30 $113.353 .1473 E .028 \mathrm{~F}, 37$ $1\left[3 . .64 .132^{2 E}{ }^{\circ} .25 E\right.$. .37 $93.256 .14 D^{7} \mathrm{~F}$. . ER $.5 \ldots 38$ $84.381 .1263 E$ it .5t6E id . . $76.352 .1247 E+.572 E .5 . .02$ $6 \div .86 .1224 E$ jo .4ะ5F 6 . ay 


\begin{tabular}{|c|c|c|c|c|c|}
\hline $\begin{array}{l}65.716 \\
59.463 \\
53.864 \\
49.684 \\
44.651 \\
39.850 \\
36.465 \\
32.634 \\
29.528 \\
26.71\end{array}$ & $\begin{array}{l}.1166 E \\
.1079 E \\
.8497 E \\
.9191 E \\
.9729 E \\
.791 C E \\
.7737 E \\
.4997 E \\
.516 C E \\
.7863 E\end{array}$ & $\begin{array}{l}88 \\
08 \\
07 \\
07 \\
67 \\
07 \\
07 \\
27 \\
67 \\
67\end{array}$ & $\begin{array}{l}.544 E \\
.459 E \\
.326 E \\
.282 E \\
.292 E \\
.296 E \\
.450 E \\
.442 E \\
.366 E \\
.451 E\end{array}$ & $\begin{array}{l}C 6 \\
16 \\
i 6 \\
i 6 \\
66 \\
06 \\
66 \\
66 \\
66 \\
26\end{array}$ & $\begin{array}{l}-69 \\
.10 \\
.10 \\
.10 \\
.10 \\
.10 \\
.10 \\
.10 \\
.110 \\
.11\end{array}$ \\
\hline $\begin{array}{l}24.17 \epsilon \\
21.875\end{array}$ & $\begin{array}{r}.7053 E \\
.7165 E\end{array}$ & $\begin{array}{l}67 \\
37\end{array}$ & $\begin{array}{l}.384 E \\
.273 E\end{array}$ & $\begin{array}{l}\text { L6 } \\
66\end{array}$ & \\
\hline $\begin{array}{l}793 \\
91: \\
256\end{array}$ & $\begin{array}{l}-E 121 E \\
-5236 E \\
.5113 E\end{array}$ & $\begin{array}{l}67 \\
07 \\
67 \\
07\end{array}$ & $\begin{array}{l}.251 E \\
.254 E \\
.213 E \\
.399 E\end{array}$ & $\begin{array}{l}36 \\
16 \\
06 \\
06\end{array}$ & $\begin{array}{l}-1 \\
.1 \\
.1\end{array}$ \\
\hline $\begin{array}{l}14.663 \\
13.263\end{array}$ & $\begin{array}{l}.5012 E \\
.4888 E\end{array}$ & & $\begin{array}{l}.399 E \\
.387 E\end{array}$ & $\begin{array}{l}06 \\
06\end{array}$ & \\
\hline 12.055 & $.5225 E$ & 67 & $.383 \mathrm{E}$ & & \\
\hline $\begin{array}{l}3.463 \\
9.829\end{array}$ & $\begin{array}{r}.5198 E \\
.46 \text { REE }\end{array}$ & $\begin{array}{l}67 \\
67\end{array}$ & & 6 & \\
\hline & .40 & 87 & & & \\
\hline $7.2 \varepsilon 2$ & $.3178 E$ & 87 & $229 E$ & .6 & .17 \\
\hline 6.589 & $.24 J E F$ & i7 & $.2-8 E$ & be & .17 \\
\hline $5.0 E 2$ & $.7424 E$ & 27 & $.1+1 F$ & & .18 \\
\hline 5.394 & $.2096 F$ & 57 & $.286 E$ & 06 & $\cdot 1$ \\
\hline $4 \cdot=81$ & $.1496 \mathrm{~F}$ & $: 7$ & $.271 E$ & U6 & \\
\hline 4.417 & $.1138 \mathrm{~F}$ & 67 & $.226 E$ & & \\
\hline 3.906 & - RE21E & of & $.216 E$ & 16 & .22 \\
\hline 3.616 & $.8039 E$ & UE & - $2 \angle 8 F$ & CE & \\
\hline 6013 & $\begin{array}{r}1571 \mathrm{~F} \\
.9771 \mathrm{~F}\end{array}$ & 2 & & & \\
\hline 2.679 & $.244 \mathrm{EE}$ & $O E$ & .1075 & & \\
\hline 2.424 & $.7728 \mathrm{~F}$ & $O G$ & $.1: 4 E$ & & \\
\hline 2.193 & $.103 \& \mathrm{~F}$ & 37 & $.9 .2 E$ & $i 5$ & .29 \\
\hline 584 & $.15 \times 3 E$ & 47 & $.126 \mathrm{~F}$ & .6 & \\
\hline & $.2169 \mathrm{E}$ & :7 & $.121 E$ & & \\
\hline & $.2377 E$ & 07 & & & \\
\hline & & & & & \\
\hline & & & & & \\
\hline
\end{tabular}

TEST LOOP

$1612.18 \mathrm{C}$

1458.761

1319.942

1194.333

119?. $E^{-1}$

977.837

884.784

393.586

724.464

555.464

593.260

536.649
$G P-201$

-1223F CR

. $1288 E O E$

- 129F 08

- 1232 EE

$.1139 E$ CE

$.1367 E$ S 8

$.1391 \mathrm{E}$ LA

- 1EgLE J8

- 1725E OR

- $198 \mathrm{CE} 08$

$.2129 E 08$
.1277E UE
$(23,2 C)$

- उe Je l6. [9]

$.429 E$ l6. C9?

$.364 E$ IE . 193

$.295 E \quad 66.293$

$.253 E$ C6. 093

$.239 E[6 .\{9\}$

$.244 E$ I6. 194

.261 ¿ 26.204

$.2 .2 E 06.094$

.3435 य6. 294

.4385 .6 .094

$.315 E \quad 06.094$
62.511

56.563

51.180

46.316

41. 903

37.915

34.327

31.342

28.088

25.415

22.997

$26.8 \mathrm{C} 8$

18.328

17.336

15.415

13.948

12.621

11.420

10.333

9.350

Q. 460

7.655

6.926

E. 267

E. 571

5.131

4.643

4. 201

3.901

3.446

3.112

2.816

2. 548

2.306

2. 086

1. 888

1.708

1.546

1. 398
$.1112 E \cup 8$

. $1022 F j 8$

$.8144 E$ ¿7

- $9938 E J 7$

$.8496 \mathrm{E} \mathrm{JT}$

$.7844 \mathrm{E} j 7$

. $709 J E: 7$

$.4656 \mathrm{E} J 7$

. $6661 E .7$

. $8088 \mathrm{E} .7$

.7205 E 37

$.7124 E J 7$

$.5649 E 37$

$.4727 E=7$

$.4994 E \mathrm{~J} J$

$.4644 E .7$

. $5098 \mathrm{E} \cdot 7$

- 5161E C7

- $4392 E$ ०

$.4169 E \quad \$ 7$

- $375 E \mathrm{E}: 7$

. $3035 E 07$

. $3164 E$ U 7

- 2542E U 7

-1960 E UT

- 20BEE J 7

.1332 E J7

. 7092E 06

- $1091 \mathrm{E}$ C7

. 3682E EE

$-.4031 E$ U 5

- $1111 E$ JE

. $1012 \mathrm{E} 36$

$.7591 \mathrm{E} 56$

$.1272 E 07$

$.2352 E$ J7

- $2382 E \quad J 7$

$.2414 E 07$

.2717 E 67
$.4 .9 E \quad C 5.100$

- 356E $: 6.13 \mathrm{~J}$

. उL5E $\ 6.161$

. 3U5E CE. .102

.259E C6.133

$.287 E$ CO.154

.4 \& 15.107

. 4 I. $2 E \quad 16.16 \%$

$.463 E$ i6.112

.3LOE lo .11*

$.356 E$ i 6.117

$.258 E .5 .121$

$.267 E$ r .124

$.238 E=6.128$

$.247 E$. .132

$.421 E$ is .136

$.417 E$. $6.1+1$

.352E PD.146

- 3E 8E - D .131

- $3: 2 E \quad 6 \quad .157$

. 311E lo .163

. $216 E$ ló .15.9

$.219 E$ L 5.176

$.191 E$ lo. .133

. $312 E$ O .191

$.251 E \quad 6.199$

$.236 E$ ló. ¿ ¿3?

.237 LD .21C

$.229 E$ l. .226

$.156 E \quad-6.23 E$

$.134 E$ ED . 247

.118 CE . 25.

- 1ـ1E :6. 67 .

. 9a0E 25.283

$.154 E$ Uó .296

. $131 E: 6.311$

$.113 E$ l 6.325

. 111E É. .341

.112 E ló. 358

\begin{tabular}{|c|c|c|c|c|c|}
\hline 1533.553 & $.1358 E$ & $2 t$ & $.39 C E$ & 66 & \\
\hline 1387.616 & $.1283 E$ & $=\varepsilon$ & . $396 E$ & 16 & \\
\hline 1255.567 & & $\begin{array}{l}38 \\
18\end{array}$ & & $\begin{array}{l}\text { C6 } \\
\text { tj }\end{array}$ & \\
\hline 1.27 .972 & $.1233 \mathrm{E}$ & -9 & $.245 E$ & $\$ 5$ & \\
\hline 930.145 & $.1297 \mathrm{E}$ & $2 E$ & $.261 E$ & 0 & \\
\hline 841.633 & $.1446 \mathrm{E}$ & 6 & - $228 E$ & -0 & \\
\hline 541 & $.1543 \mathrm{E}$ & 48 & $.2 E 4 E$ & $: 6$ & \\
\hline 571 & $.165 E E$ & 8 & $.228 E$ & 06 & \\
\hline 3.407 & $.1871 E$ & 38 & & .6 & \\
\hline 164 & $.2658 E$ & 28 & $.413 E$ & .6 & \\
\hline .476 & $.2683 E$ & .8 & - $3 E: E$ & 6 & \\
\hline
\end{tabular}




\begin{tabular}{|c|c|c|c|c|c|c|c|c|c|c|c|}
\hline 485.583 & Cᄂ 1 AF & c n & $4: 5 \mathrm{~F}$ & $\checkmark 6$ & .194 & 461.991 & $.190 \mathrm{PF}$ & je & .3021 & 4.5 & - 94 \\
\hline 439,371 & $1795 \mathrm{~F}$ & 08 & $289 E$ & 26 & .694 & 417.94 .3 & $.1650 \mathrm{~L}$ & $U E$ & $.3 \times 2 E$. & 15 & .694 \\
\hline $307.55^{-}$ & 171 AF & of & $4.9 E$ & 46 & .194 & $378.17 u$ & $.1794 \mathrm{~F}$ & 18 & $\therefore 43 F$ & $\mathrm{Co}$ & .094 \\
\hline $79.72^{-}$ & $.1951 \mathrm{~F}$ & 68 & $233 F$ & 46 & - $\mathfrak{c}^{9}$ & 42.183 & $198 L^{\circ} \mathrm{F}$ & $G A$ & $.26,4 t$ & in & 0.44 \\
\hline $3=5.404$ & $.2161 \mathrm{~F}$ & Je & .2555 & CE & .094 & 309.620 & .22064 & $\therefore B$ & $.5,9 E$ & 15 & $\ldots 34$ \\
\hline 204.523 & $.2265 E$ & C 8 & $.474 C$ & $\lceil 6$ & .095 & 280.1 & $.2354 E$ & J 8 & $.440 \mathrm{~F}$ & $\therefore 2$ & .45 \\
\hline $26 n .492$ & $227.3 F$ & OP & $.4+5 \mathrm{~F}$ & 86 & .895 & & & 38 & $.419 E$ & in & \\
\hline 241.132 & $.2 \times 31 E$ & C8 & $.4 E 1 t$ & $i 6$ & .092 & 229.572 & $.2147 t$ & 38 & $.4 \div 0 t$ & כי & 195 \\
\hline$P 18.18 h$ & $.2131 \tau$ & CF & $.394 \mathrm{~F}$ & $c 6$ & .695 & 207.545 & $.2186 \mathrm{~F}$ & Jo & $.2 .25 F$ & 15 &. .95 \\
\hline $1 c \cdot .423$ & $.2144 r$ & oa & $.469 F$ & 66 & .095 & 94 & $.2285 \mathrm{~F}$ & 08 & $.364 E$ & 16 & .195 \\
\hline $17^{\circ} \cdot 435$ & .22335 & i8 & $.398 E$ & $O 5$ & .095 & 169.92 .3 & $.2232 \mathrm{~F}$ & JP & $.363 E$ & .6 & .496 \\
\hline $1+1 .+36$ & $.2422 E$ & ¿A & $.342 E$ & 56 & .096 & & & 18 & . $3 A G F$ & $: 5$ & .136 \\
\hline $14 k \cdot 254$ & .24885 & $O A$ & - 361E & 66 & - 196 & 9.121 & $.245 \mathrm{EE}$ & $j H$ & .3134 & 6 & .95 \\
\hline $13.3 \times 5$ & $.2562 F$ & 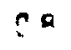 & $.3 t 1 F$ & $: 6$ & .296 & 125.882 & $.2634 E$ & $J F$ & $.3: 41$ & 5 & $\ldots r_{i} t_{i}$ \\
\hline 119.743 & $.2645, E$ & is & $.31 \mathrm{CE}$ & $\therefore 6$ & - 197 & 113.963 & $.257: E$ & 48 & $.2^{\prime} 1 t$ & r & $.1 \neq 7$ \\
\hline $1: 2.345$ & .25 & 66 & $.2 T 4 E$ & 66 & .697 & $103 .: 64$ & $37 E$ & 38 & $.2^{2} 4 t$ & 1,6 &. .97 \\
\hline$q_{*} \cdot x^{\circ}$ & $.237 Z E$ & JP & $.3 C 4 E$ & ¿6 & . $\mathrm{C9^{ \circ }}$ & $3 . ? 56$ & $.2248 E$ & 38 & .6311 & .5 & .99 \\
\hline $89.7^{n}$ & $.234 C F$ & $C^{A}$ & $.764 E$ & $C_{6}$ & .199 & 4.381 & $62 \mathrm{E}$ & $\therefore 8$ & $.7: 6 F$ & $" 6$ & 099 \\
\hline AJ.26E & $.2415 E$ & 68 & $.763 \mathrm{~F}$ & $\mathrm{C} \bar{C}$ & - $\cos$ & 2 & $27 r$ & 28 & $.8+1 t$ & $(6$ & .199 \\
\hline $72 \cdot 62^{8}$ & $.221 \mathrm{CE}$ & $C B$ & $.774 \mathrm{E}$ & $j 6$ & .091 & 65.38 & $14 E$ & 38 & $.712 \mathrm{~F}$ & 15 & .99 \\
\hline 65.716 & $.217 C E$ & 56 & $.658 \mathrm{~F}$ & $C 6$ & - 199 & & 335 & 08 & $.738 E$ & Dj & .100 \\
\hline 59.463 & .18 & 38 & $.6 \in 2 E$ & $i 6$ & .100 & 563 & $39 E$ & 36 & $.621 \mathrm{~F}$ & Ch & .106 \\
\hline 53.854 & $.147 \mathrm{LF}$ & 04 & $.470 E$ & 66 & .101 & $51 \cdot 180$ & $6 E$ & 38 & $.443 f$ & 46 & .121 \\
\hline $4^{2} .684$ & $\cdot 15$ & 48 & $.4 .6 F$ & 06 & .101 & & $2 E$ & 98 & $.456 \mathrm{E}$ & 65 & .102 \\
\hline 44.6 & & 68 & & 66 & .102 & & $E E$ & 28 & $.482 E$ & $i_{5}$ & .163 \\
\hline 79.259 & .14 & 28 & $.3 t$ & 36 & .153 & & - 1 & 38 & $.349 E$ & 5 & .124 \\
\hline $36 \cdot c 66$ & $7 E$ & 00 & .30 & $C 6$ & & & $73 F$ & 38 & $.622 \mathrm{E}$ & 25 & .127 \\
\hline 32 & & 37 & & 66 & .108 & .342 & $51 \mathrm{~F}$ & 07 & - $6.9 E$ & 86 & .109 \\
\hline 29.529 & $.9211 \mathrm{E}$ & ن 7 & .55 & 06 & $.11:$ & 088 & $41 \mathrm{E}$ & 38 & $.5, B E$ & .6 & .112 \\
\hline $\begin{array}{l}26.718 \\
24.176\end{array}$ & & $\begin{array}{l}O E \\
O F\end{array}$ & & $\begin{array}{l}06 \\
c 6\end{array}$ & & & & $\begin{array}{l}08 \\
08\end{array}$ & & $\begin{array}{l}5 \\
10\end{array}$ & $\begin{array}{r}114 \\
.117\end{array}$ \\
\hline 21.875 & $.1292 E$ & $3 t$ & $.493 E$ & C6 & .119 & 808 & $.1215 \mathrm{E}$ & 08 & $.391 E$ & 8.6 & .121 \\
\hline 93 & & is & $.359 E$ & $i 6$ & 123 & 828 & $3 E$ & is & $.330 E$ & نó & $1: 24$ \\
\hline 17 & & 07 & $.311 E$ & 26 & & 36 & $2 E$ & di & $\cdot 3$ & -0 & - \\
\hline $1 c .2 i=$ & $54 E$ & 07 & . $321 F$ & 36 & 13 & 415 & . $\$ 981 E$ & $\therefore 7$ & $.296 t$ & in & .132 \\
\hline 14 & & 27 & $.343 \mathrm{E}$ & 26 & .134 & & $3 F$ & $\therefore 7$ & $.546 \mathrm{~F}$ & j & $.13 E$ \\
\hline 268 & $3 E$ & 67 & $.577 E$ & $C E$ & .139 & 21 & $34 E$ & 37 & - $533 E$ & Có & .141 \\
\hline $1:$ & $6 E$ & 37 & & $C 6$ & .143 & & $7 E$ & 07 & $.523 E$ & 66 & .146 \\
\hline & & $0 ?$ & $.4 \times 7 E$ & LE & .149 & 3 & .8 & ง7 & $4 E$ & Ló & .151 \\
\hline 829 & & $c 7$ & $.489 E$ & 26 & & & & & & 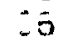 & .157 \\
\hline 94 & .55 & $c 7$ & $.411 E$ & $D E$ & .16 & 462 & $.4847 E$ & 07 & $.377 E$ & Ć́ & .153 \\
\hline & & 07 & & 16 & & & & 37 & $.340 E$ & .5 & \\
\hline & $7 E$ & $\{7$ & $.311 E$ & 16 & .172 & 926 & $E E$ & 87 & $.2 E 5 E$ & 40 & .170 \\
\hline & $33 F$ & :.7 & $.266 E$ & ¿6 & .179 & 7 & $14 E^{\circ}$ & ن 7 & $.245 \mathrm{E}$ & Lh & .123 \\
\hline & .38 & $C 7$ & $.274 E$ & (6) & $1 \mathrm{e}$ & & $1 E F$ & 37 & $.2 \equiv 6 E$ & Co & .191 \\
\hline & $.2459 F$ & $C 7$ & $.2 C O E$ & $O E$ & .19 & & $76 E$ & 07 & $.495 E$ & เ. & .199 \\
\hline & $1 E$ & 37 & $.514 E$ & 06 & .203 & & $7 E$ & 37 & - $4.8 E$ & 65 & .207 \\
\hline & $.2554 \mathrm{E}$ & i 7 & $.426 \pi$ & $\therefore 6$ & .212 & $4.2 E 1$ & $77 E$ & 37 & $.447 E$ & 65 & $.2: 6$ \\
\hline & $.1391 E$ & 07 & $.4: 8 E$ & $C 6$ & .221 & C 1 & $54 E$ & is 7 & $.370 E$ & ió & .226 \\
\hline & $.1454 E$ & 07 & $.394 E$ & $i 6$ & .231 & $44 i$ & $.1220 \mathrm{~F}$ & 87 & $.358 t$ & "b & .236 \\
\hline & $.4156 E$ & UE & $.277 E$ & 56 & .242 & 3.112 & $.4,13 E$ & $j 6$ & $.227 E$ & 16 & .247 \\
\hline & 1: 227 & OE & 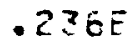 & 66 & 0253 & $2.81 E$ & $-\because 22 Z E$ & jE & $.223 E$ & $\dot{0}$ & .258 \\
\hline 2.579 & $.2735 F$ & 0 & $.2 .2 E$ & 66 & $.2 E 4$ & 2.548 & $.4794 E$ & $j t$ & $.1 \vdash 9 E$ & $\therefore 5$ & $.27 i$ \\
\hline
\end{tabular}


2.424

. 1822E J6

$.178 E$ CE . 27

2.193

$.7155 E \quad 06$

1.944

1.796

1.625

1.470

1. $33 \%$ $C 25$

$1612.19 \mathrm{~J}$
$1458.7 E 1$
1319.942
1194.333
108.077

977.537

984.784

मी? $.59 \mathrm{C}$

724.400

555.464

593.189

536.649

$485.58 \mathrm{~J}$

430.371

$32+.55=$

350.727

325.404

$294.5 ?$,

266.432

241.132

$21 * .185$

197.423

178.635

161.636

$14 E .254$

132.335

110.743

1.8 .349

98.637

86.754

83.266

72.628

$E=.716$

59.463

53.814

$4 E \cdot E^{2} 4$

$44 . C^{5} 1$

39.659

$36 .: E E$

32.634

20. 528

$26.71 \%$

$24.17 E$

21.875

12.793
.2758 E J7

.2775 U J7

. 3753 E J7

. 3455 \& 4

. $3941 E 07$

GOUNDAFY

$.7599 \mathrm{~F}$ U 6

- $7535 E$ CE

- 8J 9CE C6

. 78 s2f la

- T\&22E JE

$.7978 E$ ie

- o8zle ú

- 9794 E IE

$.104 \mathrm{CE} J 7$

- $1242 E$ OT

. 12 ISE OT

$.1235 E 07$

.1176F J7

- 1C 53E 07

$.1237 \mathrm{~F} \mathrm{JT}$

$.1053 E \quad 77$

. 1215E 07

.1339E 07

. $1359 E$ OT

. $123 \mathrm{E}$ J7

$.1242 F \quad 07$

- 1321F U

$.1357 E$ IT

$.1369 F$ OP

$.1454 E 07$

. 1469E $=7$

$.1659 \mathrm{E} J 7$

- $1508 E U^{7}$

$.1357 E$ :7

. 13 R6E 37

.1290537

$.1229 E^{\circ} 7$

$.1134 \mathrm{E}$ : 7

$.1175 \mathrm{~F} ; 7$

.1250 E j7

.1511537

$.9667 E$ DE

. .259E If

$.7833 E+6$

$.7 J 15 \mathrm{E} \mathrm{Q6}$

$.3945 E$ DE

$.6125 E$ I 6

. TR J6E -6

- $E 718 F=6$

$.5921 E j 6$
.174 E UE. .29 I

$.252 \mathrm{E} \quad 66.353$

$.241 E$ U . 319

. 2165 JE . 333

. 2I $1 E$ I6 . 34 9

.2 2E $\quad 6 \quad .366$

$(18,13)$

. उETE . 5.493

.330E IE . C93

$.255 E \quad 5.693$

$.272 \mathrm{~F}$ C5. 693

$.247 E \quad C 5.093$

$.258 E: 5.19$ ?

. $226 E$ i5. 194

. 221E CE. C94

$.233 F 05.094$

$.383 E$ UE.094

$.4 .8 E$ U . .894

. 352E l5 . 194

$.381 E l 5.694$

$.258 E \quad 65.094$

$.2-4 E \quad C 5 \cdot C 9_{4}$

$.271 E \quad 5.694$

$.409 E \quad 65 \cdot 094$

$.4 E 1 E=5.195$

. EL5E 25.195

$.544 \mathrm{E} l 5.295$

$.462 F$ : . 695

$.469 \mathrm{E} r 5.195$

$.4 C 0 E$ C5. 095

$.418 E$ ᄂ5.096

$.358 E$ 25.196

$.273 E$ ¿5.096

$.365 E: 5.297$

. 254E 2E. . 237

$.635 E+5.597$

$.538 E$.5 . C9A

$.535 E$ US. 598

$.540 E$ US. 293

$.455 E \quad 05.699$

$.472 E \quad 5.10^{\circ}$

$.375 E: 5.101$

$.286 E \cdot 5.101$

$.347 E=5.102$

$.258 E \quad 45.133$

$.275 E$ C5. 105

$.344 E$ C5.10

. 3R LE T5.11.

$.3 \vdash 3 E$ L5.113

$.322 \mathrm{E}$ i5.11E

$.336 \mathrm{~F}$ ᄂ .117

$.234 \mathrm{E} \quad \mathrm{S} 5.122$
$2.306 .6677 E$ Uं . $176 E$ CO .233

$2.386 \quad .1628 E$ J7 .159E l6 .296

$1.888 .2426 E \quad 37 \quad .230 E$ is .311

$1.708 .3188 E$ J $.223 E$ C6 . 325

$1.546 .3742 F$ \& $.219 E$ 55 .341

$1.398 .3654 \mathrm{E} \quad \mathrm{i} \quad .108 \mathrm{~B} \quad 15.359$

$1533.553 \quad .7936 \mathrm{E}$ I $6 \quad .432 E \quad \mathrm{C} \quad .133$

$1387.616 \quad .6849 E$ :36 . $355 E$ \&. .33

$1255.567 .8679 E \quad 36 \quad .259 F \quad 55.593$

$1136.385 \quad .7762 \mathrm{~F} \quad 06 \quad .255 E \quad 45.193$

$1,27.972 .03075 E$ LE . $278 E$ i5. . 93

931.148 . $8558 E$ UE .2W2E $1>.453$

$\$ 41.633 .9285 E$ O5 .235E .;. . 94

$761.541 .1013 F, 7 \quad .246 E: 3 . .94$

$689.071 .1047 E$ \& 7 .341E 45.294

$\$ 23.497 .120$ EE $07.434 E$ C5.[34

$564.164 \quad .126$ SE J7 .3.9E $\quad 5.654$

$510.476 .1186 E$ J7 .414E 3.54

461.398 . 111RE J7. $260 E$ LS.J94

417.743 . 1J87E J7 . 397E UJ .494

$378.17 \mathrm{~J}$. 1U6UE 67 . $232 E$ IJ . . $\$ 4$

$342.183 \quad .1148 E$ I7 .253F 15.694

$309.520 \quad .1282 E$ U 7 .545E 65.494

$28.156 .1341 E$ J $.529 F \quad 3 . .95$

$253.495 .1430 E$ U .54 . 23.495

$229.372 .1277 E$ J $.5 .3 E-5.35$

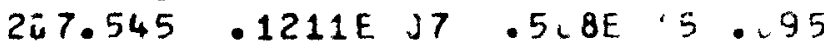

$187.794 \quad .1347 E \quad J 7 \quad .432 E \quad C 5 \quad \ldots 55$

$169.923 .1409 E$ \& .371 L $E^{-} .496$

$153.753 \quad .1381 E: 7 \quad .344 E: 5 . .36$

$139.121 \cdot 1454 E=7 \quad \cdot 235 t-5.496$

$125.882 .1626 E$ J . 313E U5. 896

113.9[3 . 1666E :7 . 339E $[5.297$

103.264 . 1433F 67 . 3. EE :3. . .97

$93.256 .1136 E+7 \quad .5 \succeq 3 E$ i5. $19 \%$

$84.381 .1368 \mathrm{E}$ J $.577 \mathrm{E} .5 .298$

$76.352 .1280 E$ U 7 .450E 65.199

69.386 . $1158 E$ OT . $455 E$ IJ . I 99

$62.511 .1253 E+7 \quad .512 E .5 .16$.

$5 E .563 .1314 E: 7 \quad .432 E: 5.100$

51.18 . $1099 E$ \& $.311 E$ U5.101

$46.31 \mathrm{~g} .9897 \mathrm{~F}: 6 \quad .273 E$ IS.1.2

$41.3 C 3.9459 E$ JK .2E EE C5.113

$37.315 .9668 E$ JE .2Z4E 5.504

$34.347 .7568 E-6 \quad .431 E \quad 15.107$

$31.342 .4687 E$ ?E .422E 5.139

28.289

25.415

22.997

20.808

18.828
- $4895 E$ JO

$.7228 E-6$

$.6867 E .5$

$.6776 F \quad j 6$

$.4922 E \quad 0 E$
$.418 \mathrm{E} ; .112$

$.429 E: 5.114$

$.362 E$. 5.117

$.246 E 55.121$

$.200 E .5 .124$ 


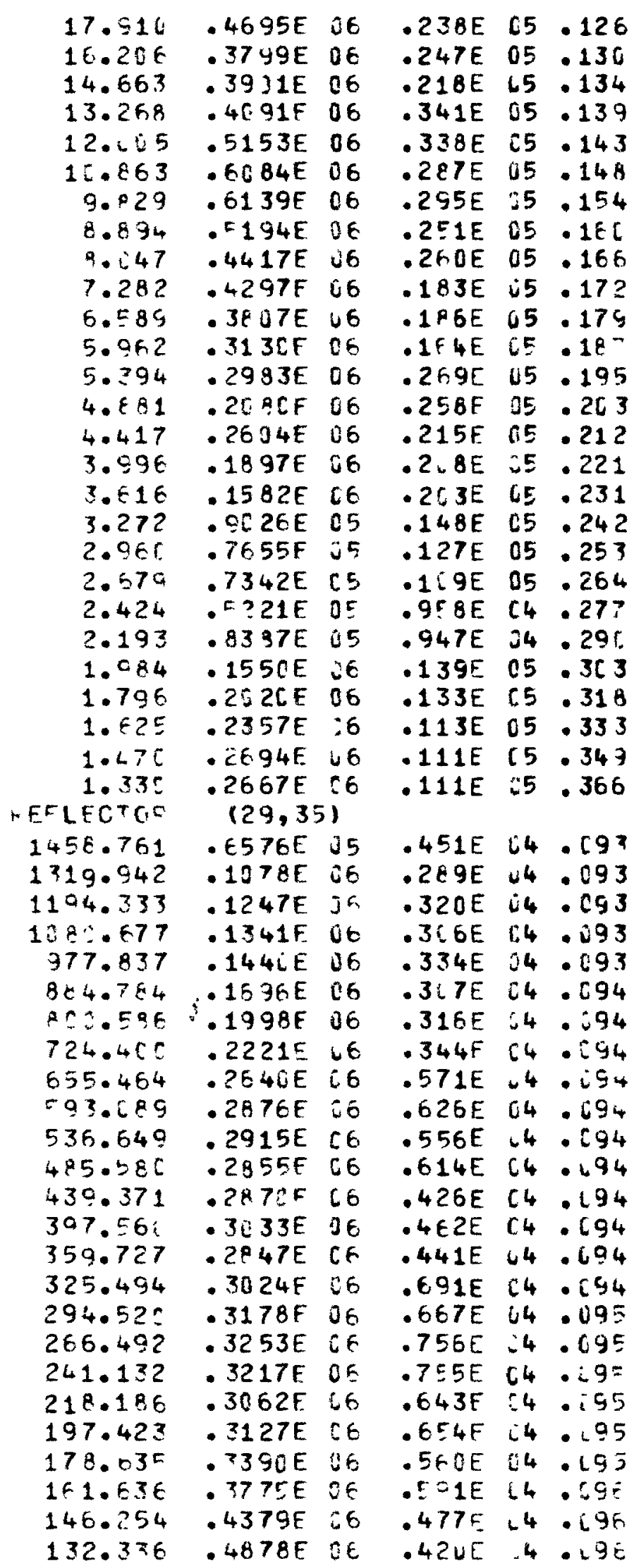

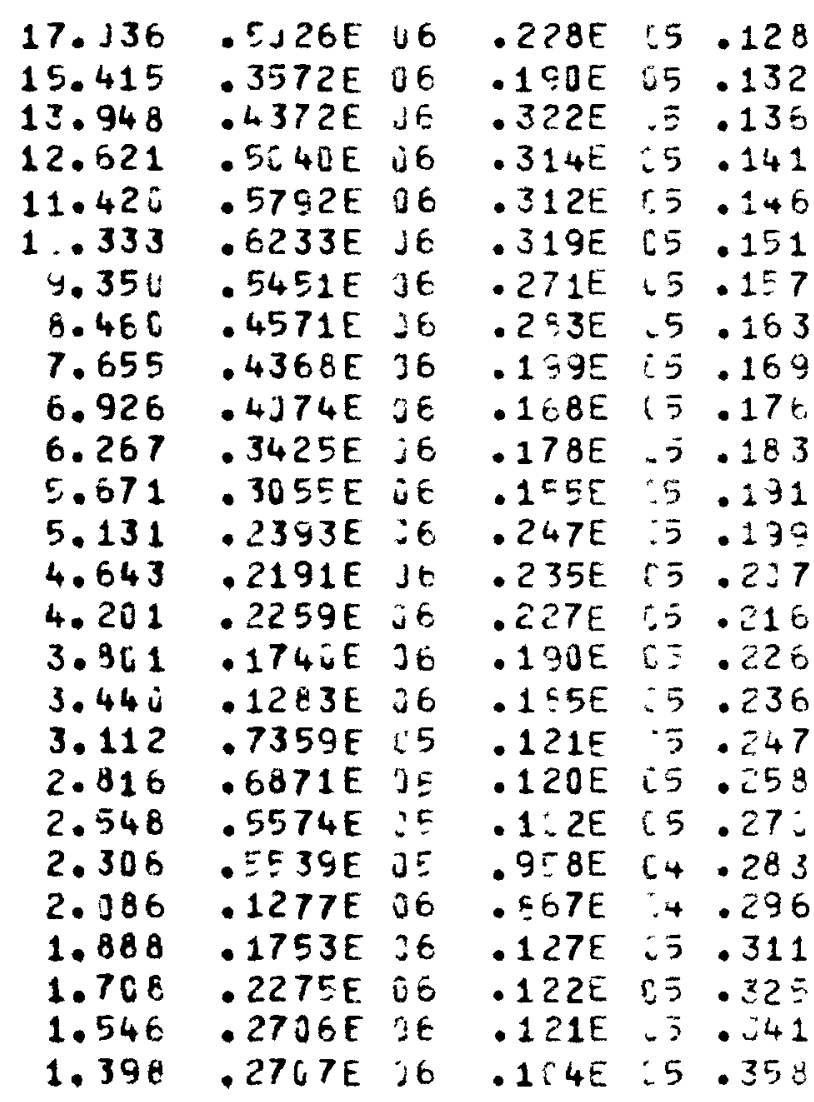

$1387.616 .9068 E$. $\quad .421 E \mid 4 . .93$ $1255.567 \quad .1142 E$ OE $.364 E \quad 4.693$ $1136.485 \quad .1333 E$ : $6 \quad .36 \mathrm{BE}: 4 \quad \ldots 93$ $1.27 .972 .1425 E$ :6 .351E i4. 494 $936.148 .1647 E$ :0 .323E I4. $\$ 41.633$. 175iE I6 .329E 14.694 761.541 . 2126E 36 .356E 64.494 $689.071 .2190 E$ J6 .5EOE it. . 94 $623.497 .2767 E=6 \quad .655 E$ I. . . 94 $564.164 .2398 E$ IE .4E2E :4..54 $51.476 .2936 E \quad 26 \quad .660 E$ C4.294 $461.998 .2699 E \quad 36 \quad .457 E \quad C 4.094$ $417.343 .3072 E .6 . E 54 \mathrm{E} . . .94$ $378.17 C .2984 E$ \& $6 \quad .378 E \quad 44.694$ $342.183 .2958 E$ WE .412E $14 . .94$ $309.620 .2981 E$ tE .825E +.094

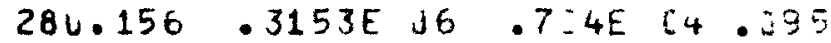
$253.495 .3422 E$ : 6 .7 0 . 44.69 ? $229.372 \cdot 3: 36 E$-6́ .7. EE 14.235 $207.545 \quad .3167$ : $6 \quad .7 .9 E \quad .4 .35$ $167.794 .3196 E$ U6 .E.4E C4 . L95 $169.923 \quad .3722 E \quad \& \quad .522 E \quad \& 4.496$

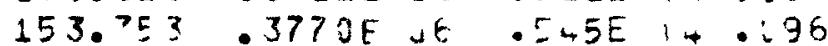
$139.121 .4587 E \quad 6 \quad .443 E \div 4.996$ $125.882 .5357 E$ JE . $455 E \mathrm{C}+.696$ 


\begin{tabular}{|c|c|c|c|c|c|c|c|c|c|c|c|}
\hline & & & & & & & & & & & \\
\hline $119.74 \%$ & - $5359 F$ & 16 & $577 E$ & 64 & . 097 & 13.903 & $.5289 E$ & $\sqrt{6}$ & $-542 E$ & 24 & - 491 \\
\hline $\begin{array}{r}1 C 2.34 R \\
9.87\end{array}$ & $\begin{array}{r}.4727 E \\
4733 E\end{array}$ & 06 & $.4 \angle 6 E$ & 64 & - 197 & $103 \cdot j 64$ & $.4368 E$ & 66 & $.477 E$ & $\hat{n} 4$ & $\begin{array}{r}-97 \\
\because 08\end{array}$ \\
\hline $\begin{array}{l}98 \cdot \div 37 \\
88.768\end{array}$ & $\begin{array}{r}.42331 \\
.3771 E\end{array}$ & $\begin{array}{l}O E \\
O E\end{array}$ & $\begin{array}{l}.120 E \\
.120 E\end{array}$ & $\begin{array}{l}05 \\
ن 5\end{array}$ & $\begin{array}{r}197 \\
. \quad 695\end{array}$ & $\begin{array}{l}93.256 \\
84.381\end{array}$ & $\begin{array}{l}.4105 E \\
.3382 E\end{array}$ & $\begin{array}{l}36 \\
36\end{array}$ & $\begin{array}{l}.111 E \\
.110 E\end{array}$ & 55 & $\begin{array}{l}-\because 98 \\
.698\end{array}$ \\
\hline 80.266 & $.3197 E$ & 36 & $.1-1 E$ & 05 & .698 & 76.352 & $.2949 E$ & 26 & . $111 E$ & c5 & \\
\hline $72.62 \varepsilon$ & $.2712 E$ & 06 & - $1 C 1 E$ & 65 & .699 & 69.366 & $.2361 E$ & C6 & $.525 E$ & .4 & - 69 \\
\hline 65.716 & $.1947 E$ & 46 & 1. $3 E$ & 55 & . 499 & & $.3029 E$ & 56 & $.776 E$ & $t_{4}$ & \\
\hline 59.463 & $.4400 E$ & 66 & $876 E$ & {$[4$} & .103 & 563 & $.5009 E$ & 06 & $.755 E$ & 64 & .100 \\
\hline 53.804 & $.4212 \mathrm{E}$ & 36 & $.635 E$ & 24 & .101 & & .36 & 36 & $.6 .19 E$ & -4 & . 10 \\
\hline 48.684 & $9 E$ & 36 & $=2 E$ & 64 & .101 & & E & 06 & $6 \mathrm{E}$ & .4 & \\
\hline $44 . t 51$ & $.2957 E$ & 66 & $5 E 4 E$ & 04 & .102 & 41.903 & $.2336 E$ & 36 & $.538 E$ & $\int_{4}$ & 6 \\
\hline 39.050 & $.2496 E$ & $c E$ & & 04 & .103 & & & $\$ 6$ & $.574 E$ & 4 & \\
\hline $36 \cdot-56$ & $.2158 \mathrm{~F}$ & 06 & $.876 E$ & $C_{4}$ & .105 & 34.307 & $.18: 6 E$ & .6 & $.939 E$ & 14 & \\
\hline $32 \cdot E 34$ & - II $3 C E$ & 36 & $.859 E$ & 04 & .152 & 31.642 & $.1475 E$ & $J E$ & $.7 म 2 E$ & 54 & \\
\hline 29.528 & $.1421 E$ & 86 & $.713 E$ & $C_{4}$ & .113 & 28.588 & $.1397 \mathrm{E}$ & $\downarrow \epsilon$ & $.778 E$ & 14 & \\
\hline 25.718 & $.1473 E$ & $\dot{\imath E}$ & $.669 E$ & 64 & .113 & 25.415 & $.1745 \mathrm{E}$ & 36 & $.648 E$ & 14 & + \\
\hline $24.17 E$ & $.1744 E$ & $0 t$ & $.727 E$ & 64 & .116 & 22.997 & $.1542 E$ & 36 & $.669 E$ & 64 & \\
\hline 21.675 & $.1267 E$ & $0 E$ & $.499 E$ & 04 & .119 & 20.808 & $.1215 E$ & .36 & $.470 E$ & 04 & \\
\hline $1=.793$ & $.1374 E$ & 46 & $.522 E$ & 64 & .122 & 18.828 & $.5962 E$ & 25 & $.476 E$ & 4 & \\
\hline $17 . c 1 i$ & $.7737 E$ & 85 & $.456 E$ & 64 & .126 & 17.336 & $.7033 E$ & 05 & $.422 E$ & 64 & \\
\hline $15.2: 6$ & $.6305 E$ & 65 & $.372 E$ & 84 & .137 & 15.415 & $.5833 \mathrm{E}$ & 05 & $.426 t$ & $c_{4}$ & \\
\hline $14.6 F ?$ & $.3133 E$ & ن5 & $.549 E$ & 14 & .134 & 13.948 & $.7565 \mathrm{E}$ & 35 & $.084 E$ & $6+$ & 3 \\
\hline $12.2+c$ & $.7905 E$ & 05 & $.625 E$ & C 4 & .139 & 12.621 & $.93: 2 F$ & J 5 & $.671 E$ & 14 & 14 \\
\hline $12 \ldots: 5$ & .124 IE & 36 & $.615 E$ & 34 & .143 & 11.420 & $.1443 E$ & L6 & $.5 E 7 t$ & $: 4$ & 4 \\
\hline $1-x \in 3$ & $.16 j 4 E$ & 96 & $.629 E$ & 54 & .148 & 10.333 & $.1809 \mathrm{E}$ & 36 & . EPGE & 14 & • \\
\hline 3.829 & $.1795 E$ & 36 & $.540 E$ & 64 & .154 & $9.35 \mathrm{c}$ & $.1622 \mathrm{E}$ & $\therefore 6$ & $.5: 4 E$ & 84 & . 15 \\
\hline $2 .-34$ & $.1567 E$ & 96 & $.572 E$ & {$[4$} & $.16 \mathrm{~s}$ & $8.46 i$ & $.1456 E$ & $j 6$ & $.527 E$ & 14 & • \\
\hline$=-47$ & $.1464 \mathrm{E}$ & 06 & $.384 E$ & 84 & .166 & 7.655 & $.1437 \mathrm{E}$ & $j 6$ & $3 E 7 E$ & 14 & \\
\hline 7.282 & $.1261 E$ & $J E$ & $.389 E$ & 64 & .172 & 6.926 & $.1253 \mathrm{E}$ & 36 & $.376 E$ & $C_{4}$ & $1 /$ \\
\hline 6.rpg & $.1199 \mathrm{~F}$ & 06 & $.3 E 2 E$ & 24 & . 179 & 6.267 & $.1079 E$ & 06 & $.334 E$ & 84 & 13 \\
\hline $5 .=52$ & $.9551 E$ & j5드 & $.318 \mathrm{E}$ & $C_{4}$ & .187 & E. 071 & $1 E$ & 05 & $.526 \varepsilon$ & $x_{0} 4$ & 13 \\
\hline 5.204 & - $8391 \mathrm{E}$ & 45 & $.4 E 3 E$ & 04 & .195 & 5.131 & $.7362 E$ & 15 & $.443 E$ & $\therefore 4$ & 13 \\
\hline 4.921 & $.6173 E$ & 05 & $.462 E$ & 84 & .263 & 4.643 & $.6796 E$ & 35 & $.488 E$ & $\therefore 4$ & $\cdot 25$ \\
\hline 4.417 & - RU $97 E$ & 05 & $.369 E$ & 64 & .212 & 4.201 & $.7483 E$ & 35 & $.411 E$ & .4 & 31 \\
\hline $3.99 E$ & $.6771 E$ & 05 & $.378 E$ & $C_{4}$ & .221 & 3.301 & $.6505 E$ & نj & $.4 C 6 E$ & 64 & 62 \\
\hline $3 \cdot t 1 E$ & $.8287 E$ & 35 & $.373 E$ & 64 & .231 & $3.44 \hat{\mathrm{U}}$ & $.5927 E$ & 35 & $.331 E$ & .4 & \\
\hline 3.272 & $.5 F 19 E$ & 05 & $.274 E$ & 04 & .242 & 3.112 & $.5245 E$ & j 5 & $.286 E$ & $i_{4}$ & .24 \\
\hline $2.96:$ & $.4586 E$ & 05 & $.2 E B E$ & $i_{4}$ & .253 & 816 & 41 & ن 5 & $.251 E$ & 54 & - 25 \\
\hline 2.579 & $.40 \mathrm{JgE}$ & 05 & $.229 E$ & .4 & .264 & 548 & $.3582 E$ & 35 & $.214 E$ & 84 & .2 \\
\hline 2.424 & $.3922 F$ & 05 & $.2 \angle B E$ & C4 & .277 & 306 &.$\cong 128 \mathrm{E}$ & 05 & $.216 E$ & 24 & 2 \\
\hline$? .193$ & - E959E & 55 & $.199 \mathrm{~F}$ & 24 & .293 & 386 & $.7178 E$ & 05 & $.434 E$ & $(4$ & .25 \\
\hline 84 & $.6799 E$ & 65 & $.353 E$ & 24 & .303 & 888 & .76 & 35 & $.371 E$ & {$[4$} & • \\
\hline & $8696 \mathrm{~F}$ & 05 & $.343 E$ & 64 & .316 & 708 & $.13 i$ & 36 & $.318 E$ & $\therefore 4$ & \\
\hline $1 \cdot F 2=$ & $.1099 E$ & $G$ & $.34 w E$ & Ch & .333 & 546 & $.1104 \mathrm{E}$ & 26 & $.315 E$ & -4 & - 3 \\
\hline $1.47 C$ & $.119 \mathrm{CE}$ & 66 & $.2^{2} 6 E$ & 14 & .349 & & & $j 6$ & $6 E$ & 14 & \\
\hline & $.1118 \mathrm{~F}$ & $C E$ & $.296 E$ & 54 & .360 & & & & & & \\
\hline &, 381 & & & & & & & & & & \\
\hline $19:$ & $.1936 \mathrm{E}$ & $\therefore 3$ & $.711 E$ & 02 & - $\operatorname{cg} 3$ & $1: 3 x \cdot 553$ & $.5409 E$ & 03 & $.776 E$ & i2 & \\
\hline & - $8147 \mathrm{E}$ & 03 & $.938 E$ & $: 2$ & .193 & 1387.616 & - 14 & 04 & $J E$ & $: 2$ & 6 \\
\hline 42 & $.1334 \mathrm{E}$ & 04 & $.956 E$ & 32 & .693 & 1255.567 & $.1550 E$ & 34 & $.766 E$ & $\therefore 2$ & \\
\hline 333 & $.1919 E$ & 04 & $.944 E$ & $c .2$ & . $c 93$ & $1136 .: 85$ & $.2325 \mathrm{E}$ & $j 4$ & $.9 C 6 E$ & $E 2$ & \\
\hline$E>7$ & $.2851 E$ & 04 & $.982 E$ & $c 2$ & $\cdot \operatorname{css}$ & 1.27 .972 & . Зड & 34 & $.1 \therefore E E$ & 63 & \\
\hline 977. & $.4223 E$ & 64 & $.112 E$ & 43 & .093 & $53 i \cdot 149$ & $.4333 \mathrm{E}$ & 34 & $.13 \mathrm{CE}$ & $\therefore 3$ & \\
\hline
\end{tabular}




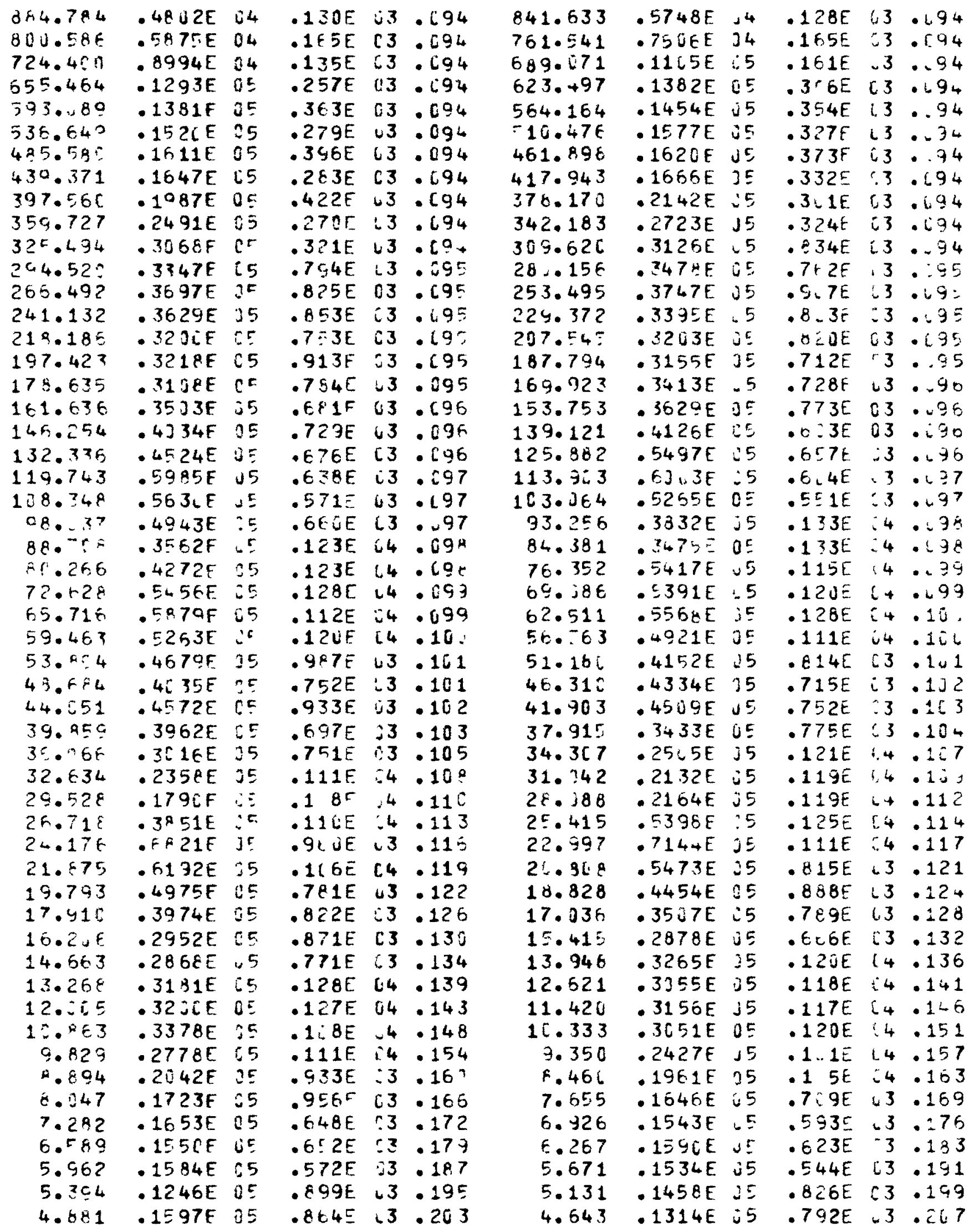




$\begin{array}{llllll}4.417 & .1349 E & 35 & .728 E & C 3 & .212 \\ 3.99 E & .1546 E & 05 & .728 E & 03 & .221 \\ 3.616 & .1299 E & 05 & .698 E & 03 & .231 \\ 3.272 & .1219 E & 0 E & .510 E & C 3 & .242 \\ 2.96 E & .943 C E & 04 & .446 E & 03 & .253 \\ 2.679 & .8545 E & 04 & .387 E & 03 & .264 \\ 2.424 & .7764 E & 04 & .347 E & 03 & .277 \\ 2.193 & .9322 E & 04 & .345 E & 03 & .293 \\ 1.924 & .1356 E & 65 & .567 E & 33 & .363 \\ 1.796 & .1477 E & 05 & .48 B E & i 3 & .318 \\ 1.625 & .1738 E & 05 & .418 E & 03 & .333 \\ 1.475 & .1877 E & C 5 & .412 E & J 3 & .347 \\ 1.33 E & .1956 E & 05 & .415 E & C 3 & .366\end{array}$

$4.201 .1515 F \div 5.771 E: 3.216$ $3.801 .1435 E \quad 35$. $653 E$ D3.226 3.440 .1360 E I5 .643E $: 3.236$ $3.112 .1064 E$ JE . $423 E$ L3 .247 $2.816 .3126 E$ C $4 \quad .423 E$ ¿3 .25B $2.548 .8636 E$ i4 . $3 E 6 E$ ¿3.27 $2.306 .7870 E \quad 54 \quad .347 E \quad 3.283$ $2.086 .116 J E$ J5 .319E U3 .296 $1.888 .1401 E$ IS .4E5E :3.311 $1.708 .1618 E$ O5 .45E C3.325 $1.546 \quad .1855 \mathrm{E} \quad 05 \quad .447 \mathrm{E}(3.341$ 1.398.1955E DE . 386E 03.358 


\section{APPENDIX B}

\section{RESULTS OF 42-GROUP SPECTRUM CALCULATIONS}

Tabulated below are the spectra obtained from the 42-group diffusion theory calculations made with the 2DBS program. These calculations are described in Section 4.2 and the results summarized in Section 5.3. The locations for which data are given are defined in Table 3.1 and the energy bounds of each of the 42 groups are given in Table 4.1 . 


\begin{tabular}{|c|c|c|c|}
\hline GFOUE & $\begin{array}{l}\text { CORE } \\
\text { CENTFD }\end{array}$ & $G P-201$ & $55-625$ \\
\hline---- & $--\infty-\infty-\infty$ & $-\cdots$ & $--\infty-\infty--\infty$ \\
\hline 1 & $.63500 E-02$ & $.52540 E-02$ & $.52760 E-02$ \\
\hline 2 & - 2ECBOF-01 & - 2 C4ODE- 1 & - $20523 E-C 1$ \\
\hline 3 & $.59480 F-01$ & $.51560 \mathrm{~F}-\mathrm{C} 1$ & $5144=E-C 1$ \\
\hline 4 & $.9357 \mathrm{CE}-\mathrm{J} 1$ & $.86910 E-71$ & - $883435-C 1$ \\
\hline 5 & $.11960 E+00$ & $.10730 E+00$ & $.11050 E+00$ \\
\hline 6 & $.19170 E+00$ & $13410 E+\approx 0$ & $.19220 E+C=$ \\
\hline 7 & $.16260 E+00$ & $.16330 \mathrm{~F}+30$ & . $15660 E+0]$ \\
\hline B & $.23950 F+D C$ & $.22770 E+0 C$ & $.22222 E+03$ \\
\hline 9 & $.26120 F+00$ & $.2562 C E+C 0$ & $.24660 E+C D$ \\
\hline 10 & $.2427[F+03$ & $.24450 E+C C$ & $.23320 E+n 9$ \\
\hline 11 & $.21100 F+00$ & $.210 E 0 E+00$ & $.19930 E+C D$ \\
\hline $1 ?$ & $.14: 70 E+00$ & $.1425 C E+O C$ & $.14192 E+3 n$ \\
\hline $1 ?$ & $.1192 \mathrm{jF}+0 \mathrm{C}$ & $.126305+7 C$ & $12312 E+0 ?$ \\
\hline 14 & $.13750 E+00$ & $.14210 E+50$ & $.13412 E+0 Z$ \\
\hline 15 & $.98755 F-01$ & $.10300 F+50$ & $.07330 E-01$ \\
\hline 15 & $.73080:-31$ & . 7 RF CUE- I1 & $.740935-01$ \\
\hline 17 & $.413905-01$ & - $311 C E-: 11$ & $.43920 E-61$ \\
\hline 19 & $.24>005-31$ & $.19300 E-r 1$ & $.19445 E-E 1$ \\
\hline $1 ?$ & - EL12DE-02 & $.34 B 30 E-=2$ & $.35000 E-C 2$ \\
\hline 20 & $.10005-02$ & $.42293 E-52$ & $.42500 E-: 2$ \\
\hline 21 & $.15830 F-01$ & .18COJE- 1 & $.19 E 43 E-21$ \\
\hline 22 & $.26660 E-01$ & $.4011 D E-01$ & $.45570 E-C 1$ \\
\hline 23 & $.18050 E-01$ & $.27730 F-01$ & $.32340 E=n_{1}$ \\
\hline 24 & $.999005-32$ & $.14740 F-1$ & $.1977 J \equiv-: 1$ \\
\hline 25 & $.46040 E-32$ & $.70302 F-2$ & $.1216 Z F-{ }^{r} 1$ \\
\hline 26 & $.29580 F-02$ & $.45 E 40 E-02$ & $.82780 E-02$ \\
\hline 27 & $.12 E 80 F-02$ & $.30 C^{5} .0 F-52$ & $. \equiv 2220 E-12$ \\
\hline 28 & $.51430 E-03$ & $.32120 E-33$ & $.354405-2 ?$ \\
\hline 29 & $.16290 \mathrm{E}-03$ & $.27780 E-.3$ & $.2272 \cap E-C 2$ \\
\hline 32 & $.957305-04$ & $.13270 \mathrm{~F}-0^{2}$ & $.2550 C E-.2$ \\
\hline 31 & $.23000 E-04$ & $.39960 E-C 4$ & $.1332 J E-C ?$ \\
\hline 32 & $.21430 E-0 E$ & $.1304 D F=! 4$ & $.10190 \mathrm{E}-0 ?$ \\
\hline 33 & $.1937 C 5-05$ & $.359507-55$ & $.5413:[-73$ \\
\hline 34 & $.14 ? 70 F-05$ & $.17240 \mathrm{r}-05$ & $.55323 F-63$ \\
\hline 35 & $.91900 E-06$ & $.93690 E-.56$ & $.43020 E-03$ \\
\hline 36 & $.17200 E-j 6$ & - 2998DE- & 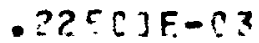 \\
\hline 37 & $.23110 E-07$ & $.63320 F-7$ & $.1024: E-C 3$ \\
\hline 38 & $.41 C O C E-98$ & $.134: 0 E-: 7$ & $.47350 E-04$ \\
\hline 39 & $.617305-109$ & $.247200^{\circ}-38$ & $.18470 E-64$ \\
\hline 40 & $.10520 F-67$ & $.4376 C E-C O$ &.$(44163 E-05$ \\
\hline 41 & $.19350 E-13$ & $.73 B 10 E-10$ & $.19290 E-E 5$ \\
\hline 42 & $\cdot 2=310 E-11$ & $.1050 C E-10$ & $.38243 E-66$ \\
\hline
\end{tabular}




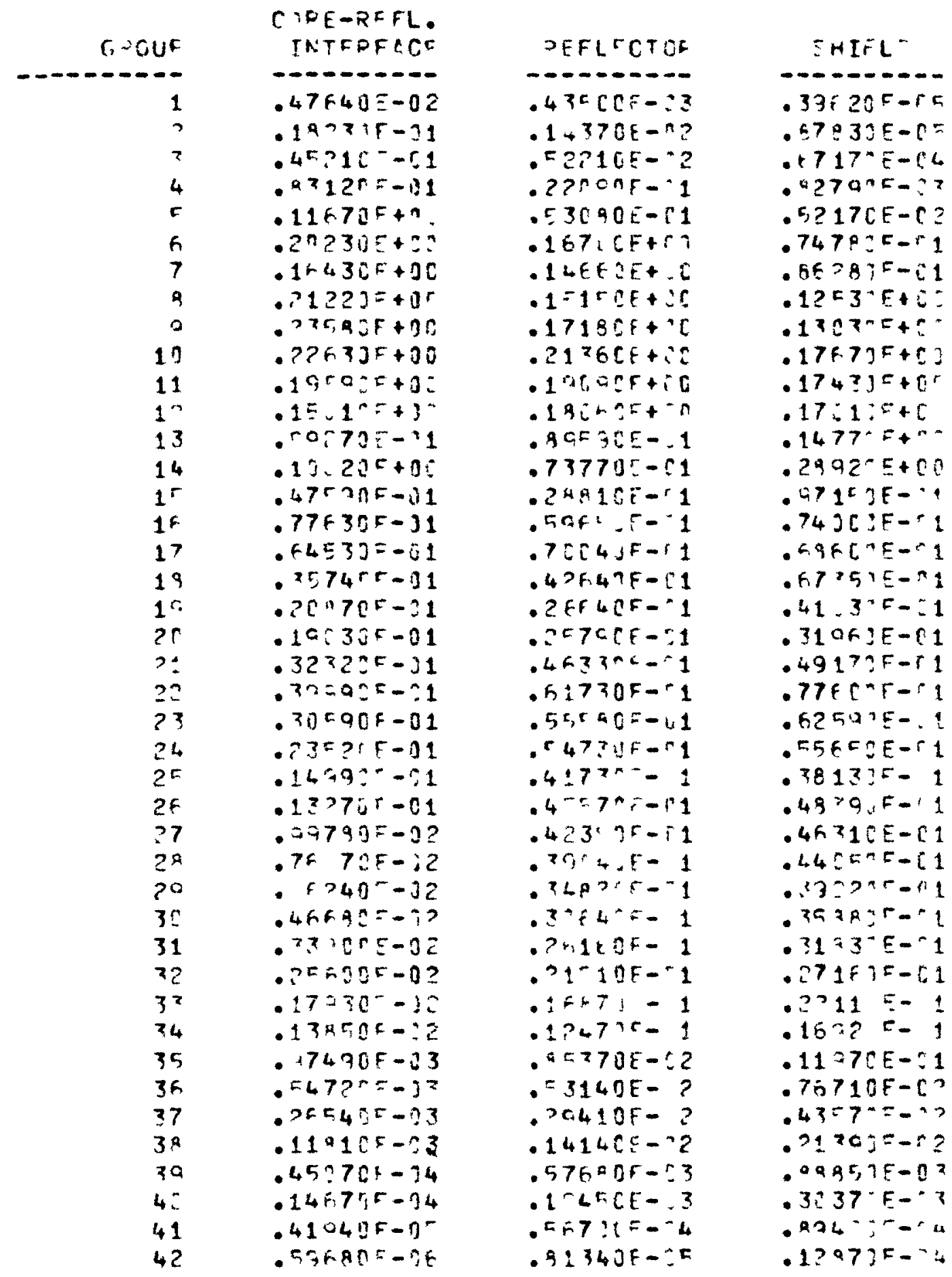

